\title{
Grottes du Banat (Roumanie) explorées en 1963
}

\author{
Par Şt. Negrea, A. Negrea, V. Sengu et L. Botoşaneanu ${ }^{1}$ )
}

Avec planches 79 (1) - $103(25)$

Ce travail rend compte des résultats de l'exploration de 23 cavités souterraines du Banat, visitées par les auteurs en 1963.

Le plan de l'exposé est, en général, le même que celui que nous avons suivi dans un travail précédent («Recherches sur les grottes du Banat et d'Olténie, Roumanie», 1959-1962) dans lequel nous présentions les premières 75 grottes du Banat roumain explorées par nous. ${ }^{2}$ )

Parmi les 23 grottes explorées en 1963, quelques-unes sont situées dans des zones karstiques déjà étudiées dans le travail que nous venons de citer (bassin de la Bîrzava au S et au SE de Reşița, bassin du Caraş, gorges de la Nera, bassin du Danube dans la zone Moldova Noua - Sf. Elena, et défilé du Danube de Cazane); d'autres sont creusées dans des noyaux karstiques dont nous parlerons ici pour la première fois (bassin supérieur de la Bega, bassin du Poganiş, à Barbosu-Valeapai, bassin de la Bîrzava au NO de Reşița - fig. 1). Ce sont pour la plupart des cavités naturelles, mais on a exploré aussi trois cavités artificielles qui se sont montrées intéressantes au point de vue biospéléologique.

Les 23 grottes représentent un total de $1490 \mathrm{~m}$ de salles et galeries explorées.

Nous allons donner d'abord un index des grottes explorées, suivi par la description des grottes (groupées par zones karstiques, chaque zone avec une succincte présentation), enfin un tableau synoptique récapitulatif.

Les auteurs remercient leurs collaborateurs: l'alpiniste Em. Cristea qui les a aidés dans l'exploration de la majorité des grottes, ainsi que les étudiants G. Lazarovici et H. Pischl de Reşița, qui les ont accompagnés dans quelques-unes de leurs excursions.

\footnotetext{
1) Institut de Spéologie "Emil Racovitza», Str. Dr. Capsa, No 8, Bucarest 35 , Roumanie.

$\left.{ }^{2}\right)$ Le travail cité comprenant une ample caractérisation géologique et physico-géographique des Mts. du Banat Roumain, il serait superflu de revenir ici sur les généralités du karst du Banat. Le lecteur y trouvera en outre un glossaire des termes roumains avec leur traduction en français.
} 


\section{Index des grottes du Banat décrites dans ce travail}

(ordre de la succession dans le texte)

Grottes situées dans le bassin supérieur de la Bega.

1. Peştera de la Romîneşti.

2. Peştera $n^{0} .1$ din Stînca lui Florian.

3. Peştera Gaura din Cioaca Birtului.

4. Peştera din Piatra Fetii.

5. Galeria de explorare (= galerie de mine) din Valea cu Baia.

Grottes situées dans le bassin du Poganiş.

6. Peştera Urieşilor.

7. Peştera Casa Lotrilor.

Grottes situées dans le bassin de la Bîrzava au NO de Reşița.

8. Peştera din Dealul Colțan.

9. Galeria de explorare (= galerie de mine) din Dealul Colțan.

10. Abatajul lui Anton.

Grottes situées dans le bassin de la Bîrzava au S et au SE de Reşița.

11. Peştera cu oase de la Stîrnic.

12. Avenul de la Cantonul Pin.

Grottes situées dans le bassin du Caras.

13. Peştera din Drumul Prolazului.

14. Peştera cu Fereastra.

15. Peştera Vraşka.

16. Peştera Galațiului.

Grottes situées dans les gorges de, la Nera.

17. Peştera din Culmea Lacului.

18. Peştera mica de la Lacu Dracului.

19. Peştera de la Lacu Dracului.

Grottes situées dans le bassin du Danube à Moldova Noua.

20. Avenul de la Vranovaț.

21. Avenul de la Izvoru Şicli.

Grottes situées dans le massif Sucaru Mare (défilé du Danube de Cazane).

22. Peştera no. 1 de la Gura Ponicovei.

23. Peştera no. 2 de la Gura Ponicovei. 


\section{Grottes situées dans le bassin supérieur de la Bega}

(Fig. 2)

Le bassin supérieur de la rivière $\mathrm{Bega}^{3}$ ) est constitué, dans sa quasitotalité, des schistes cristallins épizonaux du domaine gétique (c'est d'ailleurs le cas de l'ensemble du Massif de Poiana Ruscai, auquel ce bassin appartient). Les recherches géologiques (Papiu, 1956; P apiu et collab., 1961) montrent que cette zone se caractérise par la présence de dolomies et de calcaires cristallins d'âge silurien. Ces roches se présentent sous l'aspect de massifs individualisés; mais ces dolomies et calcaires cristallins sont aussi associés à la série schisteuse. Les principales croupes de cette région sont formées par ces roches carbonatées, qui permettent le développement d'un relief typiquement karstique de surface et de profondeur, ce qui imprime sa note caractéristique au paysage.

Parmi les grottes - fort peu nombreuses - de cette zone, nous avons exploré: Peştera de la Romîneşti (la plus grande et la plus intéressante de toutes; c'était d'ailleurs la seule connue au point de vue archéologique); Peştera No. 1 din Stînca lui Florian; Peştera Gaura din Cioaca Birtului; Peştera din Piatra Fetii; une galerie de mine à Valea cu Baia.

\section{Peştera de la Romîneşti}

(Fig. 3)

Synonymie. Facsádi-barlang; Rumunyeszt-barlang; Peştera (ou Peştera cu Apa); Peştera Romaneşti-Fereşeşti.

Bibliographie. Orth ma y r, T. (1872; géologie; description; faune; citée sous le nom de Rumunyesty barlang); Bokor, E. (1821; faune; citée sous le nom de Facsádi-barlang-Rumuniestyei b.); D u mitrescu, M., Tanas a chi, J., Orghidan, T. (1962-63; faune; citée sous le nom de Peştera Romaneşti-Fereşeşti); Cristea, E. (1964; exploration; citée sous le nom de Peştera cu Apa).

Date de l'exploration. 22. V.1963 (L. Botoşaneanu, V.Sencu, Şt. Negrea, A. Negrea).

3) A vrai dire, il s'agit de deux cours d'eau portant le même nom de Bega. Le premier prend ses sources à l'O du sommet Moşiuța (1249 m); il porte le nom de Caprişoara jusqu'à sa confluence avec le ruisseau Stîlpului, et traverse ensuite les villages Luncani, Tomeşti et Romîneşti. Le second est situé plus à l'est et il traverse les villages Poeni, Crivina de sus et Pietroasa, s'unit avec le premier à Curtea, et ses divers segments portent le nom des villages traversés. Pour simplifier, nous les désignerons respectivement par Bega Luncanilor et Bega Poienilor. 
Emplacement. La grotte est située au SE du village de Romîneşti (commune Curtea, rayon Faget); elle est creusée dans le versant gauche, bien boisé, de la Vallée Pustinia, à $2,2 \mathrm{~km}$ en amont du confluent de ce ruisseau avec le Bega Poienilor, plus exactement dans le versant N (connu sous le nom de «Dosu Peşterii») de Dealu (= la colline) lui Filip. Altitude absolue $370 \mathrm{~m}$, alt. relative $105 \mathrm{~m}$. Comme c'est l'unique grotte des environs du village elle est bien connue des habitants. Elle est accessible soit à partir de la vallée Pustinia (à $2,2 \mathrm{~km}$ en amont du confluent de celle-ci avec la Bega, et un peu en aval d'une carrière de calcaire, on monte sur le versant gauche - sentier sur pente fort abrupte, dénivellation $105 \mathrm{~m}$ jusqu'à l'entrée de la grotte), soit en empruntant une route qui commence au village, suit la ligne de partage des eaux, enjambe le Dealul Stîrc et le Merişorul jusqu'à un petit ensellement, à partir duquel l'on continue par un sentier descendant vers la grotte (1 heure de marche à partir du village). L'entrée de la grotte est orientée NNO.

Description. Grotte moyenne (longueur totale $340 \mathrm{~m}$ ). Fossile, horizontale (avec des portions faiblement ascendantes ou descendantes). Entrée rectangulaire, large de 9,5 m, haute de $2 \mathrm{~m}$. Zone directement éclairée fort courte; zone à éclairage diffus relativement longue (jusqu'aux points fixes 9-12); le reste est plongé dans l'obscurité.

La grotte est formée d'une galerie à peu près rectiligne, de grandes dimensions, présentant des élargissements correspondant à l'intersection des fissures tectoniques (le plus important c'est "Sala Liliecilor»); à partir de la salle que nous venons de nommer, 3 galeries, situées à des niveaux différents, se dirigent vers le $\mathrm{S}$; d'autres galeries, ayant leur origine dans cette même salle, se dirigent vers l'O, et deviennent bientôt impénétrables par rétrécissement. Des boyaux fort étroits se dégagent de la galerie principale, des salles et des galeries secondaires, et il se forme de la sorte un labyrinthe de galeries hautes et étroites. Les galeries et boyaux sont, pour la plupart, développés sur des fissures tectoniques et suivent fidèlement la direction de celles-ci.

Eau de condensation et d'égouttage abondante un peu partout. Accumulations d'eau: quelques gours et microgours, flaques d'eau sur l'argile ou sur le calcaire, eau dans des "têtes» de stalagmites.

Sur les parois et le plafond de la grotte (surtout dans la portion terminale) on remarque des septes et hiéroglyphes de corrosion, des anneaux et piliers d'érosion. Dans de nombreux endroits, on note de l'argile de décalcification déposée sur les parois sous forme de "peau de léopard» (aspects typiques). Nous n'avons pas observé des niveaux d'érosion. 
La grotte se trouve actuellement dans une phase incipiente de la stalagmitation (stalactites fistuleuses, coulées pariétales variées, croûte stalagmitique sur le plancher supportant stalagmites, dômes, colonnes, gours à perles de caverne). Matériel clastique, depuis celui de dimensions fort petites jusqu'à d'énormes blocs (écroulés dans la Sala Liliecilor); depôts d'argile et de guano; il n'y a pas de matériel alluvionnaire, ni sable, ni gravier.

La grotte de Romîneşti avait été creusée sur des fissures de nature tectonique le long desquelles l'eau d'infiltration a pu circuler. Elle est creusée, depuis l'entrée et jusqu'au point fixe 21, dans des calcaires dolomitiques faiblement stratifiés et métamorphisés, gris ou blanc jaunâtre; depuis le point fixe 21 et jusqu'au fond, elle est developpée dans une brèche tectonique (c'est jusqu'à présent l'unique grotte de Roumanie développée dans des brèches). Dans ce secteur, nous avons $\mathrm{pu}$ identifier des blocs calcaires, des schistes chloriteux-sériciteux et des quartzites, le tout enchâssé dans une masse argileuse; un rôle dominant dans la genèse de ce secteur de la grotte à été certainement joué par la suffusion mécanique. Il y a des différences dans la morphologie des deux secteurs de la grotte. Dans le secteur de la brèche tectonique, par suite de l'érosion différentielle et de l'insolubilité de certaines roches, divers éléments sont restés en relief sur les parois et le plafond. La plus grande hauteur de la grotte dans ce secteur, s'explique par la fréquence accrue des éboulements par rapport au secteur des calcaires dolomitiques.

Spé o climat. Température $(9 \mathrm{~h})$ : à l'extérieur, air $10,2^{\circ} \mathrm{C}$; au point fixe 5 , air $7^{\circ} \mathrm{C}$, plancher $6,5^{\circ} \mathrm{C}$, eau d'un gour $6,7^{\circ} \mathrm{C}$; entre les points 13-14, air $6,5^{\circ} \mathrm{C}$, plancher $6,2^{\circ} \mathrm{C}$; dans la Sala Liliecilor, air $8,4^{\circ} \mathrm{C}$, plancher $8,3^{\circ} \mathrm{C}$ (poche d'air chaud à cet endroit!). Humidité relative: $100 \%$ dans les portions à eau de condensation et d'égouttage; 95-98\% dans la majeure partie de la grotte; un peu moindre en proximité de l'entrée. Grotte statique, pas de courants d'air.

Ressources trophiques. Riches: importantes quantités de guano, soit sec ou très sec, soit humide ou fort humide, mélangé ou non avec de l'argile; du matériel ligneux en quantité, mais normalement sec, rarement transformé en détritus; déjections desséchées de carnivores.

Biospéologie. Echantillons de la flore. (22. V. 1963, leg. L. B., A. N.).

1. Fungi sur bois pourri, guano sec et déjections.

2. Algae sur les parois (semiobscurité). 
Echantillons de la faune (22. V. 1963, leg. L. B., A. N., Şt. N.):

1. Faune pariétale dans la zone semi-obscure, entre le commencement de celle-ci et le point fixe 5: Polydesmidae, Coleoptera, Trichoptera, Diptera, Araneina, Opiliones.

2. Idem, entre les points fixes 5 et 8-9: Trichoptera, Diptera, Araneina, Opiliones.

3. Faune collectée sur le plancher, à l'obscurité et la semi-obscurité (sur bois, argile, détritus): Gastropoda, Isopoda, Polydesmidae, Cryptopsidae, Collembola, Coleoptera (imagines, larvae), Hymenoptera, Araneina, Opiliones.

4. Faune du guano extrêmement humide, dans la Sala Liliecilor; Diptera (larvae, pupae).

5. Filtrage de l'eau d'un gour: Oligochaeta, Nematoda, Collembola, Acari (ces derniers tombés à l'eau).

6. Filtrage de l'eau extraite de microgours et de "têtes» de stalagmites: Oligochaeta, Collembola.

7. Parasites sur Miniopterus schreibersi: Nycteribiidae, Acari.

8. Chiroptera.

Riche association pariétale dans la zone directement éclairée et dans celle semi-obscure; mais cette association s'arrête brusquement au niveau des point fixes $8-9$; ces points représentent aussi la limite pour la végétation d'algues recouvrant les parois (surtout la gauche). La faune est quantitativement riche dans le guano fort humide, mais elle est extrêmement pauvre dans le reste du depôt de guano. La faune du plancher est, à son tour, pauvre, car le matériel ligneux est trop sec; elle est mieux représentée dans la zone semi-obscure. Faune aquatique pauvre, dépourvue d'intérêt. Colonie de chauves-souris (Rhinolophus?) dans la Sala Liliecilor, à $20 \mathrm{~m}$ de hauteur; Miniopterus schreibersi isolés, inactifs.

Restes osseux actuels (22. V. 1963, leg. L. B., A. N., Şt. N.): Chiroptera, Rodentia, Carnivora.

Varia. Restes osseux fossiles: Ursus spelaeus (canine); des pièces de U.spelaeus provenant de cette grotte sont exposées dans le Musée de Timişoara.

Des sondages archéologiques systématiques avaient été exécutés dans cette grotte; le résultat fut la découverte d'un gîte néolithique (dépôt de céréales, céramique appartenant aux cultures de Tisa et de Coțofeni, foyer actuellement reconstitué dans le Musée de Timişoara). Des recherches paléontologiques et archéologiques pourront encore donner de bons résultats. 
Grotte non protégée, non aménagée, $\left.{ }^{4}\right)$ partiellement dégradée, fréquemment visitée par les paysans qui avaient organisé aussi l'exploitation rudimentaire du guano. Remarquable surtout sous l'aspect géologique.

\section{Peştera no. 1 din Stînca lui Florian}

(Fig. 4)

Nom donné par les auteurs.

Date de l'exploration. 25. V. 1963 (Şt. Negrea, V. Sencu, L. Botoşaneanu).

Emplacement. La grotte est creusée dans l'extrémité aval de l'abrupt calcaire («cleantz») connu sous le nom de «Ştînca lui Florian», abrupt formant la rive droite de Bega Luncanilor à $2,5 \mathrm{~km}$ env. en direction $\mathrm{S}$ par rapport à la commune de Tomeşti (rayon Faget) et à $300 \mathrm{~m}$ env. en amont de la verrerie Tomeşti. L'entrée $(0,60 / 1,20 \mathrm{~m})$, orientée E, est située à $255 \mathrm{~m}$ d'altitude absolue et à $2 \mathrm{~m}$ seulement au dessus du thalweg de la Bega.

Description. Petite grotte $(10 \mathrm{~m})$, creusée dans des calcaires dolomitiques fort fissurés, faiblement métamophisés, d'un blanc jaunâtre, se présentant sous l'aspect de bancs épais de 0,10-0,60 m. Sous-fossile (fossile?), pratiquement horizontale, la moitié terminale obscure. Sur les parois, eau de ruissellement, venant par des cheminées. Microformes d'érosion et de corrosion: septes, lamelles, hiéroglyphes, anneaux. Quelques formations concrétionnaires; plancher avec dépôt d'argile et de sol de forêt.

C'est l'œuvre de l'eau d'infiltration, ayant élargi un système de diaclases tectoniques.

Spéoclimat. Température: air à $1 \mathrm{~m}$ au delà de l'entrée: $12,8^{\circ} \mathrm{C}$; au fond de la grotte $11^{\circ} \mathrm{C}$ (grotte chaude). Humidité relative $98 \%$, diminuant vers l'entrée. Grotte statique, sans courants d'air.

Ressources trophiques fort pauvres (beaucoup de matériel végétal, mais trop sec).

Biospéologie. Echantillon général de la faune (25. V. 1963, leg. L. B., Şt. N.): Coleoptera, Diptera, Araneina. Faune extrêmement pauvre et banale. Un chiroptère observé en vol.

Varia. Grotte non indiquée pour des recherches paléontologiques ou archéologiques.

4) D'ailleurs, toutes les grottes décrites dans ce travail sont dans la même situation: il n'y a pas de grotte protégée ou aménagée pour le tourisme etc. 


\section{Peştera Gaura din Cioaca Birtului}

(Fig. 5)

Synonymie. Gaura lui Şeitan; Gaura lui Macu.

Date de l'exploration. 25. V.1963 (V.Sencu, L. Botoşaneanu, Şt. Negrea, A. Negrea).

Emplacement. La grotte est creusée dans le versant gauche de la vallée de Bega Luncanilor, dans l'abrupt calcaire boisé Cioaca Birtului, à $2 \mathrm{~km}$ env.en aval de l'extrémité N. du village Luncani (Commune Tomeşti, rayon Faget) et à $20 \mathrm{~m}$ en amont de la borne du km 15 sur la route Tomeşti-Luncani; un sentier en pente forte conduit de cette route à entrée de l'aven, orientée NE. Alt. absolue $330 \mathrm{~m}$, alt. relative $26 \mathrm{~m}$.

Description. Petite grotte (18 $\mathrm{m}$, dont $5 \mathrm{~m}$ profondeur de l'aven), creusée dans des calcaires dolomitiques faiblement métamorphisés; les strates sont fort diaclasées. Grotte fossile, obscure. Elle est constituée par un aven profond de $5 \mathrm{~m}$ qui donne accès dans une petite salle $\mathrm{B}$ d'où se détachent deux galeries $\mathrm{A}$ et $\mathrm{C}$; la première, longue de $6 \mathrm{~m}$, d'abord ascendante puis horizontale, communique avec l'extérieur par un orifice dans l'abrupt calcaire (orifice orienté NE); la seconde, qui se détache de la base même de l'aven et se dirige vers l'O, est longue de $3 \mathrm{~m}$ et devient ensuite impénétrable.

Pas d'accumulation d'eau; eau de condensation. Formes d'érosion et de corrosion; niveaux d'érosion faiblement developpés, coupoles et hiéroglyphes de corrosion. Il n'y a pas de concrétions. A la base de l'aven et dans les galeries, matériel clastique grossier et argile.

L'aven s'est formé sur joint de stratification, les fissures tectoniques ayant aussi contribué; les galeries sont creusées sur la direction de fissures tectoniques élargies par l'eau d'infiltration.

Spéoelimat. Températures à la base de l'aven: air $8^{\circ} \mathrm{C}$, plancher $8,5^{\circ} \mathrm{C}$. Humidité $100 \%$ dans la zone obscure. Grotte dynamique, courant d'air relativement fort, descendant, favorisant d'importants échanges d'air influençant sur le régime thermique (la grotte est sans doute chaude en été, froide en hiver).

Ressources trophiques fort riches et utilisables par la faune (grande quantité de bois pourri et humide, détritus végétal grossier, un peu de guano, à la base de l'aven).

Biospé ologie. Observé: Fungi sur bois en décomposition. Echantillon général de la faune (à la base de l'aven, 25. V. 1963, leg. L. B., A. N., Şt. N.): Oligochaeta, Gastropoda, Isopoda, Diplopoda, Chilopoda [Geophilomorpha, Cryptopsidae, Lithobiidae], Collembola, Coleoptera, 
Diptera, Opiliones, Araneina, Pseudoscorpiones, Acari). Faune variée, riche, comprenant des éléments troglophiles et troglobies. Il n'y a pas de vraie association pariétale. Observé chiroptères en vol.

Restes os seux actuels (25. V. 1963, leg. L. B., A. N.): Chiroptera, Rodentia.

Varia. Grotte connue par les habitants des alentours, non indiquée pour des recherches archéologiques et paléontologiques.

\section{Peştera din Piatra Fetii}

(Fig. 6)

Date de l'exploration. 26. V. 1963 (V. Sencu, A. Negrea, Şt. Negrea).

Emplacement. La grotte est située sur la rive droite du ruisseau Caprişorul, plus exactement entre la route et le ruisseau, à l'endroit connu sous le nom de Piatra Fetii, à $6,5 \mathrm{~km}$ en amont du village Luncani (raion Faget). Alt. absolue $508 \mathrm{~m}$, alt. relative $6 \mathrm{~m}$ (fig. 2). A $1,5 \mathrm{~km}$ en aval de la grotte, le ruisseau Caprişorue conflue avec le ruisseau Stîlpului à l'endroit nommé «Intre Ape», pour former la rivière de montagne Bega Luncanilor.

Description. Petite grotte (19 $\mathrm{m}$ de longueur totale), active, creusée dans du tuf calcaire et dans des calcaires dolomitiques stratifiés. Le dépôt de tuf calcaire est l'œuvre d'un complexe de sources situé à l'E de la grotte; à la date de l'exploration, 12 sources débitaient de l'eau qui se perdait dans le massif de tuf calcaire par plusieurs fissures. L'entrée de la grotte, en forme de fente horizontale, est une fissure élargie, longue de $4 \mathrm{~m}$ et profonde de $2,5 \mathrm{~m}$; elle s'est formée par suite de l'effondrement de la rive, minée par érosion latérale. A partir de la base de la fissure, se dirige vers l'O une galerie difficilement accessible, qui aboutit dans la berge du ruisseau, à $3 \mathrm{~m}$ au dessus de l'eau. La grotte proprement dite se développe vers l'E; elle est représentée par une salle à éclairage diffus, descendante, au plancher recouvert de grands blocs de calcaire et de tuf, ainsi que d'un couloir obscur, drainé par l'eau d'un ruisselet venant du SE, qui se perd parmi les pierres du plancher, pour sortir au jour à $9 \mathrm{~m}$ en aval de la grotte (ce ruisselet est fort probablement alimenté par l'eau des sources mentionnées).

Parois formées de calcaire et presqu'entièrement recouvertes d'une croûte concrétionnaire partiellement noircie (argile). Plafond de tuf calcaire avec un petit nombre de stalactites. Sur le plancher il y a du gravier roulé et le couloir de la partie terminale, orienté $\mathrm{S}$, est colmaté par des blocs de tuf éboulés. 
A l'exception du couloir drainé par le ruisselet, et qui s'est développé sur une fissure tectonique, la grotte est l'œuvre de l'érosion latérale du ruisseau Caprişorul, qui a creusé une niche dans le dépôt de tuf calcaire. A $10 \mathrm{~m}$ en amont de cette grotte, est située la grotte A (fig. 6), longue de $8 \mathrm{~m}$ et dont la génèse est similaire. La base de l'entrée de celle-ci se trouvant au niveau de l'eau du ruisseau, une première portion de cette grotte est inondée, l'eau se perdant partiellement par un suçoir.

Spéoclimat. Température à $12 \mathrm{~h}$ : à l'extérieur, air $23,5^{\circ} \mathrm{C}$; à la base de l'entrée verticale, air $21,5^{\circ} \mathrm{C}$; près du cours d'eau souterrain, air $12^{\circ} \mathrm{C}$, plancher $9,2^{\circ} \mathrm{C}$ (grotte chaude). Humidité relative $100 \%$ (il y a de l'eau de condensation; grotte fort humide). Grotte dynamique; faibles courants d'air.

Ressourcestrophiques relativement riches (bois pourri, détritus végétal fin, argile).

Bios pé ologie. Echantillon de la flore (26.V.1963, leg. A. N.); Fungi sur bois pourri à la semi-obscurité.

Echantillons de la faune (26. V. 1963, leg. Şt. N., A. N.), sur bois pourri et dans du détritus végétal déposé sur l'argile ou sur le sable, à la semi-obscurité: Oligochaeta, Gastropoda, Isopoda, Diplopoda, Geophilomorpha, Lithobiidae, Simphila, Diplura, Collembola, Diptera (imagines, larvae, pupae), Araneina, Opiliones.

Association pariétale pratiquement inexistante (quelques formes banales de diptères et d'aranéides). Faune du plancher riche et variée, concentrée dans des secteurs restreints avec bois pourri ou détritus.

Varia. Grotte jamais visitée, ménacée de l'anéantissement par l'exploitation de la carrière de tuf; n'est pas indiquée pour des sondages paléontologiques et archéologiques.

\section{Galeria de explorare din Valea cu Baia (Fig. 7)}

Connue aussi par les paysans des alentours sous le nom de Baia (Mina) parasita de la Fîrdea (= la mine abandonnée de Fîrdea).

Date de l'exploration: 23. V. 1963 (L. Botoşaneanu, Şt. Negrea, A. Negrea).

Emplacement. On part de la Commune de Fîrdea (rayon Faget), on passe la croupe du Fraxinet, pour descendre ensuite dans Valea (= la vallée) cu Baia (affluent du ruisseau Gladna Romîna - bassin de la Bega); on traverse le ruisseau, et l'on remonte, à travers la forêt, un petit affluent droit de celui-ci, jusqu'à l'entrée de la galerie (entrée de petites dimensions - 1,80/0,70 m -, partiellement effondrée, orientée N) d'où sort l'eau du petit affluent. Env. $1 \mathrm{~h}$ de marche à partir de Fîrdea. Alt. absolue $390 \mathrm{~m}$. 
Description. Il s'agit d'une galerie artificielle d'exploration pratiquée il y a plus d'un siècle dans les roches métamorphiques de la région. Nous avons pu explorer l'ensemble du niveau inférieur (env. $200 \mathrm{~m}$ ), mais il reste à explorer d'autres secteurs au niveau supérieur, accessibles par deux cheminées (exploration extrêmement périlleuse, tous les travaux intérieurs étant au dernier degré de délabrement). La galerie que nous avons visitée avait été partiellement inondée jusqu'à la veille de notre visite, et c'est seulement le drainage de l'eau qui nous a permis d'y accéder.

Zone semi-obscure très courte. La galerie est dans sa majeure partie traversée par un ruisselet ayant son origine dans un puits de mine inondé (un filet d'eau souterraine avait probablement été intercepté au cours de la perforation de la galerie). Remplissage: beaucoup de matériel clastique, un peu de matériel sédimentaire, stalagmitation fort peu avancée (coulées pariétales, stalactites fistuleuses, ébauches de stalagmites, gours; toutes ces formations sont rougeâtres par suite de la présence d'oxydes minéraux).

Spéoclimat. Température: à l'extérieur, air $17^{\circ} \mathrm{C}$; à $2 \mathrm{~m}$ au delà de l'entrée, air $11,8^{\circ} \mathrm{C}$, à l'endroit de la rencontre de la galerie d'accès avec la principale, air $11^{\circ} \mathrm{C}$, plancher $10,8^{\circ} \mathrm{C}$, eau du cours souterrain $10^{\circ} \mathrm{C}$. Humidité relative $100 \%$. Cavité souterraine statique.

Ressources trophiques extrêmement riches (énorme quantité de bois de mine à divers stades de décomposition; guano; grandes quantités de détritus végétal grossier; argile dans le lit du ruisselet; cadavres de chauves-souris).

Biospéologie. Echantillon de la flore (23. V. 1963, leg. L. B., A. N., Şt. N.): Fungi sur bois pourri et guano. Riche flore bactérienne et d'algues dans les flaques du cours souterrain.

Echantillons de la faune (23. V. 1963, leg. L. B., A. N., Şt. N.):

1. Sur les parois, dans la zone semi-obscure: Araneina.

2. Faune du bois pourri et du détritus grossier: Oligochaeta, Collembola, Coleoptera, Diptera (larvae), Araneina, Opiliones, Acari.

3. Filtrage de l'eau du ruisselet: Nematoda, Oligochaeta, Cyclopoida, Ostracoda.

4. Dans l'eau presque stagnante de certains élargissements sur le tracé de ce ruisselet: Amphipoda, Coleoptera.

5. Parasites sur Miniopterus schreibersi: Nycteribiidae, Acari.

6. Chiroptera (isolés). 
Observé, mais non collecté: dans l'eau du ruisselet: Gordiacea, larves de Salamandra maculosa; sur les parois: Macrolepidoptera. Faune de plancher et aquatique variée et intéressante. Association pariétale pratiquement absente.

Restes osseux actuels (23. V. 1963, leg. L. B., A. N., Şt. N.): Chiroptera.

Bien qu'il s'agisse d'une cavité souterraine artificielle creusée dans des roches non calcaires, la galerie s'est montrée intéressante au point de vue biospéologique.

\section{Grottes situées dans le bassin du Poganis}

(Fig. 8)

Le Poganiş est un affluent gauche du Timiş (l'un des principaux cours d'eau du Banat). Les calcaires de la zone Barbosu-Valeapai appartiennent à la bande calcaire Ezeriş-Dognecea (voir aussi la caractérisation de la zone suivante); ils se présentent sous forme d'îlots isolés, à la partie NO de cette bande.

Les grottes sont ici fort rares et petites; nous allons en présenter deux seulement: Peştera Urieşilor et Peştera Casa Lotrilor.

\section{Peştera Urieşilor}

(Fig. 9)

Synonymie. Buoara Urieşilor.

Date de l'exploration. 25. VI. 1963 (V. Sencu, A. Negrea, Şt. Negrea).

Emplacement. Elle est située à $500 \mathrm{~m}$ de la localité de Valeapai (rayon Lugoj), dans la partie S de la colline Coasta Pietrii et dans le versant droit de Ogaşu Butorii (affluent droit du Poganiş), à 170 n d'altitude absolue et à $20 \mathrm{~m}$ d'alt. relative.

Description. Petite grotte (6 $\mathrm{m}$ de longueur), horizontale, fossile, creusée dans du tuf calcaire, éclairée sur toute sa longueur (éclairage diffus). L'entrée, en voûte (fig. 9, section I-II), est haute de $0,4 \mathrm{~m}$ et large de 1,2 m, orientée $\mathrm{S}$ et masquée par des robiniers. La grotte est haute de $0,7 \mathrm{~m}$ au plus et large de $3 \mathrm{~m}$. Remplissage fort épais (argile sableuse, fragments de tuf calcaire, graviers de quartz roulés). Pas de formations stalagmitiques, aucune forme d'érosion ou de corrosion. La grotte s'est formée par l'infiltration de l'eau de précipitation dans le tuf calcaire. 
Spéoclimat. Température à $13 \mathrm{~h}$ : à l'extérieur, air $29,5^{\circ} \mathrm{C}$; au fond, air $23^{\circ} \mathrm{C}$, plancher $18^{\circ} \mathrm{C}$ (température nettement influencée par l'extérieur). Humidité relative: $70 \%$ (grotte sèche, poudreuse). Grotte statique, sans courants d'air.

Ressourcestrophiques fort pauvres (un peu de détritus végétal, argile).

Biospé ologie. Faune collecté (25. VI. 1963, leg. A. N.) sur l'argile sèche recouverte de détritus: Isopoda, Collembola, Acari.

Observé, mais non collecté: Diptera. Faune pauvre, peu intéressante. Association pariétale absente.

Varia. Grotte non visitée et sans traces de dégradation. Indiquée pour des sondages archéologiques (un sondage pratiqué a donné une hache néolithique).

\section{Peştera Casa Lotrilor}

(Fig. 10)

Date de l'exploration. 25. VI. 1963 (Şt. Negrea, V. Sencu, A. Negrea).

Emplacement. La grotte est située à $1800 \mathrm{~m}$ en amont du village Barbosu (commune Valeapai, rayon Lugoj); elle est creusée dans le versant gauche du Ogaşul Roiban (affluent droit du Poganişul), c'està-dire dans la colline boisée Roiban (fig. 8); difficile à retrouver sans l'aide d'un guide.

Alt. absolue $290 \mathrm{~m}$, alt. relative $30 \mathrm{~m}$.

Description. Petite grotte ( $8 \mathrm{~m}$ de longueur) sous-fossile, horizontale, ensuite ascendante, presque partout éclairée (le boyau à l'O est obscur). Entrée $(0,40 / 0,80 \mathrm{~m})$ orientée NE, rectangulaire et entourée de blocs de calcaire éboulés. Elle donne accès dans une salle basse, prolongée par un couloir à parois inclinées vers le S. Après les pluies, l'eau pénètre par des fissures et inonde la grotte. Lors de notre visite, il y avait seulement une petite flaque d'eau sur l'argile, au fond, et les parois étaient humides. Stalagmitation absente. Plancher recouvert d'argile et de pierraille.

La génèse de la grotte est liée à l'eau d'infiltration ayant élargi des fissures tectoniques.

Spéoclimat. Températures à 17,30 h: à l'extérieur, air $21,8^{\circ} \mathrm{C}$; au fond, air $15^{\circ} \mathrm{C}$, plancher $10,3^{\circ} \mathrm{C}$, eau $9,7^{\circ} \mathrm{C}$ (grotte chaude). Humidité relative $95-98 \%$ (grotte humide). Grotte statique, pas de courants d'air. 
Ressources trophiques relativement pauvres (un peu de guano humide, bois pourri, détritus).

Biospéologie. Echantillon de la flore (25.VI. 1963, leg. Şt. N.): Fungi sur bois pourri.

Echantillons de la faune (25. VI. 1963, leg. Şt. N., A. N:):

1. Faune sur les parois et le plancher, à l'obscurité: Oligochaeta, Collembola, Hymenoptera, Diptera (imagines, pupae), Trichoptera (ailes détachées), Araneina.

2. Filtrage de l'eau accumulée sur l'argile: Oligochaeta, Cyclopoida, Amphipoda, Collembola, Acari.

3. Chiroptera.

Dans l'association pariétale il y a relativement beaucoup de Diptères; celle du plancher se compose de formes assez variées mais en exemplaires peu nombreux. Fort riche faune aquatique. Les chauvessouris ont été observées en exemplaires isolés et en vol.

Varia. Grotte rarement visitée, ni, dégradée, ni indiquée pour des sondages archéologiques ou paléontologiques.

\section{Grottes situées dans le bassin de Bîrzava au NO de Resita}

La zone karstique située au NO de Reşița correspond à une bande discontinue de calcaires du Barrémien-Aptien, orientée NE-SO, commençant par la localité Ezeriş (au NE) et finissant près de Cîrnecea (au SO).

Au centre de cette bande, entre Ocna de Fier et un point situé près de Dognecea, les calcaires sont métamorphisés. Bien que longue, cette bande est fort étroite (largeur maximum $1 \mathrm{~km}$ au NE de Dognecea). Sur cette bande calcaire, les phénomènes exo- et endokarstiques sont, naturellement, bien maigrement représentés. Nous avons exploré une seule grotte, Peştera din Dealul Colțan. Les mines désaffectées et les galeries d'exploration des alentours de Bocşa, Ocna de Fier et Dognecea, dont certaines sont d'âge romain, d'autres médiévales ou plus récentes, sont plus intéressantes, au moins pour le biospéléologue.

\section{Peştera din Dealul Colțan}

(Fig. 11)

Date de l'exploration. 20. VI. 1963 (V. Sencu, A. Negrea, Şt. Negrea).

Emplacement. Située en proximité des fours à chaux de Colțan, à $5 \mathrm{~km}$ au SE de Bocsa Romîna (ville de Reşița), la grotte est creusée dans le versant gauche de la vallée de Bîrzava, à $250 \mathrm{~m}$ d'altitude ab- 
solue et à $74 \mathrm{~m}$ d'altitude relative. On y accède en suivant un sentier qui remonte la pente entre les fours à chaux et la carrière de calcaire (difficile à trouver sans l'aide d'un guide).

Description. Petite grotte (12 $\mathrm{m}$ de longueur), creusée dans les calcaires du Barrémien-Aptien présentant une direction $\mathrm{N} 25^{\circ} \mathrm{O}$ et un pendage de $70^{\circ} \mathrm{NE}$; fossile, descendante (à l'exception de la portion finale qui est horizontale); un premier secteur de $5 \mathrm{~m}$ directement éclairé. Entrée orientée SSE, large de 1,4 m, haute de 1,2 m. La grotte se compose d'un couloir débouchant dans une salle formée sur l'intersection de plusieurs lignes tectoniques, ainsi que d'un boyau étroit et bas, finissant par une cheminée. Orientation des diaclases: $\mathrm{N} 30^{\circ} \mathrm{O}$, inclinaison $70^{\circ} \mathrm{O} ; \mathrm{N} 86^{\circ} \mathrm{E}$, inclinaison $60^{\circ} \mathrm{O}$.

Il y a de l'eau de condensation et d'infiltration (plancher humide, parois et plafond suintants). Dans la zone de l'entrée, hiéroglyphes de corrosion. Faible concrétionnement: plancher stalagmitique au fond, coulées pariétales banales à tubercules, et quelques stalactites fistuleuses. Dans la zone de l'entrée, remplissage de sol de forêt, feuilles mortes, pierraille; dans le reste, argile et pierraille.

La génèse de la grotte est liée à l'infiltration de l'eau des précipitations sur des fissures tectoniques et sur des synclases.

Spéoclimat. Températures à $19 \mathrm{~h}$ : à l'extérieur, air $15^{\circ} \mathrm{C}$, surface du sol $13,8^{\circ} \mathrm{C}$; au fond, air $11,5^{\circ} \mathrm{C}$, plancher $8,7^{\circ} \mathrm{C}$ (grotte chaude). Humidité relative $100 \%$ (grotte fort humide). Grotte statique, pas de courants d'air.

Ressources trophiques riches (bois pourri, amas de feuilles mortes, détritus fin, argile).

Biospéologie. Echantillons de la faune (20. VI. 1963, leg. A. N., Şt. N.): sur le plancher à l'obscurité et dans le secteur à éclairage diffus: Oligochaeta, Gastropoda, Collembola, Coleoptera, Diptera, Araneina, Opiliones, Acari.

L'association pariétale est absente; la faune du plancher, riche, est similaire à celle de la litière de la région avoisinante.

Varia. Grotte rarement visitée, pas dégradée; indiquée pour des sondages archéologiques: le musée de Reşiţa conserve des objets appartenant à la culture dite «de Coțofeni», provenant de sondages exécutés à l'extérieur, au voisinage de la grotte.

\section{Galeria de explorare din Dealul Colțan}

(Fig. 12)

Date de l'exploration. 20. VI. 1963 (A. Negrea, V. Sencu, Şt. Negrea). 
Emplacement. Galerie creusée dans la colline Colțan, au-dessus des fours à chaux, à $5 \mathrm{~km}$ en direction SE par rapport à la localité Bocşa Romîna (ville de Reşița), dans le versant gauche de la vallée de Bîrzava, à $230 \mathrm{~m}$ d'alt. absolue et $56 \mathrm{~m}$ d'alt. relative. L'entrée, cachée par des arbustes, est indiquée par la présence d'un fossé et d'un terril. Orientation E.

Description. Cavité artificielle longue de plus de $50 \mathrm{~m}$, creusée pour donner une idée sur la qualité et l'extension du calcaire en vue de son exploitation industrielle; ce creux est dépourvu de cours d'eau, horizontal (le secteur au fond ascendant), éclairé (lumière diffuse) sur les premiers $26 \mathrm{~m}$.

A $25 \mathrm{~m}$ au delà de l'entrée, on pénètre par un puits profond de $3 \mathrm{~m}$ dans une galerie inférieure; immédiatement à gauche de ce puits on observe plusieurs ramifications, fort courtes car l'on avait aussitôt rencontré des schistes cristallins; une salle s'est formée à ce carrefour, par effondrement du plafond de la galerie.

Il y a de l'eau d'infiltration formant des accumulations sur le plancher, et les parois sont humides. Nous avons remarqué de petites coulées pariétales. Sur le plancher, argile de décalcification et, dans la salle, du matériel clastique.

Spéoclimat. Température à $20 \mathrm{~h}$ : à l'extérieur, air $13,2^{\circ} \mathrm{C}$, sol $13,2^{\circ} \mathrm{C}$; au fond de la galerie, air $10,5^{\circ} \mathrm{C}$, plancher $9,2^{\circ} \mathrm{C}$. Humidité relative $100 \%$. Cavité statique, pas de courants d'air.

Ressources trophiques fort pauvres (quelques petits amas de guano dans la salle).

Bi os pé ologie. Echantillon (20. VI. 1963, leg. Şt. N.) dans la salle, à l'obscurité: Trichoptera, Diptera (pupae, exuvies dans le guano) Observé, mais non collecté: Collembola. Faune pauvre.

\section{Abatajul lui Anton}

(Fig. 13-14)

Synonymie. Abatajul Anton de Padua; Golul lui Anton.

Date de l'exploration. 22. VI. 1963 (Şt. Negrea, A. Negrea).

Emplacement. Mts. de Dognecea, vallée Johann (versant gauche). En partant de la mine de Dognecea ( $1^{\mathrm{er}}$ secteur, connu sous le nom de "Mina Ferdinand»), on remonte sur quelques centaines de m la vallée Johann, jusqu'à l'entrée principale de «l'abattage» - entrée située à proximité immédiate du chemin. Cet «abattage», d'environ $650 \mathrm{~m}$ de longueur totale, et dont nous avons exploré environ $230 \mathrm{~m}$, n'est autre 
chose qu'un tronçon de la mine Dognecea, mine creusée il y a plusieurs siècles et depuis longtemps désaffectée. Altitude absolue $440 \mathrm{~m}$.

Description. L'«abattage» avait été creusé exactement à la limite séparant les calcaires métamorphisés des schistes cristallins sousjacents du synclinal, dans le but de permettre l'extraction du minerai de fer. Les parois sont en calcaire du Barrémien-Aptien, tandis que le plancher est constitué par les schistes (on y trouve aussi du matériel clastique de calcaire ainsi que du minerai de fer extrait de l'abattage). Lors de la perforation des galeries, les mineurs avaient intercepté plusieurs galeries naturelles, formées sur des diaclases par l'eau d'infiltration.

L'entrée principale, orientée O-SO (large de $22 \mathrm{~m}$ et haute de $10 \mathrm{~m}$ ) est pratiquée dans la paroi calcaire; une autre entrée, petite celle-ci, se trouve à peu de distance, à droite. La galerie n'est pas parcourue par un cours d'eau; elle est d'abord horizontale, descendante ensuite, et arrive par endroits à $100 \mathrm{~m}$ de profondeur. Les premiers $30-40 \mathrm{~m}$ sont éclairés. Dans le secteur exploré (voir fig. 13) l'eau dégoutte partout, sans former d'accumulations. Dans les portions de galeries naturelles, il y a sur les parois des sillons d'érosion et, ça et là, des coulées pariétales épaisses parfois de $10 \mathrm{~cm}$ tandis que, sur le plafond, on observe des stalactites fistuleuses.

Spéoclimat. Températures à $13 \mathrm{~h}$ : à l'extérieur, air $29,5^{\circ} \mathrm{C}$; à la cheminée de l'abattage 21 , air $13^{\circ} \mathrm{C}$, plancher $9,8^{\circ} \mathrm{C}$; au fond de la galerie munie de cette cheminée, air $12,5^{\circ} \mathrm{C}$, plancher $9,5^{\circ} \mathrm{C}$, guano $10,5^{\circ} \mathrm{C}$. Humidité relative: $95-98 \%$. Galerie dynamique; faibles courants d'air.

Ressources trophiques relativement pauvres: bois en état pas trop avancé de décomposition, détritus végétaux, quelques monceaux de guano et, par endroits, argile.

Biospéologie. Echantillon de la flore (22. VI. 1963, leg. A. N.): Fungi sur bois de mine (cheminée de l'abattage 21).

Echantillons de la faune (22. VI. 1963, leg. A. N., Şt. N.).

1. Faune du bois humide, partiellement pourri, et des détritus végétaux, à l'obscurité: Oligochaeta, Lithobiidae, Collembola, Araneina, Opiliones, Acari.

2. Faune du guano: Coleoptera, Diptera (imagines, larvae, pupae).

Observé, mais non collecté: Carabidae, Chiroptera.

Les chauves-souris formaient quelques colonies de quelques dizaines d'exemplaires chacune au-dessus des monceaux de guano, à $10 \mathrm{~m}$ de 
hauteur; elles se sont envolées à notre approche. Association pariétale absente. La faune est concentrée dans les endroits à ressources trophiques (bois, guano).

\section{Grottes situées dans le bassin de Bîrzava, au S et au SE de Reșița}

(Fig. 15 et 17)

Cette zone karstique comprend les bassins des ruisseaux Secu, Sodolu Mare et Doman, affluents gauches de la Bîrzava. Au point de vue géologique, on y rencontre des formations appartenant au paléozoïque et au mésozoïque, formations supportées par un fondement cristallin. Le grand nombre de dolines sur les plateaux de cette zone karstique détermine leur caractère semi-endoréiques; on y remarque aussi plusieurs vallées sèches (par exemple la vallée du Sodolu Mic) ainsi que des vallées aveugles (par exemple la vallée finissant par le ponor - perte - de Dragoina). Dans notre précédent travail sur les grottes du Banat (Botoşaneanu, Negrea et Negrea, 1963) ont été décrites les grottes suivantes appartenant à cette zone: Stîrnic, Gaura de la Capu Baciului, Gaura Pîrşului de la Capu Baciului, Gaura Turcului, Gaura Pîrşului et Gaura Siomului. Nous ajoutons maintenant à cette liste: Peştera cu oase de la Stîrnic et Avenul de la Cantonul Pin. Il reste encore d'autres grottes et surtout des avens à explorer.

\section{Peştera cu oase de la Stîrnic}

(Fig. 16)

Synonymie. Peştera cu oase de la Reşița.

Bibliographie. Halaváts, G. (1888; paléontologie).

Date de l'exploration. 26. VI. 1963 (Şt. Negrea, V. Sencu, A. Negrea).

Emplacement. En partant de Reşița, on avance $1 \mathrm{~km}$ sur la route reliant cette ville à la commune de Doman, et on atteint la confluence . des vallées du Doman et du Stîrnic; à partir de cet endroit, on remonte sur $250 \mathrm{~m}$ la vallée du Stîrnic, puis le versant droit, abrupt et boisé de cette vallée, jusqu'à l'entrée de la grotte (orientation: O). Difficile à trouver sans l'aide d'un guide. Altitude absolue: $280 \mathrm{~m}$; alt. relative: $32 \mathrm{~m}$.

Description. Petite grotte (35 m de longueur totale), creusée dans des calcaires compacts du Barrémien-Aptien, fossile, horizontale, ascendante et descendante, éclairée directement ou de façon diffuse sur les 8 premiers mètres. La grotte présente un système de couloirs et 
de salles de dimensions différentes, et qui se font suite. L'exploration est rendue ardue par le colmatage accentué des salles avec des concrétions et surtout avec de l'argile (les salles du fond ont pu ètre explorées uniquement après désobstruction). L'argile est recouverte de pierraille jusqu'au point fixe 3 ; entre les points 15 et 16 elle s'est déposée sur une croûte stalagmitique, et, par endroits, c'est l'argile qui est recouverte par cette croûte présentant des dômes, des stalagmites ou colonnes. Les formations concrétionnaires au plafond et sur les parois se réduisent à des coulées pariétales variées, tubercules et stalactites.

Dans la portion finale de la grotte (commençant par la salle A), parois, plafond et plancher sont ruisselants à cause de l'eau de condensation et d'infiltration. Il y a des hiéroglyphes de corrosion.

La grotte s'est formée par élargissement de diaclases sous l'action des eaux d'infiltration. Certaines fissures tectoniques sont actuellement colmatées par l'argile ou par le concrétionnement, tandis que des racines d'arbres pénètrent dans la grotte par d'autres fissures; ce dernier fait prouve que le plafond se trouve à proximité de la surface.

Spéoclimat. Températures à $9 \mathrm{~h}$ : à l'extérieur, air $20^{\circ} \mathrm{C}$; au point fixe 2 , air $11,5^{\circ} \mathrm{C}$, plancher $8,8^{\circ} \mathrm{C}$; au point fixe 8 , air $10,5^{\circ} \mathrm{C}$, plancher $8,5^{\circ} \mathrm{C}$ (grotte chaude). Humidité relative $100 \%$, diminuant légèrement vers l'entrée (grotte humide). Grotte statique; de forts courants d'air se dirigeaient du fond vers l'entrée.

Ressources trophiques relativement pauvres (bois pourri, feuilles mortes, détritus, argile).

Biospéologie. Echantillon de la flore (26. VI. 1963, leg. A. N.). Fungi sur bois pourri et sur cadavres d'insectes.

Echantillons de la faune (26. VI. 1963, leg. Şt. N., A. N.).

1. Faune pariétale, à l'obscurité: Gastropoda, Diplopoda, Diptera, Trichoptera.

2. Faune sur l'argile, le bois pourri et les détritus, à l'obscurité: Gastropoda, Diplopoda (Gervaisiidae, Polydesmidae, Ascospermophora, Iulidae), Geophilomorpha, Collembola, Coleoptera, Acari.

L'association pariétale, dominée par les diptères, s'étend jusqu'au point fixe 10. La faune du plancher, dominée par les diplopodes, est riche et variée.

Restes osseux actuels (26. VI. 1963, leg. Şt. N., A. N.): Rodentia, Carnivora, et fossiles (leg. V. S.): Ursus spelaeus.

Varia. Grotte rarement visitée, partiellement dégradée. Des recherches paléontologiques et archéologiques devraient être poursuivies (dans la salle A l'on remarque des sondages, exécutés probablement par Halaváts). 


\section{Avenul de la Cantonul Pin}

(Fig. 18)

Nom donné par les auteurs.

Date de l'exploration. 24. VI. 1963 (V. Sencu, Şt. Negrea).

Emplacement. L'aven est placé dans la partie $\mathrm{S}$ de la colline Cîrşia, à $555 \mathrm{~m}$ d'altitude absolue et à $205 \mathrm{~m}$ d'altitude relative. A partir de la Commune de Secu (rayon Reşița), on suit jusqu'au canton «din Poiana Bichii» la route conduisant à Valiug; à partir de cet endroit, il y a encore $1700 \mathrm{~m}$ à faire, en direction SO, sur la route s'ouvrant dans la chaussée Reşița Anina à Şaua Baciului; l'aven $(\varnothing 1,5 \mathrm{~m})$ s'ouvre à $50 \mathrm{~m}$ à droite de cette route, sur un sentier, près de 3 dolines, en pleine zone boisée. Difficile à trouver sans l'aide d'un guide (fig. 17).

Description. Aven profond de $30 \mathrm{~m}$, creusé dans des calcaires du Barrémien-Aptien, sous-fossile, formé sur une diaclase verticale, directement éclairé jusqu'à la première terrasse $(-13 \mathrm{~m})$ et éclairé de façon diffuse jusqu'à la seconde terrasse $(-21 \mathrm{~m})$. Nous l'avons exploré sur $25 \mathrm{~m}$ de profondeur (suivant certains renseignements, après 5 autres mètres l'aven finit par 2 petites salles). Le secteur central se présente sous l'aspect de la moitié d'un tunnel de pression, et se continue latéralement sur des diaclases.

Parois et terrasses sont humides; par endroits l'on observe de l'eau de ruissellement (l'eau ruisselle sans doute abondamment après les averses). Hiéroglyphes et septes de corrosion. Le concrétionnement des parois est faiblement developpé (coulées pariétales, tubercules, stalactites).

L'aven s'est formé par infiltration de l'eau des précipitations sur des fissures tectoniques.

Speoclimat. Température à $17 \mathrm{~h}$ : à l'extérieur, air $29^{\circ} \mathrm{C}$; sur la seconde terrasse, air $11,5^{\circ} \mathrm{C}$, plancher $10,8^{\circ} \mathrm{C}$. Humidité relative $90-95 \%$ (aven relativement humide). Aven dynamique; faibles courants d'air ascendants.

Ressources trophiques relativement riches sur les terrasses (sol de forêt entraîné, bois pourri, amas de feuilles mortes, détritus).

Biospéologie. Echantillon de la faune générale (24. VI.1963, leg. V. S.): Oligochaeta, Gastropoda, Diplopoda, Collembola, Coleoptera, Diptera (imagines, larvae), Araeina, Opiliones, Acari.

L'association pariétale est pauvre; riche faune du plancher, ressemblant à celle de la litière à l'extérieur.

Varia. Aven peu fréquenté, non dégradé. 


\section{Grottes situées dans le bassin du Caras}

(Fig. 19)

La zone karstique explorée comprend les gorges du Caraş et celles de la Gîrlişte, avec leurs régions limitrophes - parties composantes des Mts. du Caraş. Au point de vue géologique, la zone est formée de terrains sédimentaires mésozoïques surtout calcaires du synclinorium plissé de la zone Reşița - Moldova Noua; à la base de ces formations on trouve les schistes cristallins du domaine de Semenic. L'exokarst est surtout développé sur la plateforme du Caraş, située à 400-600 m d'altitude; celle-ci est drainée par les vallées duCaraş et de la Gîrlişte, dont les eaux s'écoulent à 150-200 m plus bas, formant des gorges dans les versants desquelles est creusée la majorité des grottes. Parmi les formes de l'exokarst, ce sont les lapiez et surtout les dolines de plateau, de pente et de vallée qui sont le mieux développés. Dans notre travail antérieur (Botoşaneanu, Negrea et Negrea, 1963) nous avons présenté 14 grottes de cette zone (voir fig. 19); nous ajouterons maintenant, pour les gorges du Caraş: Peştera din Drumul Prolazului, Peştera cu Fereastra, Peştera Vraşka; et pour les gorges de la Gîrlişte: Peştera Galațiului.Il y a encore de nombreuses autres grottes et avens dans la zone; ils formeront l'objet des explorations futures; il s'agit, pour la plupart, d'accidents souterrains difficiles à trouver.

\section{Peştera din Drumul Prolazului}

(Fig. 20)

Nom donné par les auteurs.

Date de l'exploration. 10. X. 1963 (Şt. Negrea, A. Negrea).

Emplacement. Grotte située dans le versant gauche des gorges du Caraş, à $1100 \mathrm{~m}$ en amont de Peştera de sub Cetate II (fig. 19). Altitude absolue $258 \mathrm{~m}$, altitude relative: $3 \mathrm{~m}$. A partir de la commune de Caraşova (rayon Reşița), une heure de marche sur le «drumul Prolazului»; l'entrée, orientée $\mathrm{N}$, est située tout près de cette route.

Description. Petite grotte (longueur totale $11 \mathrm{~m}$ ), creusée dans des calcaires stratifiés, avec intercalations de silex en bandes, d'âge lusitanien-kimméridgien; elle est fossile, faiblement descendante, obscure presque partout. Ce n'est qu'un petit couloir qui devient impénétrable après $11 \mathrm{~m}$. Pas d'eau de condensation ou d'infiltration. Nous avons observé des septes de corrosion, un petit nombre de coulées pariétales et de tubercules; mais les parois et le plafond sont en 
général nus. Plancher colmaté par de l'argile; dans la zone de l'entrée il y a du sol de forêt et des amas de feuilles mortes.

La grotte s'est formée par élargissement d'une fissure tectonique par les eaux du Caraş.

Spéoclimat. Températures à $14 \mathrm{~h}$ : à l'éxtérieur, air $13,8^{\circ} \mathrm{C}$; au fond, air $12,9^{\circ} \mathrm{C}$ (grotte chaude). Humidité relative (psychromètre aspirateur): à l'extérieur $87 \%$; au fond de la grotte $94 \%$ (grotte relativement humide). Grotte statique, sans courants d'air.

Ressources trophiques relativement pauvres (c'est uniquement l'argile qui compte pour la zone obscure).

Biospéologie. Echantillons de la faune (10. X. 1963, leg. A. N., Şt. N.):

1. Faune pariétale à l'obscurité: Diptera, Araneina, Pseudoscorpiones.

2. Faune sur un champignon, à l'obscurité: Collembola, Acari.

Observé, mais non collecté: Macrolepidoptera.

Faune (et surtout celle du plancher) pauvre.

Varia. Grotte pas visitée, sans traces de dégradation, non indiquée pour des sondages paléontologiques et archéologiques.

\section{Peştera cu Fereastra}

(Fig. 21)

Nom donné par les auteurs.

Date de l'exploration. 10. X. 1963 (Şt. Negrea, A. Negrea).

Emplacement. La grotte est située dans le versant droit des gorges du Caraş, dans la colline Stocic, vis à vis de Peştera din Drumul Prolazului, à $256 \mathrm{~m}$ d'alt. absolue et à $1 \mathrm{~m}$ seulement d'alt. relative (fig. 19). L'entrée, orientée $\mathrm{S}$, se trouve à proximité immédiate du Caraş; elle est aisément accessible du «drumul Prolazului».

Description. Petite grotte (longueur totale $27 \mathrm{~m}$ ), creusée dans des calcaires stratifiés avec intercalations de silex en bandes ou en nodules, d'àge lusitanien-kimméridgien, les strates étant légèrement inclinés dans le sens du cours du Caraş. La grotte est fossile, horizontale (ascendante), et elle se trouve à un stade avancé de colmatage par concrétionnement (coulées pariétales proéminentes) ainsi que par les dépôts d'argile et de matériel clastique. Pas d'eau d'infiltration ou de condensation. Septes de corrosion et hiéroglyphes. Le silex se présente sous l'aspect de bandes ou de nodules. Il faut mentionner, outre les coulées pariétales, la présence de quelques tubercules, corallites, stalagmites et stalactites. 
Grotte développée sur fissures tectoniques, par suite de l'action des eaux d'infiltration.

Spé o climat. Température à $11 \mathrm{~h}$ (après la pluie) : à l'extérieur, air $12,5^{\circ} \mathrm{C}$; au fond de la grotte, air $13,8^{\circ} \mathrm{C}$ (grotte chaude). Humidité relative au psychromètre aspirateur: à l'extérieur $94 \%$, au fond de la grotte $92 \%$ (grotte relativement humide). Statique, pas de courants d'air.

Ressourcestrophiques pauvres (bois pourri, détritus).

Biospéologie. Echantillons de la faune (10. X. 1963, leg. Şt. N., A. N.):

1. Faune pariétale à l'obscurité: Diptera, Araneina.

2. Faune sur les plancher (argile, bois pourri, détritus): Gastropoda, Gervaiisidae, Collembola, Diptera (larvae).

Observé, mais non collecté: Macrolepidoptera. Faune pariétale relativement riche quantitativement; celle du plancher plus variée, mais quantitativement pauvre.

Varia. Grotte rarement visitée, pas dégradée; non indiquée pour des sondages archéologiques ou paléontologiques.

\section{Peştera Vraşka}

(Fig. 22)

Synonymie. Vraşkina pecika; Peştera Vracina.

Bibliographie. Decu-Burghele, A. (1963; citée sous le nom de Peştera Vracina).

Date de l'exploration. (31. VII. 1963 (Şt. Negrea, A. Negrea).

Emplacement. Située dans le versant gauche (Dealul Colnic) de la vallée du Caraş, à $224 \mathrm{~m}$ d'altitude absolue et $40 \mathrm{~m}$ d'altitude relative (fig. 19). L'entrée de la grotte (orientée N) regarde vers le Caraş. On y accède en montant par un sentier qui commence à la commune de Caraşova (bâtie au pied du Dealul Colnic), ou bien en empruntant la route Caraşova-Anina jusqu'à la borne du km 16, pour continuer ensuite sur un sentier à droite, qui conduit bientôt au «cleantz» (abrupt calcaire) dans lequel est creusée la grotte.

Description. Grotte de dimensions moyennes (65 m de longueur totale), creusée dans des calcaires du Barrémien-Aptien; la stratification de ceux-ci est indistincte, la roche étant masquée à l'extérieur par la végétation et à l'intérieur de la grotte par des formations concrétionnaires. Grotte fossile, faiblement ascendante, développée sur un système de diaclases (on a pu observer aussi un tronçon en tunnel de 
pression), obscure pour la majeure partie. Il y a de l'eau de condensation et d'infiltration, ce qui favorise le développement des algues et des mousses sur les parois dans la zone à éclairage diffus. D'assez nombreuses formes de corrosion: stries, microfissures et coupoles. La grotte, surtout son secteur final, se trouve dans un stade avancé du colmatage par de l'argile et par les concrétions; mentionnons des coulées pariétales proéminentes, formant par endroits des "ponts» (voir fig. 22), de grosses stalactites, des stalagmites et de petites colonnes. Dans la zone de l'entrée, il y a du sol de forêt et de la pierraille.

L'aspect de galerie méandrée, suivant la direction de certaines diaclases, prouve qu'il s'agit de l'œuvre d'un petit affluent du Caraş, jadis alimenté par les eaux d'infiltration et aujourd'hui disparu.

Spéoclimat. Températures à $13 \mathrm{~h}$ : à l'extérieur, air $20,5^{\circ} \mathrm{C}$; au premier tournant (éclairé), air $13,5^{\circ} \mathrm{C}$, plancher $12,8^{\circ} \mathrm{C}$; au fond, air $12^{\circ} \mathrm{C}$, plancher argileux $10,8^{\circ} \mathrm{C}$ (grotte chaude). Humidité relative: $100 \%$, diminuant légèrement vers l'entrée (grotte humide). Grotte statique, pas de courants d'air.

Ressources trophiques relativement pauvres: crottin de mouton et de chèvre, fort peu de guano, détritus végétal, tout ceci surtout dans le premier secteur.

Biospéologie. Echantillon de substrat (argile) pour des recherches sur la flore bactérienne (31. VII. 1963, leg. Şt. N., A. N.).

Echantillons de la faune (31. VII. 1963, leg. A. N., (Şt. N.):

1. Faune pariétale à l'obscurité: Microlepidoptera, Macrolepidoptera, Araneina.

2. Faune sur l'argile avec crottin et détritus végétaux, à l'obscurité: Oligochaeta, Polydesmidae, Cryptopsidae, Collembola, Araneina.

3. Faune des maigres accumulations de guano, à l'obscurité: Oligochaeta, Gastropoda.

Dans les registres de la collection de l'Inst. de Spéologie, figure aussi un échantillon collecté par Val. Puşcariu le 18. X. 1955: Gastropoda, Coleoptera (larvae), Diptera, Araneina.

En général la faune pariétale et celle du plancher sont assez pauvres.

Varia. Grotte assez fréquentée et partiellement dégradée. Elle est indiquée pour des sondages paléontologiques et archéologiques. 
16. Peştera Galațiului

(Fig. 23)

Synonymie. Gaura lui Ecob.

Date de l'exploration. 30. VII. 1963 (Şt. Negrea, A. Negrea).

Emplacement. Creusée dans le versant droit des gorges de la Gîrlişte, au lieu dit «Galați»; altitude absolue $362 \mathrm{~m}$, alt. relative env. $40 \mathrm{~m}$ (fig. 19). En partant de Carasova (rayon Reşița), on avance $5 \mathrm{~km}$ sur la route se dirigeant vers Anina, jusqu'à l'endroit connu sous le nom «La Cruce» (borne du km 19); on abandonne cette route pour prendre un chemin vicinal, à droite, parmi les cultures, chemin que l'on suit environ $550 \mathrm{~m}$, pour arriver au-dessus du versant droit, abrupt, des gorges de la Gîrlişte; on descend enfin, parmi les abrupts calcaires et les touffes de lilas, environ $40 \mathrm{~m}$ jusqu'à l'entrée de la grotte (difficile à trouver sans l'aide d'un guide).

Description. Grotte de dimensions moyennes (192 m de longueur totale), creusée dans des calcaires stratifiés, d'âge lusitanien-kimméridgien et présentant des intercalations stratiformes de silex. Les couches distinctes à l'intérieur de la grotte présentent une orientation SO-NE.

Il y a deux entrées (A et B, fig. 23), orientées O. Grotte fossile, horizontale, formée de 3 tronçons: le tronçon de l'entrée A faiblement ascendant, celui de l'entrée B, «du système principal», faiblement descendant, et le tronçon unissant les deux premiers ascendant - descendant. Il s'agit d'un système compliqué de diaclases se coupant sous des angles divers; mais la salle de la partie E de la grotte semble s'être formée sur synclase; dans le secteur final de la grotte, l'aspect de diaclase est estompé à cause du concrétionnement. Le tronçon de l'entrée A est en majeure partie éclairé, celui de l'entrée B surtout obscur. Dans la zone obscure du système principal il y a de l'eau de condensation sur les parois et au plafond et d'infiltration: l'eau dégoutte par de nombreuses stalactites; dans la zone à éclairage diffus, les parois sont verdies par des algues et des mousses à cause de l'humidité accrue et de la présence de la lumière. De nombreux hiéroglyphes, septes et coupoles de corrosion ont été observés surtout dans le tronçon de l'entrée A et dans celui du raccord, tandis que dans la partie finale du système principal il y a des traces d'érosion. Les formes concrétionnaires sont présentes presque exclusivement dans la portion obscure de ce système principal: stalactites (fistuleuses, en forme de tétine, anémolites, baldaquins), coulées pariétales (proéminentes ou bien peu épaisses), petits et grands gours secs, stalagmites et colonnes. Le remplissage du plancher est représenté par une couche d'argile 
mélangée de sol de forêt près des entrées recouverte d'une couche épaisse de 5-20 cm de crottin de mouton et de chèvre et de guano ancien.

La grotte s'est formée par élargissement des fissures tectoniques par l'eau d'infiltration: jadis celle-ci, parait-il, formait un petit cours d'eau souterrain, affluent de la Gîrlişte.

Spé oclimat. Températures à $17 \mathrm{~h}$ : à l'extérieur, air $22^{\circ} \mathrm{C}$; au fond du tronçon A (à l'«aven»), air $17,2^{\circ} \mathrm{C}$, plancher $16,3^{\circ} \mathrm{C}$; dans la galerie du système de raccord, air $16,8^{\circ} \mathrm{C}$, plancher $16,2^{\circ} \mathrm{C}$; dans la zone à éclairage diffus du système $\mathrm{B}$, air $12,5^{\circ} 3$, plancher $12^{\circ} \mathrm{C}$; au fond du système $\mathrm{B}$, air $10,2^{\circ} \mathrm{C}$, guano $9,9^{\circ} \mathrm{C}$ (grotte chaude). Humidité relative: $100 \%$ dans la zone obscure du système B, mais descendant jusqu'à $90 \%$ dans le reste (grotte humide). Grotte dynamique; fort courant d'air se dirigeant de la galerie de raccord vers celle du système principal (B).

Ressources trophiques riches en restes d'origine animale (crottin de chèvre et de mouton, guano ancien), tandis que ceux d'origine végétale sont absents.

Biospéologie. Echantillons de la faune (30. VII. 1963, leg. A. N., Şt. N.):

1. Faune pariétale dans le système B, à l'obscurité: Microlepidoptera, Macrolepidoptera, Trichoptera, Diptera, Araneina.

2. Faune dans les déjections humides de mouton, de chèvre et de chauves-souris, à l'obscurité: Lithobiidae, Collembola, Microlepidoptera.

La faune pariétale est variée, mais pas trop riche; faune pauvre de plancher. Nous n'avons pu observer aucune chauve-souris.

Restes osseux actuels (30. VII. 1963, leg. Şt. N.): Carniøora.

Varia. Grotte visitée uniquement par les chevriers avec leurs troupeaux, et sans traces de dégradation. Indiquée pour des sondages paléontologiques et archéologiques.

\section{Grottes situées dans les gorges de la Nera}

(Fig. 24, 25)

La Nera - l'un des cours d'eau les plus importants du Banat - prend ses sources dans le cristallin des Mts. Semenic; elle coupe transversalement, en gardant une direction générale $\mathrm{SE}-\mathrm{NO}$, la grande plateforme de calcaires mésozoïques de la zone de Reşița - Moldova Noua, en formant des gorges d'un extrême pittoresque, sauvages et 
d'exploration difficile; ces gorges s'étendent sur plus de $20 \mathrm{~km}$ entre les villages Şopotu Nou et Sasca Romîna. Le thalweg se maintient ici au-dessous de $200 \mathrm{~m}$ d'altitude, étant dominé par des hauteurs atteignant 400-600 m d'altitude. De l'E à l'O, les gorges coupent une succession de bandes calcaires orientées $\mathrm{N}-\mathrm{S}$, appartenant à divers étages du Crétacé et du Jurassique. Parmi les phénomènes de l'exokarst il faut mentionner des ponts naturels, de fortes émergences karstiques (par exemple Ochiul Beului et Iordanul) des cours d'eau au lit fort concrétionné (la Beuşnița et ses «cascades»), des dolines, etc.

Dans les versants escarpés des gorges s'ouvrent de nombreuses grottes; neuf parmi celles-ci avaient déjà été présentées dans notre travail précédent (Botoşaneanu, Negrea et Negrea 1963). En 1963, nous nous sommes occupés surtout des grottes de Culmea Lacului, abrupt situé en aval de Poiana Haimeling (fig. 25); il s'agit de Peştera din Culmea Lacului, Peştera Mica de la Lacu Dracului et Peştera de la Lacu Dracului, cette dernière abritant un lac à son entrée.

Quatre autres grottes (longues de 6-8 m), ainsi qu'un tunnel naturel, sont creusées dans les deux versants de la Nera, $200 \mathrm{~m}$ en aval de Peştera de la Lacu Dracului; toutes celles-ci sont développées dans des calcaires tithoniques (voir fig. 25). La grotte D se trouve à $4 \mathrm{~m}$ au dessus du thalweg, son entrée est ovale, le plancher horizontal. La grotte E est située à $10 \mathrm{~m}$ au NO de la précédente, son entrée est masquée par la végétation, le plancher en est ascendant. La grotte F, elle, a l'entrée au niveau même de l'eau; son plancher est ascendant. La grotte G est creusée dans la Pìnza Albinii (versant droit de la Nera); c'est un tunnel étroit, cependant accessible, creusé par l'eau s'étant écoulée le long d'une faille perpendiculaire à la direction des strates; après $10 \mathrm{~m}$ survient une portion de $6 \mathrm{~m}$ rendue inaccessible par des éboulements, mais le tunnel continue ensuite. Dans ce même abrupt calcaire se trouve une autre grotte, grande celle-ci, et encore inexplorée (Peştera din Pînza Albinii).

\section{Peştera din culmea Lacului}

(Fig. 26)

Nom donné par l'auteur.

Date de l'exploration. 3. X. 1963 (V. Sencu).

Emplacement. Située dans le versant gauche des gorges de la Nera, plus exactement dans le versant NO de Culmea Lacului, à $420 \mathrm{~m}$ en aval du petit moulin d'eau de Poiana Haimeliug et à $200 \mathrm{~m}$ 
en aval du confluent du ruisseau Ogaşu Tercovița (fig. 24, 25). «Culmea Lacului», hauteur complètement boisée, représente un prolongement en direction NO du sommet Clabat; c'est un niveau d'érosion. La Nera contourne cette hauteur, ce qui détermine la formation d'un intéressant méandre.

L'entrée de la grotte, orientée E, est presque complètement masquée par la végétation et elle est perchée dans l'abrupt baigné à sa base par les flots de la Nera: on peut y accéder uniquement en traversant la rivière en canot. Altitude absolue $208 \mathrm{~m}$, alt. relative $6 \mathrm{~m}$.

Description. Petite grotte (14 $\mathrm{m}$ de longueur), creusée dans des calcaires stratifiés, d'âge lusitanien-kimméridgien, ayant une direction de $\mathrm{N} 44^{\circ} \mathrm{O}$, une inclinaison de $41^{\circ} \mathrm{SO}$, et présentant des intercalations de silex en bandes. Il s'agit d'une salle presque circulaire, haute de $9 \mathrm{~m}$ et complètement éclairée; de la partie $\mathrm{E}$ de cette salle se détache, au niveau du plancher, une petite galerie qui se dirige vers la Nera. Dans la zone de l'entrée il y a de nombreux blocs de calcaire éboulés du plafond; ces blocs forment, avec les amas de feuilles mortes et de sol de forêt, une pente vers la salle. Pour le reste, le dépôt de remplissage est constitué par de l'argile mélangée de sable et de limon, formant à la surface un réseau de petits polygones quand elle se dessèche. A la partie terminale de la grotte, un dôme stalagmitique avec gours contenant des perles de caverne. Sur le plafond, au-dessus du point fixe 5, un candélabre de grandes dimensions et, tout au voisinage, une coulée pariétale et quelques stalactites. On observe, sur des synclases, une série de petits sillons formés par l'eau d'infiltration.

L'entrée de la grotte s'ouvre à $6 \mathrm{~m}$ au-dessus de l'eau de la Nera et le plancher de la salle se trouve à $3 \mathrm{~m}$ seulement au-dessus de ce niveau (fig. 26 section $\mathrm{I}_{-} \mathrm{I}^{\prime}$ ). Par hautes eaux, la grotte est done inondée par des fissures et par la galerie A; quand l'eau se retire, elle laisse sur le plancher le mélange de limon, d'argile et de sable.

La génèse de la grotte avait été conditionnée par l'infiltration des eaux de la Nera et de celle provenant de précipitations, sur des synclases et diaclases.

Spéoclimat. Sous l'influence directe des conditions de l'extérieur.

Ressources trophiques relativement riches (bois pourri, détritus végétal).

Biospé ologie. Faune banale épigée. Aucun échantillon prélevé.

Varia. Grotte jamais visitée, pas dégradée. Elle n'est pas indiquée pour des sondages paléontologiques et archéologiques. 
18. Peştera mica de la Lacu Dracului

(Fig. 27)

Nom donné par les auteurs.

Date de l'exploration. 3. X. 1963 (Şt. Negrea, V. Sencu).

Emplacement. Creusée dans le versant gauche des gorges de la Nera, $20 \mathrm{~m}$ en amont de Peştera de la Lacu Dracului et à une distance de $15 \mathrm{~m}$ de la rivière (fig. 24, 25). Alt. absolue $210 \mathrm{~m}$, alt. relative $2 \mathrm{~m}$. L'entrée de la grotte, orientée NNE, se trouve à la base d'une paroi calcaire haute de $15 \mathrm{~m}$, appartenant à la hauteur boisée «Culmea Lacului».

Description. Petite grotte (longue de $16 \mathrm{~m}$ ), sous-fossile, presque partout obscure, développée dans des calcaires stratifiés, d'âge lusitanien-kimméridgien, présentant des intercalations de silex en bandes, la direction des strates étant de $\mathrm{N} 30^{\circ} \mathrm{O}$ et le pendage de $48^{\circ} \mathrm{SO}$.

C'est une galerie, d'abord descendante puis horizontale, qui devient impénétrable à cause d'un petit lac terminal. Aussitôt après l'entrée de ce couloir se détache à droite un diverticule long de $2 \mathrm{~m}$ et haut de $0,8 \mathrm{~m}$; ce diverticule s'élargit au milieu pour former une petite salle circulaire haute de 1,2 m.

La zone de l'entrée et le secteur qui lui fait suite sont colmatés par de la pierraille calcaire venant de l'extérieur, par de l'argile et des feuilles mortes; dans la salle il y a des blocs de calcaire et de l'argile, et le plancher de la zone terminale est recouvert d'un limon argileux d'un jaune-gris. Parois et plafond nus (exception: quelques stalactites et petites coulées pariétales). Dans la zone de la salle, il y a des septes calcaires et des formes d'érosion. Par suite de l'indice différent de solubilité, le silex reste en relief sur les parois de la galerie, soit sous l'aspect de longues «consoles», soit sous celui de nodules noirs ou d'un noir-rougeâtre.

Il y a de l'eau de condensation. Le plancher du secteur terminal se trouve approximativement au même niveau que la Nera et que le plancher de Peştera de la Lacu Dracului; par hautes eaux, les flots de la rivière pénètrent par des fissures et inondent la grotte; il est d'autre part possible que l'eau de petit lac terminal soit en communication avec celle de la salle D de Peştera de la Lacu Dracului. D'ailleurs, nos observations ont montré que ces deux grottes avaient jadis formé une unité, et qu'elles se sont séparées soit à cause des effondrements, soit par colmatage (voir galeries B et E de Peştera de la Lacu Dracului).

La grotte est développée sur synclases et représente le résultat de l'érosion et de la corrosion exercées par les eaux de la Nera et par 
les eaux d'infiltration, ces dernières ayant élargi des fissures pour former des cheminées.

Spé o climat. Températures à $17 \mathrm{~h}$ : à l'extérieur, air $16^{\circ} \mathrm{C}$; au fond de la grotte, air $15,4^{\circ} \mathrm{C}$, plancher argileux $15^{\circ} \mathrm{C}$, eau du lac $15,2^{\circ} \mathrm{C}$ (grotte chaude). Humidité relative (psychromètre aspirateur) à $18 \mathrm{~h}$ : à l'extérieur $88 \%$; près du lac terminal 100\% (grotte fort humide). Grotte statique, courants ascendants fort faibles.

Ressources trophiques riches (bois pourri, feuilles mortes et détritus végétal, argile).

Biospé ologie. Echantillon de la flore (3.X.1963, leg. Şt. N.): Fungi sur bois et mycélies sur argile avec détritus (le tout à l'obscurité).

Echantillons de la faune (3. X. 1963, leg. Şt. N.).

1. Faune sur bois pourri et sur détritus végétaux, à l'obscurité: Gastropoda, Polydesmidae, Acari.

2. Filtrage de l'eau du petit lac terminal à fond d'argile: Oligochaeta, Ostracoda, Asellidae, Hydrachnellae.

Observé mais non collecté: Diptera, Araneina. Association pariétale pauvre et banale. Faune du plancher riche et intéressante. La faune aquatique comprend aussi quelques éléments dignes d'intérêt.

Varia. Grotte jamais visitée et non dégradée, pas indiquée pour des sondages paléontologiques ou archéologiques.

\section{Peştera de la Lacu Dracului}

(Fig. 28, 29)

Dates de l'exploration. (30. IX. 1962 (Şt. Negrea) et 3. X. 1963 (V.Sencu, Şt. Negrea, A. Negrea).

Emplacement. Développée dans le versant gauche des gorges de la Nera, plus exactement dans le versant NO de Culmea Lacului, à $500 \mathrm{~m}$ en aval du moulin d'eau sur l'ogaşul Haimeliug et à $80 \mathrm{~m}$ en aval de Peştera din Culmea Lacului (fig. 24, 25). On quitte le sentier qui longe la rive gauche de la Nera, à un certain endroit qu'il est difficile de trouver sans l'aide d'un guide, et l'on monte sur le versant boisé; on se trouve après $35 \mathrm{~m}$ auprès du «Lacu Dracului» (Lac du Diable), installé dans l'énorme entrée de la grotte, orientée NE. Altitude absolue: $210 \mathrm{~m}$; alt. relative $3 \mathrm{~m}$ à l'entrée et $-2 \mathrm{~m}$ au point le plus bas du plancher de la grotte.

Description. Grotte de dimensions moyennes (68 $\mathrm{m}$ de longueur totale), creusée dans des calcaires stratifiés et avec des intercalations 
de silex en bandes, d'âge lusitanien-kimméridgien, présentant une direction de $\mathrm{N} 28^{\circ} \mathrm{E}$ et une inclinaison de $46^{\circ} \mathrm{SO}$. Elle est ascendante, sous-fossile, éclairée (lumière directe ou diffuse) dans sa majeure partie. La grotte se compose d'un vestibule A et d'une salle D à partir de laquelle se détachent plusieurs galeries. On arrive dans la salle par la galerie descendante $\mathrm{C}$, avec un dépôt de remplissage massif de pierraille calcaire et d'argile, le tout venant de l'extérieur. Dans la salle, on remarque des coulées pariétales, des stalactites d'où l'eau filtre et des stalagmites, une grande quantité d'argile apportée par les eaux s'infiltrant par cheminées et galeries et déposée sous l'aspect d'un cône de déjection, ainsi que de la pierraille calcaire. A la partie gauche de la salle il y a une petite flaque d'eau, tandis qu'à droite on arrive, après avoir escaladé une petite pente argileuse, à un puits rempli d'eau situé à l'entrée dans la galerie F conduisant au-dessus du lac. Le puits dont nous venons de parler, ainsi que la niche G (remplie d'eau dont la profondeur atteint $9 \mathrm{~m}$ ) communiquent avec le lac par une galerie impénétrable. D'un autre côté, la galerie $\mathrm{E}$ se détache de la salle; elle est partiellement colmatée par de l'argile au-dessus de laquelle s'est formé un plancher stalagmitique. Du vestibule A c'est la galerie B qui se détache; on y remarque des coulées pariétales, stalactites, stalagmites et colonnes. En général, nous n'avons pas pu observer des formes de corrosion et d'érosion.

Nos observations nous ont conduit à la conclusion que la grotte s'est développée sur synclases, surtout sous l'action de la circulation des eaux de la Nera, l'action des eaux d'infiltration ayant joué un rôle secondaire. Dans le passé géologique, l'entrée de la grotte avait été barrée aussi bien par les alluvions transportées par la Nera que par les éboulements du versant calcaire, et un lac s'était installé ici dans une cuvette, probablement marmite à l'origine. Par suite de l'effondrement du plafond de la grotte, le lac est actuellement abrité de façon incomplète sous la paroi $\mathrm{O}$ de celle-ci. Il est alimenté aussi bien par la Nera le long de certaines fissures tectoniques que par l'eau des précipitations. Plusieurs observations viennent à l'appui de cette hypothèse concernant la génèse du lac, à savoir: le versant dans lequel est creusée la grotte est formé, en amont et en aval de celle-ci, par la roche nue et c'est seulement dans la zone de la grotte qu'il est formé d'alluvions déposées par la Nera et constituant deux petites terrasses; la paroi $O$, surplombante au-dessus du lac, prouve que la grotte s'était jadis continuée dans ceite direction, recouvrant entièrement le lac; la corrélation des données bathymétriques avec le sens de l'inclinaison des strates, montre que la cuvette du lac s'est formée sur synclase, tout comme la grotte (fig. 29). 
Spéoclimat. Températures à 3. X. 1963, h 13,30: à l'extérieur, air $19^{\circ} \mathrm{C}$; dans la salle, air $11,4^{\circ} \mathrm{C}$, plancher $11^{\circ} \mathrm{C}$ (grotte chaude). Humidité relative au psychromètre aspirateur le 3. X. 1963: à l'extérieur $41 \%$, dans la salle de la grotte 100\% (grotte fort humide). Grotte statique; faibles courants d'air à l'entrée.

Ressourcestrophiques pauvres: un peu de bois pourri, détritus végétaux.

Biospéologie. Echantillon de la faune (3. X. 1963, leg. A. N., Şt. N.). Faune dans le bois pourri et les détritus végétaux, à l'obscurité: Oligochaeta, Gervaisiidae, Polydesmidae, Collembola, Diptera (imagines, larvae), Acari, Pseudoscorpiones.

Observé, mais non collecté: Macrolepidoptera, Chironomidae.

Association pariétale faiblement représentée; faune du plancher assez riche et variée dans le boyau obscur de la salle, où il y avait une abondance de matériel trophique.

Varia. Grotte assez fréquemment visitée, pas dégradée: le lac, bien que difficilement accessible, est une attraction pour les touristes du Banat. On pourrait éventuellement exécuter des sondages paléontologiques dans le dépôt de remplissage de l'entrée.

\section{Grottes situées dans le bassin du Danube à Moldova Noua}

(Fig. 30)

Il est question ici de la zone comprise entre une ligne unissant les localités Moldova Noua - Padina Matei - Gîrnic au Nord, et le Danube au Sud. C'est un plateau calcaire d'une grande étendue, situé au S du grand synclinorium plissé de la zone de Reşița - Moldova Noua. Au point de vue géologique, la zone calcaire se continue vers le $\mathrm{N}$ jusqu'à Reşița, flanquée à l'E par les granits de Sichevița (éruptif ancien) et à l'O par le cristallin continué par des dépôts pléistocènes. Les calcaires sont d'âge jurassique et crétacé. Le pléistocène occupe, à l'intérieur de cette zone mais surtout dans sa partie S (Plateau de Coronini), d'importantes surfaces de dimensions variées. Le relief exokarstique est particulièrement bien développé aux alentours des villages Sfînta Elena et Gîrnic (bâtis sur le calcaire); on y trouve en grand nombre des dolines, poljés, avens, champs de lapiez, lacs de doline, ponts naturels, dêpôts de travertin, etc.

Dans notre travail antérieur (Botoşaneanu, Negrea et Negrea 1963) nous avons déjà présenté 11 grottes de cette zone; nous complétons en présentant deux avens: Avenul de la Vranovaț et et Avenul de la Izvoru Şicli. 


\section{Avenul de la Vranovaț}

(Fig. 31)

Synonymie. Propasti ot Vranovac.

Date de l'exploration. 28. VII. 1963 (Şt. Negrea, A. Negrea).

Emplacement. Creusé dans la hauteur Vranovaț (Mts. de l'Almaj). Pour le trouver, on part du village de Sfînta Elena (commune de Coronini, rayon Moldova Noua) et on avance $2,5 \mathrm{~km}$ env. sur la route se dirigeant vers "Garîna", jusqu'au sommet du Vranovaț; on descend ensuite quelques centaines de mètres sur une route latérale, à droite, vers le ruisseau ogaşu Vranovaț (= Čeuca); l'aven s'ouvre dans une doline sur la propriété de Stelik Alois (fig. 30); difficile à trouver sans l'aide d'un guide. Altitude absolue: $460 \mathrm{~m}$ env.

Description. Aven de $12 \mathrm{~m}$ de profondeur, creusé dans les calcaires de l'Aptien supérieur. Fossile. Il est plongé dans l'obscurité, car sa petite entrée est bouchée par des branches et masquée par des arbustes; mais quand on le désobstrue, c'est uniquement la petite salle latérale au fond qui reste obscure, la lumière diffuse pénétrant alors jusqu'au fond de l'à-pic. Parois et plancher ruisselants par eau d'infiltration. On remarque des vagues d'érosion et des coupoles de corrosion. Formations concrétionnaires de calcite seulement dans la petite salle (stalactites, stalgmites, une colonne, coulées pariétales). A vrai dire, le plancher est constitué par un bouchon d'argile ayant colmaté l'aven. A la base de l'à-pic, agglomération de bois et de branches pourris.

L'aven s'est formé par élargissement de petites fissures tectoniques par l'eau d'infiltration ayant pénétré dans la doline.

Spéoclimat. Températures à $13 \mathrm{~h}$ : à l'extérieur, air $29,5^{\circ} \mathrm{C}$; au fond de l'aven, air $10,2^{\circ} \mathrm{C}$, argile du plancher $9,3^{\circ} \mathrm{C}$. Humidité relative: $100 \%$ (fort humide). Pas de courants d'air.

Ressources trophiques riches (bois pourri, détritus).

Biospéologie. Echantillon de la faune (28. VII. 1963, leg. A. N., Şt. N.): faune du plancher (argile et bois pourri): Gastropoda, Isopoda, Coleoptera, Homoptera, Araneina, Opiliones, Acari.

Faune pariétale absente; celle du plancher pauvre.

\section{Avenul de la Izvoru şicli}

Synonymie. Propasti ot Izvoru Şicli.

Date de l'exploration. 28. VII. 1963 (E. Cristea, Şt. Negrea).

Emplacement. Creusé tout comme l'aven de Vranovaț, dans la colline du même nom. A partir de l'aven de Vranovaț on descend 
encore $500 \mathrm{~m}$ sur le chemin latéral, jusqu'à l'endroit dit «Izvoru Şicli», situé en proximité du ogaşu Vranovaț (fig. 30). L'aven s'ouvre dans la pente herbeuse d'une doline, il est difficile à trouver sans l'aide d'un guide. Altitude absolue: $410 \mathrm{~m}$ env.

Description. Aven creusé dans les calcaires de l'Aptien supérieur, fossile, directement éclairé jusqu'à $8 \mathrm{~m}$. C'est un à-pic de $22 \mathrm{~m}$ de profondeur et fort exigu (l'entrée a $0,75 / 0,50 \mathrm{~m}$ et la largeur maximum, au niveau de la plateforme 3 , est de $1,5 \mathrm{~m}$ à peine). Il y a 4 petites "plate-formes»sur le trajet: la première est un seuil rocheux, la $2^{\mathrm{e}}$ et la $3^{\mathrm{e}}$ sont constituées par des alluvions cimentées par du sol tombé d'en haut, la dernière par un bloc.

L'eau s'infiltre entre les plateformes 2 et 3 . Nombreux septes de corrosion jusqu'à la plate-forme 3 . Les parois sont nues, partiellement recouvertes d'argile humide. Le fond de l'aven est constitué par une agglomération de blocs (provenant d'éffondrements). Une stalagmite sur la plateforme 3 .

Aven formé par élargissement d'une fissure tectonique par l'eau infiltrée dans la doline.

Spéoclimat. Températures à $15 \mathrm{~h}$ : à l'extérieur, air $29,5^{\circ} \mathrm{C}$; au fond de l'aven, air $12,5^{\circ} \mathrm{C}$, plancher $11,5^{\circ} \mathrm{C}$. Humidité relative: 95-98\%. Pas de courants d'air.

Ressources trophiques pauvres (quelques détritus végétaux).

Biospéologie. Echantillon de la faune (28. VII. 1963, leg. E. C.) prélevé au fond de l'aven: Oligochaeta, Araneina.

Faune pauvre. Observé, mais non collecté, mycélies de champignons.

Varia. L'aven est parfaitement masqué et protégé par les arbustes et les branchages.

\section{Grottes situées dans le Massif Sucaru Mare (defilé du Danube de Cazane)}

(Fig. 32)

Sucaru Mare est un massif calcaire isolé, d'âge crétacé, situé sur la rive roumaine du Danube entre les localités Plavişevița et Ogradena; son hauteur maximum est de $297 \mathrm{~m}$. Ses parois verticales et par endroits surplombantes, forment une partie de la rive gauche du défilé sauvage et d'une grande beauté de Cazanele Mari. Deux grottes importantes (Gura Ponicovei et Pînza Curii-Veterani), déjà décrites dans notre travail antérieur (Botoşaneanu, Negrea et Negrea 1963), sont creusées dans ce massif. C'est maintenant le tour de deux petites grottes d'être décrites: Peştera Nr. 1 et Peştera Nr. 2 de la Gura Ponicovei. 


\section{Pestera No 1 de la Gura Ponicovei}

(Fig. 33)

Synonymie. Peştera du km 21 (nom donné par Şt. Negrea).

Bibliographie. Capuşe, I., Georgescu, M. (1962-63; faune; citée sous le nom de Peştera au km 21 Plavişevița); Decu-Burghele, A. (1963; faune; citée sous le nom de Peştera du km 21 Plavişevița); Grossu, Al., Negrea, A. (1962-63; faune; citée sous le nom de Peştera km 21).

Dates de l'exploration: 12. XII. 1956 (Şt. Negrea, I. Tabacaru) et 27. VII. 1963 (Şt. Negrea, A. Negrea).

Emplacement. Grotte située dans le massif Sucaru Mare (défilé du Danube), un peu en amont de Peştera Gura Ponicovei. Si l'on se dirige de Orşova vers Plavişevița, on dépasse d'abord le pont enjambant la résurgence de Ponicova, on atteint la borne $\mathrm{du} \mathrm{km} \mathrm{21,} \mathrm{et,}$ après $50 \mathrm{~m}$, on quitte la route et on monte quelques mètres jusqu'à la base de l'abrupt où se trouve la grande entrée de la grotte, orientée SE. Altitude absolue $60 \mathrm{~m}$.

Description. Petite grotte ( $47 \mathrm{~m}$ de longueur totale). Creusée dans des calcaires qui représentent le tithonique et éventuellement le néocomien, fossile, horizontale-ascendante, le tiers au fond obscur. Eau d'infiltration dans le secteur final seulement. De nombreux hiéroglyphes sur les parois et de petits septes de corrosion sur le plafond. Processus de concrétionnement fort peu avancé: il y a seulement des tubercules et des corallites sur les parois. Sur le plancher, beaucoup de matériel clastique autochtone, un peu d'argile, et dans la zone de l'entrée, sol de forêt.

Grotte creusée sur des synclases sous l'action de l'eau d'infiltration ayant jadis formé un cours souterrain; des traces peu nettes d'érosion ont été observées. La stratification est évidente.

Spéoclimat. Températures: le 12. XII. 1956, $14 \mathrm{~h}$ dans la zone à éclairage diffus, air $6^{\circ} \mathrm{C}$; le 27. VII. $1963,17 \mathrm{~h}$, à l'extérieur, air $22,5^{\circ} \mathrm{C}$; au fond, air $15,5^{\circ} \mathrm{C}$, plancher $14,5^{\circ} \mathrm{C}$ (grotte chaude). Humidité relative à 27. VII. 1963: 90-95\%. Grotte statique, pas de courants d'air.

Ressources trophiques pauvres (déjections de chêvre, de mouton et de carnivores; un peu de bois pourri).

Biospéologie. Echantillons de la faune:

Le 12. XII. 1956 (leg. St. N., I. T.), échantillon général: Gastropoda, Isopoda, Lepidoptera, Diptera, Araneina, Pseudoscorpiones. 
Le 27. VII. 1963 (leg. A. N., Şt. N.):

1. Faune pariétale, à l'obscurité et dans la zone à éclairage diffus: Microlepidoptera, Macrolepidoptera, Hymenoptera, Diptera, Araneina.

2. Faune auprès des déjections animales sur l'argile humide: Gastropoda, Isopoda.

L'association pariétale est assez riche dans les zones éclairées; celle du plancher, assez pauvre, est dominée par les isopodes. Le 12. XII. 1956, observé un chiroptère en vol. Signalons aussi la présence de restes squelettiques actuels (Aves, Cervidae).

Varia. Grotte rarement visitée, sans traces de dégradation. La zone de l'entrée est indiquée pour des sondages paléontologiques et archéologiques.

\section{Peştera No 2 de la Gura Ponicovei}

(Fig. 34)

Synonymie. Peştera de la Curba Periculoasa (nom donné par Şt. Negrea).

Bibliographie. Capuşe, I., Georgescu, M. (1962-63; faune; citée sous le nom de Peştera de la Curba Periculoasa).

Dates de l'exploration. 12. XII. 1956 (Şt. Negrea, I. Tabacaru) et 27. VII. 1963 (Şt. Negrea, A. Negrea).

Emplacement. Située dans le massif Sucaru Mare (défilé du Danube). Accessible de la même route que la grotte précédente; à partir de celle-ci, on avance encore $250 \mathrm{~m}$ dans la direction de Plavișevița, et l'on monte ensuite une pente de quelques mètres, à droite, jusqu'à la base de la paroi calcaire; on trouve ici un abri sous roche (large de plus de $40 \mathrm{~m}$, haut de $25 \mathrm{~m}$ et profond de $10 \mathrm{~m}$ ), et c'est dans cet abri que se trouve l'entrée de la grotte, orientée E. Altitude absolue: $60 \mathrm{~m}$.

Description. Grotte de dimensions moyennes $(58 \mathrm{~m}$ de galeries explorées), creusée dans des calcaires qui représentent le tithonique et éventuellement le néocomien, fossile, horizontale, à plancher pratiquement plan, dans sa majeure partie obscure ou bien à éclairage diffus. Elle se compose de quelques galeries basses développées sur un système de diaclases perpendiculaires les unes sur les autres. Il y a, dans la zone obscure, de l'eau de condensation et d'infiltration. Sur les parois: hiéroglyphes ainsi que vermiculations de décalcification; sur le plafond: petits septes de corrosion. Processus de concrétionnement faiblement développé: quelques tubercules sur les parois, une colonne, quelques stalactites et stalagmites dans la diaclase finale. Dépôt de 
remplissage constitué d'argile dans le secteur final, de matériel clastique autochtone dans le reste de la grotte, et de sol de forét dans la zone de l'entrée.

La grotte s'est formée par élargissement de fissures tectoniques par l'eau d'infiltration.

Spé o climat. Températures, le 27. VII. 1963 à 18 h: à l'extérieur, air $22,5^{\circ} \mathrm{C}$; au fond de la grotte, air $14,8^{\circ} \mathrm{C}$, plancher $13^{\circ} \mathrm{C}$ (grotte chaude). Humidité relative, aux deux dates de l'exploration: 100\%, diminuant légèrement vers l'entrée (grotte humide). Grotte statique, pas de courants d'air.

Ressources trophiques relativement pauvres (argile à détritus végétal, un peu de crottin de chèvre et de mouton).

Biospéologie. Echantillons de la faune:

Le 12. XII. 1956 (leg. Şt. N., I. T.), échantillon général: Isopoda, Lepidoptera, Pseudoscorpiones.

Le 27. VII. 1963 (leg. Şt. N., A. N.):

1. Faune pariétale à l'obscurité: Macrolepidoptera, Diptera.

2. Faune sur l'argile recouverte de débris végétaux et animaux: Oligochaeta, Isopoda, Polydesmidae, Lithobiidae, Coleoptera, Diptera.

Assez riche faune pariétale dans la zone obscure. La faune du plancher est variée, mais le nombre des exemplaires vus était faible aux deux dates de l'exploration.

Restes osseux actuels (27. VII. 1963, leg. A. N.): Artiodactyla.

Varia. Grotte sans traces de dégradation, car elle n'est pas fréquentée. Il serait intéressant d'effectuer des sondages archéologiques et paléontologiques dans le dépôt de remplissage de l'entrée.

\section{RÉSUMÉ}

Le travail comprend la description de 23 cavités souterraines naturelles et artificielles des Monts du Banat, groupées par zones karstiques. Il représente de tous points de vue une continuation d'un travail précédent (B o toş aneanu, Negrea et Negrea, 1963) sur les grottes du Banat roumain.

\section{SUMMARY}

The paper contains the description of 23 natural or artificial underground cavities in the Banat mountains, grouped in karst zones. It is in all respects a continuation of a preceding volume (Botoşaneau, Negrea et Negrea, 1963) on the caves of the rumanian Banat. 
Tableau synoptiqu

Dans la colonne 2, on a tenu compte uniquement de la galerie principale $d_{1}$ à l'exception des grotte

\begin{tabular}{|c|c|c|c|c|c|c|c|}
\hline & \multirow{2}{*}{$\begin{array}{l}\text { Nom de la grotte } \\
(\mathrm{P}=\text { Pestera })\end{array}$} & \multirow{2}{*}{$\begin{array}{c}\text { Grotte: } \\
\text { vertic. (V) } \\
\text { horiz. (H) } \\
\text { ascend. (A) } \\
\text { descend. (D) }\end{array}$} & \multicolumn{2}{|c|}{$\begin{array}{l}\text { Altitude } \\
(\mathrm{m})\end{array}$} & \multirow{2}{*}{$\begin{array}{l}\text { Lon- } \\
\text { gueur } \\
(\mathrm{m})\end{array}$} & \multirow{2}{*}{$\begin{array}{l}\text { Orien- } \\
\text { tation } \\
\text { entrée }\end{array}$} & \multirow{2}{*}{$\begin{array}{c}\text { Grotte: } \\
\text { active (A) } \\
\text { fossile (F) } \\
\text { sous- } \\
\text { fossile (S) }\end{array}$} \\
\hline & & & Abs. & Relat. & & & \\
\hline 0 & 1 & 2 & 3 & 4 & 5 & 6 & 7 \\
\hline 1. & P. de la Romîneşti & $\mathrm{H} \rightarrow \mathrm{A}$ & 370 & 105 & 340 & NNO & $\mathrm{F}$ \\
\hline 2. & P. No. 1 din Stînca lui & & & & & & \\
\hline 3. & $\begin{array}{l}\text { Florian } \\
\text { P. Gaura din Cioaca }\end{array}$ & $\mathrm{H}$ & 255 & 2 & 10 & $\mathrm{E}$ & $\mathrm{S}$ \\
\hline & Birtului & $\mathrm{V} \rightarrow \mathrm{D}$ & 330 & 26 & 18 & $\mathrm{NE}$ & $\mathrm{F}$ \\
\hline 4. & P. din Piatra Fetii & $\mathrm{D}$ & 508 & 6 & 19 & $\mathrm{O}$ & $\mathrm{A}$ \\
\hline 5. & $\begin{array}{r}\text { Galeria de explorare } \\
\text { din Valea cu Baia }\end{array}$ & D & 390 & & 200 & $\mathrm{~N}$ & A \\
\hline 6. & P. Urieşilor & $\mathrm{H}$ & 170 & 20 & 6 & S & $\mathrm{F}$ \\
\hline 7. & P. Casa Lotrilor & $\mathrm{H} \rightarrow \mathrm{A}$ & 290 & 30 & 8 & NE & $\mathrm{s}$ \\
\hline 8. & P. din Dealul Colțan & $\mathrm{D} \rightarrow \mathrm{H}$ & 250 & 74 & 12 & SSE & $\mathrm{F}$ \\
\hline 9. & $\begin{array}{l}\text { Galeria de Explorare } \\
\text { din Dealul Colțan }\end{array}$ & $\mathrm{H} \rightarrow \mathrm{A}$ & 230 & 56 & 50 & $\mathrm{E}$ & $\mathrm{F}$ \\
\hline 10. & Abatajul lui Anton & $\mathrm{H} \rightarrow \mathrm{D}$ & 440 & & 230 & $\begin{array}{c}\mathrm{OSO} \\
\mathrm{O}\end{array}$ & $\mathrm{F}$ \\
\hline 11. & P. cu oase de la Stîrnic & $\mathrm{H} \rightarrow \mathrm{A} \rightarrow \mathrm{D}$ & 280 & 32 & 35 & $\mathrm{O}$ & $\mathrm{F}$ \\
\hline 12. & $\begin{array}{l}\text { Avenul de la Cantonul } \\
\text { Pin } \\
\text { P. din Drumul }\end{array}$ & V & 555 & 205 & -30 & - & $\mathrm{S}$ \\
\hline & Prolazului & $\mathrm{H}$ & 258 & 3 & 11 & $\mathrm{~N}$ & $\mathrm{~F}$ \\
\hline 14. & P. cu Fereastra & A & 256 & 1 & 27 & $\mathrm{~S}$ & $\mathrm{~F}$ \\
\hline 15. & P. Vraşka & $\mathrm{H} \rightarrow \mathrm{A}$ & 224 & 40 & 65 & $\mathrm{~N}$ & $\mathrm{~F}$ \\
\hline 16. & P. Galațiului & $\mathrm{H} \rightarrow \mathrm{A}$ & 362 & 40 & 192 & $\mathrm{O}$ & $\mathrm{F}$ \\
\hline 17. & P. din Culmea Lacului & $\mathrm{H}$ & 208 & 6 & 14 & $\mathrm{E}$ & $\mathrm{S}$ \\
\hline 18. & $\begin{array}{l}\text { P. mica de la Lacu } \\
\text { Dracului }\end{array}$ & $\mathrm{D} \rightarrow \mathrm{H}$ & 210 & 2 & 16 & NNE & $\mathrm{S}$ \\
\hline 19. & P. de la Lacu Dracului & $\mathrm{D}$ & 210 & 3 & 68 & $\mathrm{NE}$ & $\mathrm{S}$ \\
\hline 20. & Avenul de la Vranovaț & V & 460 & & -12 & - & $\mathrm{F}$ \\
\hline 21. & Avenul de la Izvoru Şicli & V & 410 & & -22 & - & $\mathrm{S} ?$ \\
\hline 22. & $\begin{array}{l}\text { P. No. } 1 \text { de la Gura } \\
\text { Ponicovei }\end{array}$ & A & 60 & & 47 & SE & $\mathrm{F}$ \\
\hline 23. & P. No. 2 de la Gura & & & & & & \\
\hline & Ponicovei & $\mathrm{H}$ & 60 & & 58 & $\mathrm{E}$ & $\mathrm{F}$ \\
\hline
\end{tabular}


des grottes explorées

chaque grotte; le sens que nous avons suivi est de l'entrée vers le terminus, actives $\mathrm{N}^{0} 4$ et 5

\begin{tabular}{|c|c|c|c|c|c|c|c|}
\hline \multirow{2}{*}{$\begin{array}{l}\text { Developpée } \\
\text { sur: } \\
\text { diaclases (D) } \\
\text { synclases (S) }\end{array}$} & \multirow{2}{*}{$\begin{array}{l}\text { Humidité } \\
\text { relative, } \\
\text { en pro- } \\
\text { fondeur (\%) }\end{array}$} & \multicolumn{3}{|c|}{$\begin{array}{l}\text { Température en } \\
\text { profondeur }\left({ }^{\circ} \mathrm{C}\right)\end{array}$} & \multirow{2}{*}{$\begin{array}{c}\text { Grotte: } \\
\text { statique (S) } \\
\text { dynamique (D) }\end{array}$} & \multirow{2}{*}{$\begin{array}{c}\text { Ressources } \\
\text { trophiques: } \\
\text { pauvres }+ \\
\text { riches }++ \\
\text { très } \\
\text { riches }+++\end{array}$} & \multirow{2}{*}{$\begin{array}{c}\text { Faune: } \\
\text { pauvre }+ \\
\text { riche }++\end{array}$} \\
\hline & & Air & $\begin{array}{l}\text { Plan- } \\
\text { cher }\end{array}$ & Eau & & & \\
\hline 8 & 9 & 10 & 11 & 12 & 13 & 14 & 15 \\
\hline $\mathrm{D}+\mathrm{S}$ & 100 & 8,4 & 8,3 & - & $\mathrm{S}$ & ++ & ++ \\
\hline $\mathrm{D}$ & 98 & 11 & & - & $\mathrm{S}$ & + & + \\
\hline $\mathrm{S}+\mathrm{D}$ & 100 & 8 & 8,5 & - & D & +++ & ++ \\
\hline $\mathrm{D}$ & 100 & 12 & 9,2 & & D & ++ & ++ \\
\hline- & 100 & 11 & 10,8 & 10 & $\mathrm{~S}$ & +++ & ++ \\
\hline tuf & 70 & 23 & 18 & - & S & + & + \\
\hline $\mathrm{D}$ & 98 & 15 & 10,3 & 9,7 & $\mathrm{~S}$ & + & ++ \\
\hline$D+S$ & 100 & 11,5 & 8,7 & - & $\mathrm{S}$ & ++ & ++ \\
\hline - & 100 & 10,5 & 9,2 & - & $\mathrm{S}$ & + & + \\
\hline- & 98 & 12,5 & 9,5 & - & D & + & ++ \\
\hline D & 100 & 10,5 & 8,5 & - & $\mathrm{S}$ & + & ++ \\
\hline D & 95 & 11,5 & 10,8 & - & D & ++ & + \\
\hline D & 94 & 12,9 & & - & $\mathrm{S}$ & + & + \\
\hline D & 100 & 12 & 10,8 & - & $\mathrm{S}$ & + & + \\
\hline $\mathrm{D}$ & 100 & 10,2 & 9,9 & - & D & ++ & + \\
\hline $\mathrm{S}+\mathrm{D}$ & & & & & $\mathrm{S}$ & ++ & + \\
\hline $\mathrm{S}$ & 100 & 15,4 & 15 & 15,2 & S & ++ & ++ \\
\hline $\mathrm{S}$ & 100 & 11,4 & 11 & & $\mathrm{~S}$ & + & + \\
\hline D & 100 & 10,2 & 9,3 & - & $\mathrm{S}$ & ++ & + \\
\hline D & 98 & 12,5 & 11,5 & - & $\mathrm{S}$ & + & + \\
\hline $\mathrm{S}$ & 95 & 15,5 & 14,5 & - & $\mathrm{S}$ & + & + \\
\hline $\mathrm{D}$ & 100 & 14,8 & 13 & - & $\mathrm{S}$ & + & + \\
\hline
\end{tabular}




\section{B I B LI O GRAP H I E}

Воков, E. (1921) - A magyarhoni barlangok izeltlábui (Arthropoden der ungarischen Grotten). Barlangkutatás, $I X, 1-4$, pp. 1-22, 45-49.

Botosaneanu, L., Negrea, A. et Negrea, St. (1963) - Grottes du Banat explorées de 1960 à 1962. In: Recherches sur les grottes du Banat et d'Olténie (Roumanie; 1959-1962). Paris.

Capuşe, I., et Georgescu, M. (1962-1963) - Contribuții la studiul lepidopterelor cavernicole. Lucr. Inst. Speol. "Emil Racovița», I-II, pp. 495-502.

Cavaillé, A. (1962) - Le système karstique et l'évolution des grottes. Spelunca, mém., 2.

Codarcea, Al. (1940) - Vues nouvelles sur la tectonique du Banat méridional et du Plateau de Mehedinți. An. Inst. Geol. $X X$, pp. 1-74.

Cristea, Em. (1963) - In munții Poiana Rusca. Almanah turistic O.N.T. Carpați, Bucureşti, pp. 35-37.

Čvisıč, J. (1960) - La géographie des terrains calcaires. Beograd.

Decu-Burghele, A. (1963) - Contribuții la studiul dipterelor cavernicole din peşterile R. P. Romîne. Lucr. Inst. Speol. «Emil Racovița», $I-I I$, pp. 475-494.

Dumitrescu, M., Tanasachi, J., et Orghidan, T. (1962-1963) - Raspîndirea chiropterelor în R. P. Romîna. Lucr. Inst. Speol. «Emil Racovița», $I-I I$, pp. 509-576.

Ehrenberg, E. (1962) - Über Grenzen und Gliederung der Speläologie. Die Höhle, 1.

GÈze, B. (1953) - La genèse des gouffres. Ier Congr. Intern. Spéléol. II.

Grossu, Al., et Negrea, A. (1962-1963) - Contribuții la cunoaşterea moluştelor din peşterile din R. P. Romîna. Lucr. Inst. speol. «Emil Racovița", I-II, pp. 503-508.

Halaváts, G. (1888) - Zelentés az 1888, évben Dognácika és Vaskö Kornyékén eszközolt veszletes Zoldtani felvételvöl. A Magyar Foldtani Intezet Evé zelent. 1888 év., pp. 95-103.

Martonne, Emm. de (1922) - Munții Metaliferi ai Banatului şi Culuarul Caransebeş. Lucr. Inst. Geogr. Univ. Cluj, I, pp. 115-164.

Овтниаув, T. (1872) - A barlangok paläontologiai és történeti jelentösége, tekintettel Magyarország, de különösen Délmagyarország barlangjaiva. A Magyar orvosok és termeszetvizsgálok 1872 - ben Herkules fürdön tartott vándorgyülésének munkálatai, pp. 279-290.

PaPIU, G. V. (1956) - Cercetari geologice pe versantul de NW al Masivului Poiana Rusca. D. S. Com. Geol. XL (1952-1953), p. 135.

Papiu, C. V., Popescu, A., et Serafimovici, V. (1961) - Consideraţii petrogenetice asupra carbonatitelor epizonale din masivul Poiana Ruscai. Com. Şt. Congr. V. Asoc. Geol. Carpato-Balcanica, II, p. 137.

Raileanu, Gr. (1957) - Considerațiuni generale asupra geologiei Banatului de vest. Anal. Rom. Sov. Ser. Geol-Geogr., 4, pp. 5-20.

Trомве, F. (1952) - Traité de Spéléologie. Paris.

Wolf, B. (1934-1937) - Animalium Cavernarum Catalogus. Vol. I: Prefatio, Introductio, Bibliographia; vol. II : Cavernarum Catalogus. pp. 1-108, 1-616. Dr. W. Junk Verlag's. Gravenhage. 


\section{EXPLICATIONS DES PLANCHES}

Fig. 1: Carte des zones karstiques du Banat roumain, et des régions limitrophes, avec la délimitation des périmètres explorés en 1963 (V. Sencu). $a$, calcaires mésozoïques; $b$, calcaires paléozoïques et protérozoïques; $c$, limites des zones explorées (le numéro près de chaque bordure correspond au numéro de la carte de la zone respective dans l'énumération qui suit).

Fig. 2: Emplacement des grottes de la zone Romînesti-Luncani (bassin supérieur de la Bega (V. Sencu). 1, chemin vicinal; 2, grotte.

Fig. 3: Pestera de la Romînesti (V. Sencu, Em. Cristea et Şt. Negrea, Mai 1963). $1 a$, entrée; $b$, limite de la pénétration de la lumière; $2 a$, boyau inaccessible; $b$, point fixe; $3 a$, cheminée; $b$, hauteur en mètres; $4 a$, paroi concrétionnée; $b$, colonne stalagmitique; 5 , blocs éboulés; $6 a$, argile; $b$, pierraille; $\%$, courbes de niveau; 8 , paroi intérieure; 9 , sondage archéologique; $10 a$, ligne tectonique; $b$, ligne de profil.

Fig. 4: Pestera No 1 din Stînca lui Florian (V. Sencu, Mai 1963). 1 a, entrée; $b$. limite de la pénétration de la lumière; $2 a$, ligne de profil; $b$, hauteur en $\mathrm{m} ; 3$, argile; $4 a$, fissure inaccessible; $b$, dénivellation brusque et sa valeur; 5 , cheminée.

Fig. 5: Pestera Gaura din Cioaca Birtului (V. Sencu et Em. Cristea, Mai 1963). $1 a$, entrée; $b$, limite de la pénétration de la lumière; $2 a$, pierraille; $b$, argile; $3 a$, cheminée; $b$, débris végétaux; $4 a$, puits; $b$, hauteur en $\mathrm{m} ; 5 a$, ligne de profil, $b$, boyau inaccessible.

Fig. 6: Pestera din Piatra Fetii (V. Sencu, Mai 1963). $1 a$, puits; $b$, hauteur en $\mathrm{m} ; 2 a$, entrée; $b$, seuil (dénivellation); 3 , blocs éboulés; $4 a$, blocaille; $b$, pierraille; $5 a$, courbes de niveau; $b$, perte d'eau dans la grotte; 6 , fissure; 7 , trajet probablement suivi par l'eau; 8 , section transversale.

Fig. 7: Galeria de explorare din valea cu Baia (Şt. Negrea, Mai 1963). 1 a, hauteur en m; $b$, seuil (dénivellation); $2 a$, courbes de niveau (équidistance $1 \mathrm{~m}) ; b$, coulées pariétales; $3 a$, cours d'eau souterrain, son sens; $b$, puits de mine inondé d'où provient l'eau du ruisseau.

Fig. 8: Emplacement des grottes de la zone Barbosu - Valeapai, bassin du Poganis (V. Sencu). 1, route principale; 2, route secondaire; 3, grotte.

Fig. 9: Pestera Uriesilor (V. Sencu, Juin 1963). $1 a$, entrée; $b$, ligne de profil; $c$, hauteur en $\mathrm{m} ; 2 a$, argile; $b$, pierraile.

Fig. 10: Pestera Casa Lotrilor (V. Sencu, Juin 1963). $1 a$, entrée; $b$, limite de la pénétration de la lumière; $2 a$, argile; $b$, blocaille; $3 a$, point fixe; hauteur en $\mathrm{m} ; 4$, ligne de profil; 5 , fissure tectonique.

Fig. 11: Pestera din Dealul Coltan (V. Sencu, Juin 1963). 1a, entrée; $b$, limite de la pénétration de la lumière; $2 a$, argile; $b$, blocaille; 3 , courbes de niveau; $4 a$, point fixe; $b$, hauteur en $\mathrm{m} ; 5$, ligne de profil; 6 , fissure tectonique; 7 , direction et pendage des strates.

Fig. 12: Galeria de explorare din Dealul Coltan (V. Sencu et Em. Cristea, Juin 1963). $1 a$, point fixe; $b$, hauteur en $\mathrm{m} ; 2$, courbes de niveau; 3 , puits de mine.

Fig. 13: Abatajul lui Anton. Plan horizontal. 
Fig. 14: Abatajul lui Anton. Profil.

Fig. 15: Emplacement des grottes de la zone Resita - Doman (V. Sencu). 1 , route principale; 2 , route secondaire; 3 , grotte.

Fig. 16: Pestera cu oase de la Stîrnic (V. Sencu et Em. Cristea, Juin, 1963). $1 a$, entrée, $b$, limite de la pénétration de la lumière; $2 a$, points fixes; $b$, fissure inaccessible; $3 a$, pilier calcaire; $b$, seuil (dénivellation); $4 a$, argile; $b$, blocaille; $5 a$, cheminée; $b$, hauteur en $\mathrm{m}$; $6 a$, ligne de profil; $b$, colonne; 7 , courbes de niveau; 8 , fissure tectonique.

Fig. 17: Emplacement des grottes de la zone Secu-Cuptoare (V. Sencu). 1 , route principale; 2 , route secondaire; 3 , abrupt calcaire; 4 , grotte; 5 , source karstique; 6 , doline; 7 aven; 8 , hutte.

Fig. 18: Avenul de la Cantonul Pin (V. Sencu, Em. Cristea, Şt. Negrea, Juin 1963).

Fig. 19: Emplacement des grottes des gorges du Caras et de la Gîrliste (V. Sencu). 1, grotte explorée; 2, grotte encore non-explorée; 3, gorges; 4 , route.

Fig. 20: Pestera din Drumul Prolazului (Şt. Negrea et Em. Cristea, Octobre 1963). $1 a$, argile; $b$, sol de forêt; $2 a$, blocaille; $b$, amas de feuilles mortes; $3 a$, hauteur en $\mathrm{m}$; $b$, limite séparant la zone éclairée et la zone obscure; $4 a$, profil transversal; $b$, écoulement pariétal.

Fig. 21: Pestera ou Fereastra (Şt. Negrea et Em. Cristea, Octobre 1963). $1 a$, argile; $b$, bois pourri; $2 a$, grands blocs; $b$, blocaille; $3 a$, fissure tectonique; $b$, seuil (dénivellation); $4 a$, hauteur en $\mathrm{m} ; b$, formations stalagmitiques pariétales variées; $5 a$, limite séparant les zones à éclairage direct et diffus; $b$, limite séparant la zone à éclairage diffus et la zone obscure; $6 a$, profil transversal; $b$, courbes de niveau (équidistance $1 \mathrm{~m}$ ).

Fig. 22: Pestera Vraska (Şt. Negrea et A. Negrea, Juillet 1963). 1 a, argile; $b$, sol de forêt; $2 a$, déjéctions d'animaux; $b$, guano; $c$, bois; $3 a$, amas de feuilles mortes; $b$, végétation; $4 a$, pierraille; $b$, stalagmite; $c$, colonne; $5 a$, formations concrétionnaires pariétales variées; $b$, coulées pariétales; $6 a$, courbes de niveau (équidistance $1 \mathrm{~m}$ ); $b$, coulées stalagmitiques sur le plancher; $\% a$, fissure tectonique; $b$, profil transversal; $8 a$, limite séparant la zone directement éclairée de celle à éclairage diffus; $b$, limite entre la zone à lumière diffuse et la zone obscure; $c$, hauteur en $\mathrm{m}$.

Fig. 23: Pestera Galatiului (Şt. Negrea et A. Negrea, Juillet 1963). 1 a, argile; $b$, sol de forêt; $c$, stalactites; $2 a$, profondeur en $\mathrm{m} ; b$, dénivéllation; $c$, hauteur en $\mathrm{m}$; $3 a$, déjections d'animaux; $b$, guano; $c$, végétation; $4 a$, coulées stalagmitiques sur le plancher; $b$, gours à sec; $c$, barrages stalagmitiques; $5 a$, puits; $b$, paroi séparant deux galeries; $6 a$, blocs; $b$, pierraille; $7 a$, stalagmites; $b$, colonnes; $8 a$, formations concrétionnaires variées sur les parois; $b$, coulées pariétales; $c$, courbes de niveau (équidistance $1 \mathrm{~m}$ ); $9 a$, fissure tectonique; $b$, profil transversal; $10 a$, limite séparant la zone directement éclairée de celle à éclairage diffus; $b$, limite de la zone à lumière diffuse et de la zone obscure.

Fig. 24: Le secteur amont des gorges de la Nera (V.Sencu). 1, route principale; 2 , gorges; 3 , grotte; 4 , doline. 
Fig. 25: Emplacement des grottes creusées dans les gorges de la Nera en aval de Poiana Haimeling (V. Sencu). 1, gorges; 2, grottes (A - peştera din Culmea Lacului; B - peştera mica de la Lacu Dracului; G - peştera de la Lacu Dracului; D, E, F et G - grottes anonymes); 3 , pont naturel; 4 , perte.

Fig. 26: Pestera din Culmea Lacului (V. Sencu et Em. Cristea, Octobre 1963). $1 a$, entrée; $b$, point fixe; 2 , blocs éboulés; $3 a$, courbes de niveau; $b$, argile; 4 , ligne de profil.

Fig. 27: Pestera mica de la Lacu Dracului (V. Sencu et Em. Cristea, Octobre 1963). $1 a$, entrée; $b$, limite de la pénétration de la lumière; $c$, hauteur en $\mathrm{m} ; 2 a$, argile; $b$, pierraille; 3 , courbes de niveau; $4 a$, lac; $b$, ligne de profil; 5 , cheminée.

Fig. 28: Pestera de la Lacu Dracului (V. Trufaş, Septembre 1962). 1, entrée; 2 , sentier conduisant à la grotte; 4 , isohypses; $5 a$, limite de la pénétration de la lumière; $b$, inclinaison du plancher; 6 , paroi séparant des galeries; 7 , paroi concrétionnée; 8, plancher nu; 9, plancher concrétionné; 10, colonne; 11, stalagmites; 12, cône d'argile; 13, argile; 14, matériel clastique; 15, dénivellations; 16, direction et inclinaison des strates; $1 \%$, accumulation d'eau; 18, isobathes.

Fig. 29: Profil transversal schématique (V. Sencu) à travers Lacul Dracului (= le lac du Diable) et la Nera.

Fig. 30: Emplacement des grottes de l'extrémité $S$ de la zone Resita-Moldova Noua (V. Sencu). 1, grotte; 2, aven; 3, doline; 4, route.

Fig. 31: Avenul de la Vranovat (Şt. Negrea, A. Negrea et Em. Cristea, Juillet 1963). $1 a$, argile; $b$, stalactites; $2 a$, blocs; $b$, stalagmites; $3 a$, courbes de niveau (équidistance $1 \mathrm{~m}$ ); $b$, entrée de l'aven; $4 a$, coulées pariétales; $b$, bois pourri, branchages; $5 a$, profil transversal; $b$, fissure tectonique.

Fig. 32: Emplacement des grottes du défilé du Danube de Cazane (V. Sencu). 1 , grotte; 2 , route.

Fig. 33: Pestera Nr. 1 de la Gura Ponicovei (Şt. Negrea, A. Negrea et Em. Cristea, Juillet 1963). $1 a$, argile; $b$, sol de forêt; $2 a$, déjections d'animaux; $b$, bois pourri; $c$, végétation; $3 a$, blocs éboulés; $b$, pierraille; $4 a$, blocs calcaires cimentés au plancher; $b$, courbes de niveau (équidistance $1 \mathrm{~m}$ ); $5 a$, hauteur en $\mathrm{m} ; b$, profil transversal; $6 a$, limite séparant la zone directement éclairée de celle à lumière diffuse; $b$, limite entre la zone à lumière diffuse et la zone obscure.

Fig. 34: Pestera Nr. 2 de la Ponicovei (Şt. Negrea, A. Negrea et Em. Cristea, Juillet 1963). $1 a$, argile; $b$, sol de forêt; $2 a$, détritus végétaux; $b$, déjections d'animaux; $c$, végétation; $3 a$, blocs, $b$, pierraille; $4 a$, blocs cimentés au plancher; $b$, plancher stalagmitique; $5 a$, fissure tectonique; $b$, profil transversal; $6 a$, limite séparant la zone directement éclairée et la zone à lumière diffuse; $b$, limite entre la zone à lumière diffuse et la zone obscure; $7 a$, hauteur en $\mathrm{m} ; b$, coulées pariétales. 


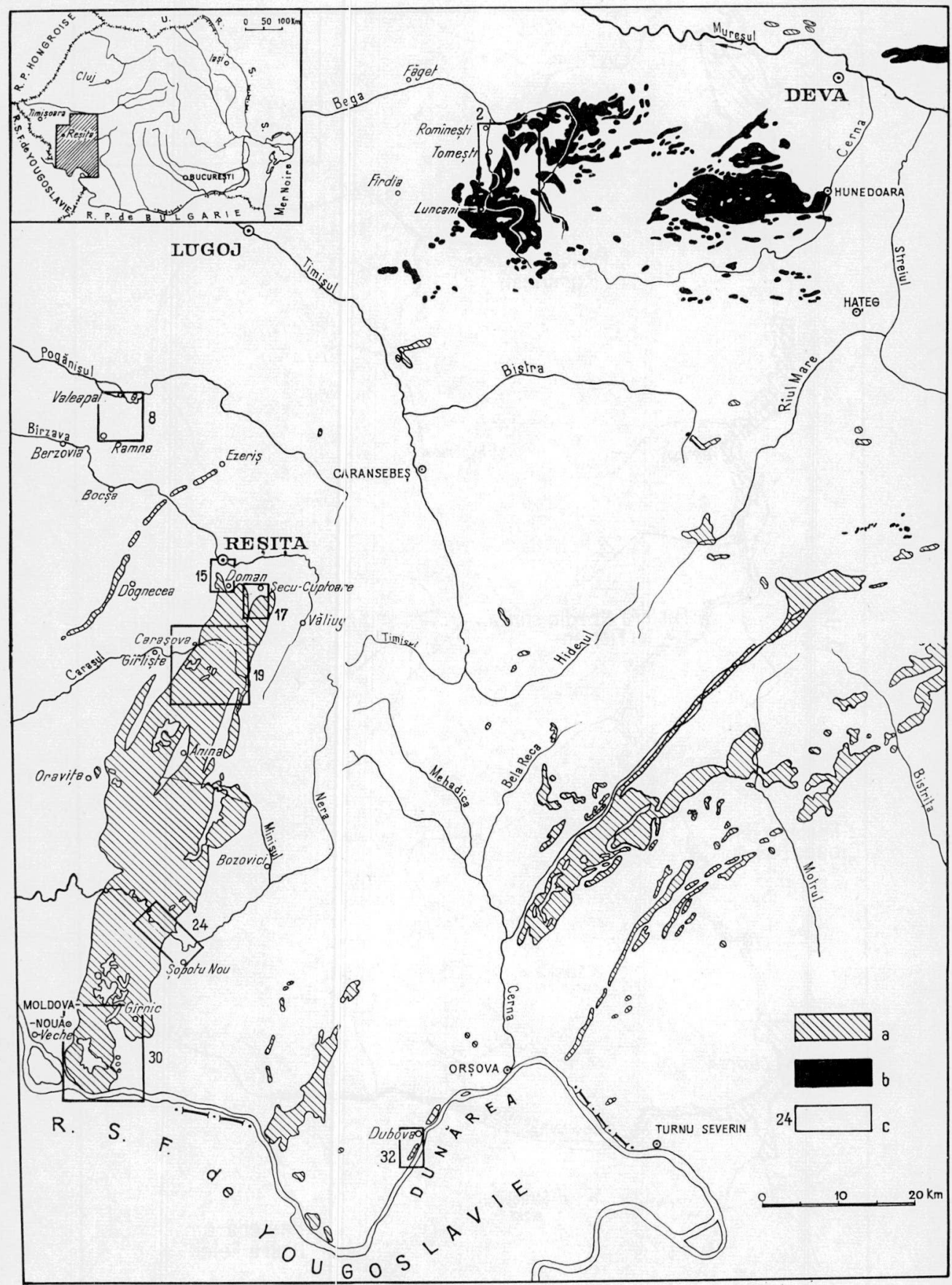




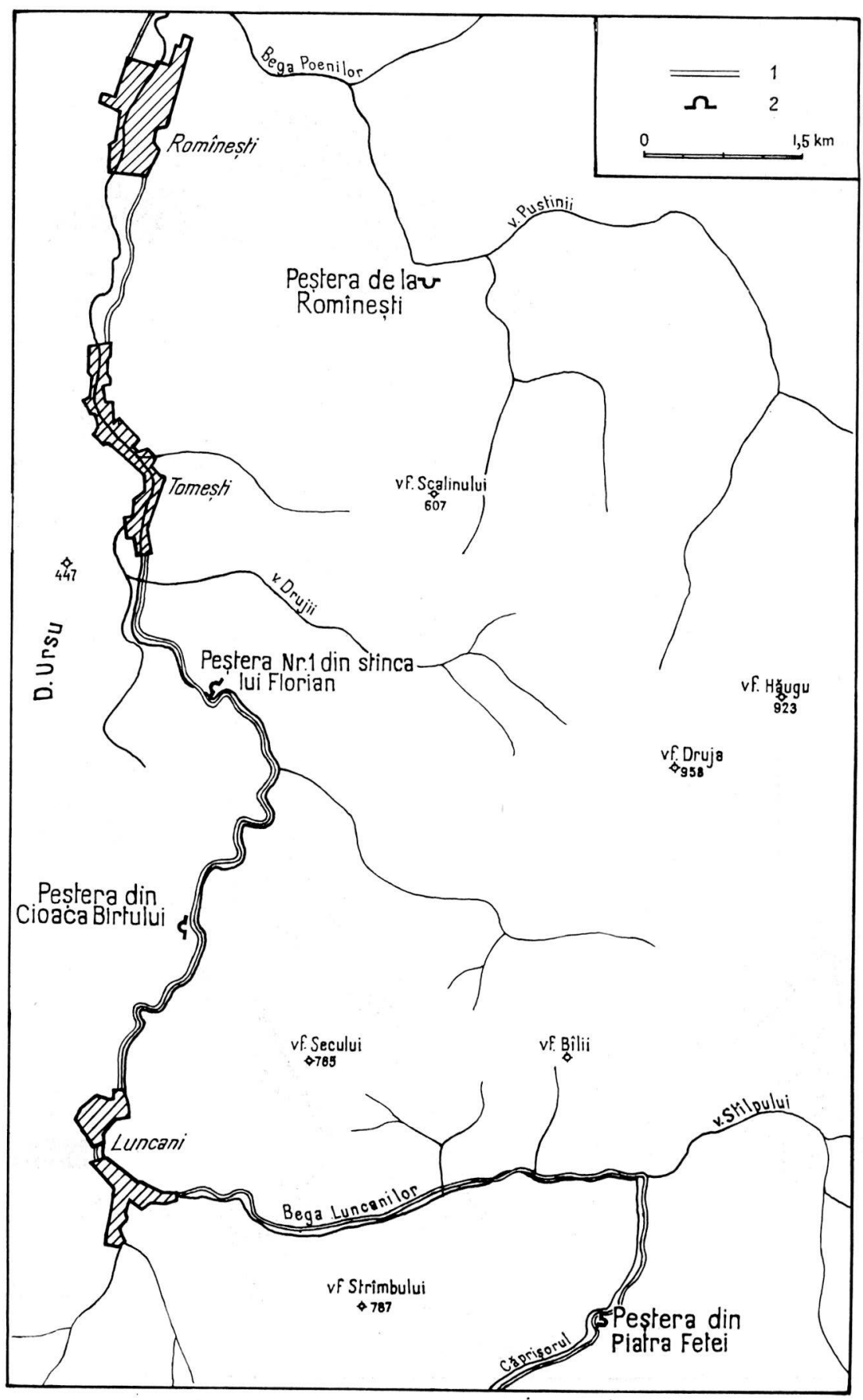




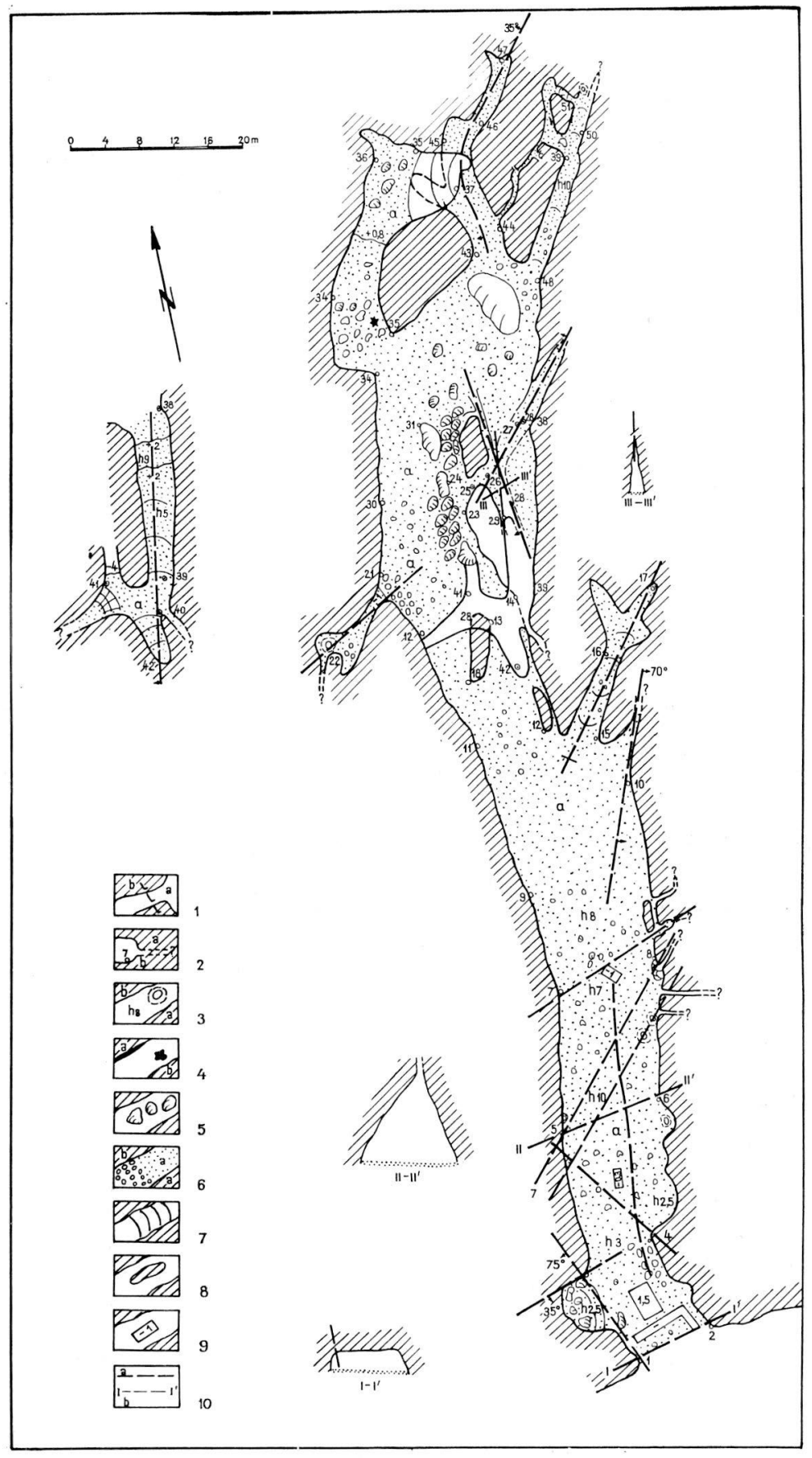




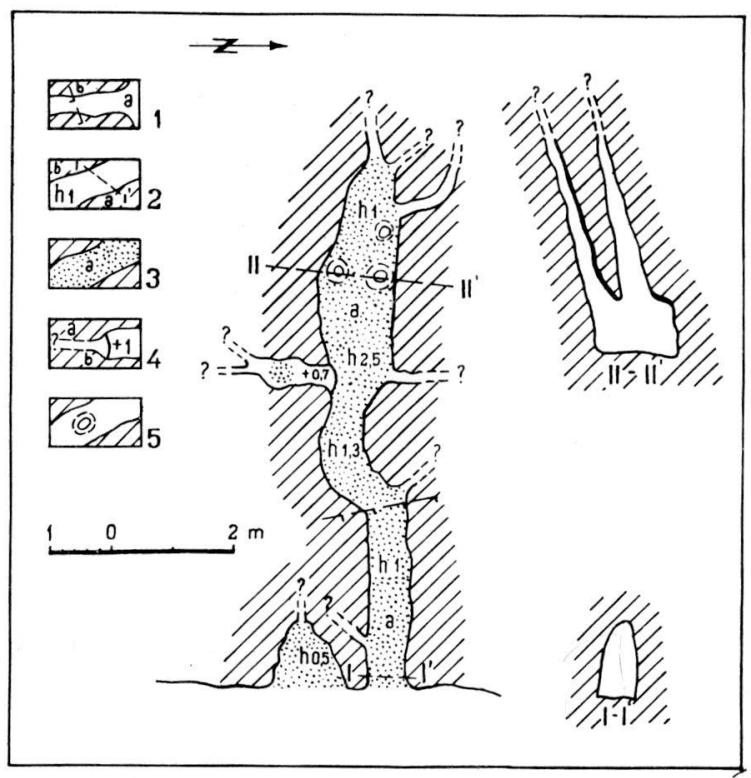

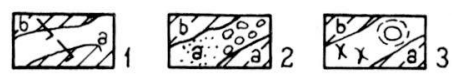

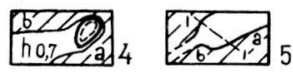

$11-11.0$
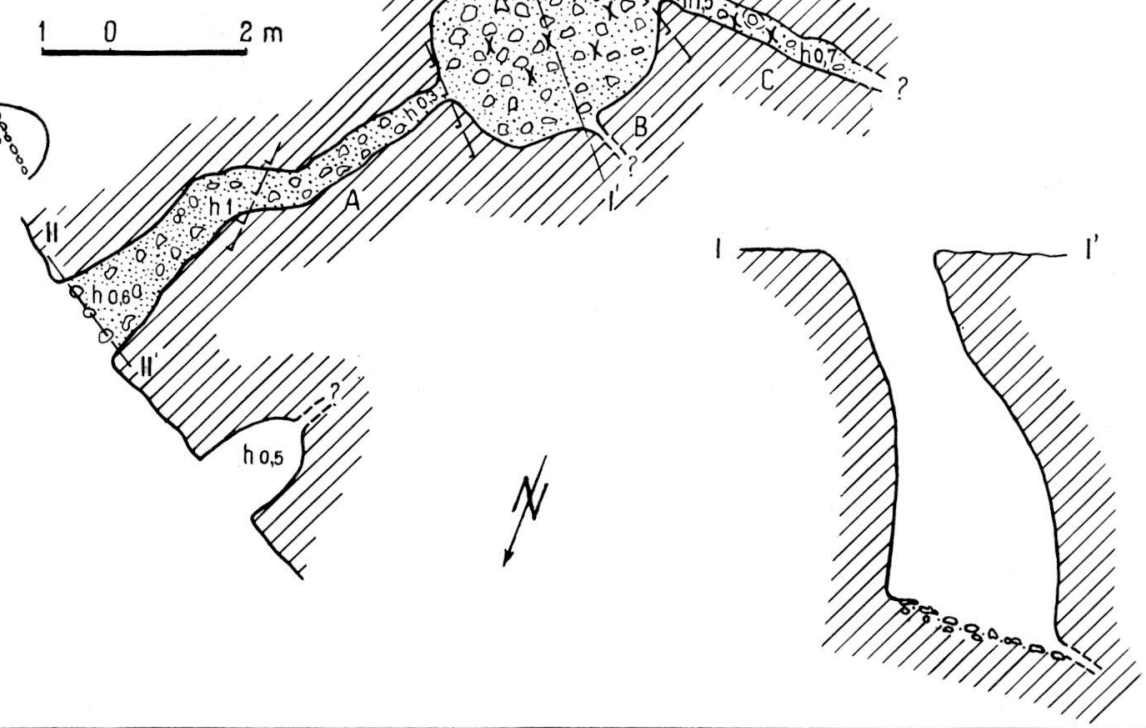


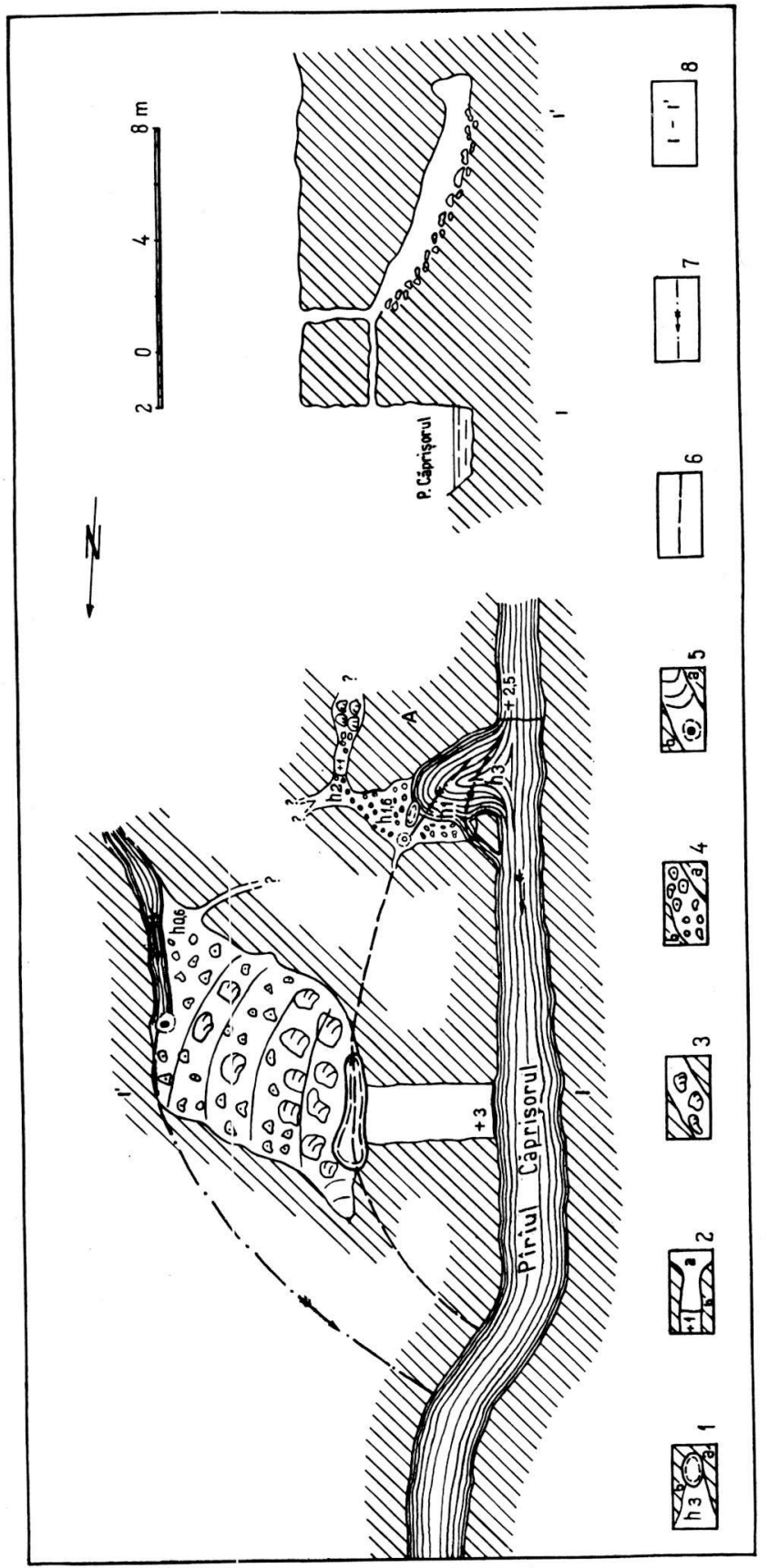



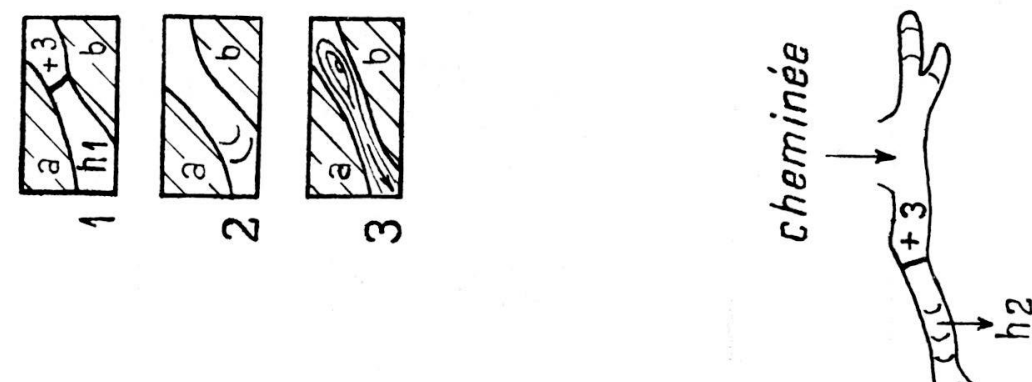

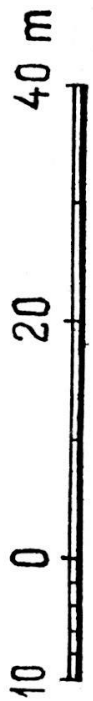

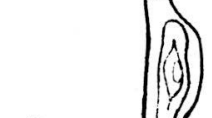

a

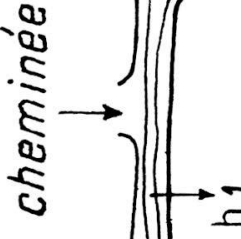

$\stackrel{\infty}{-}$

v
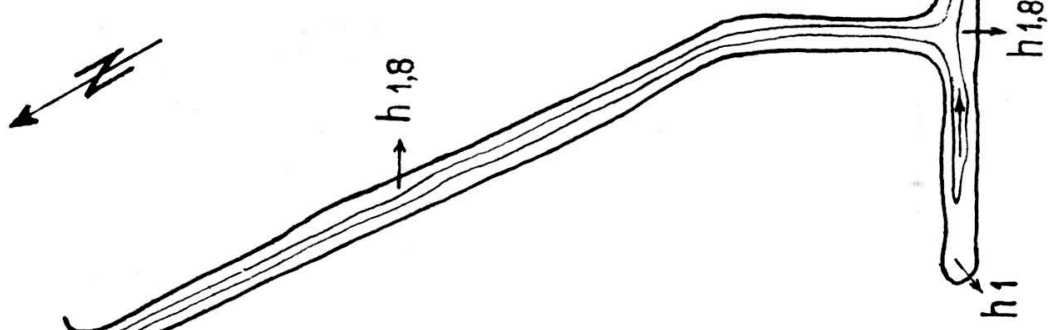


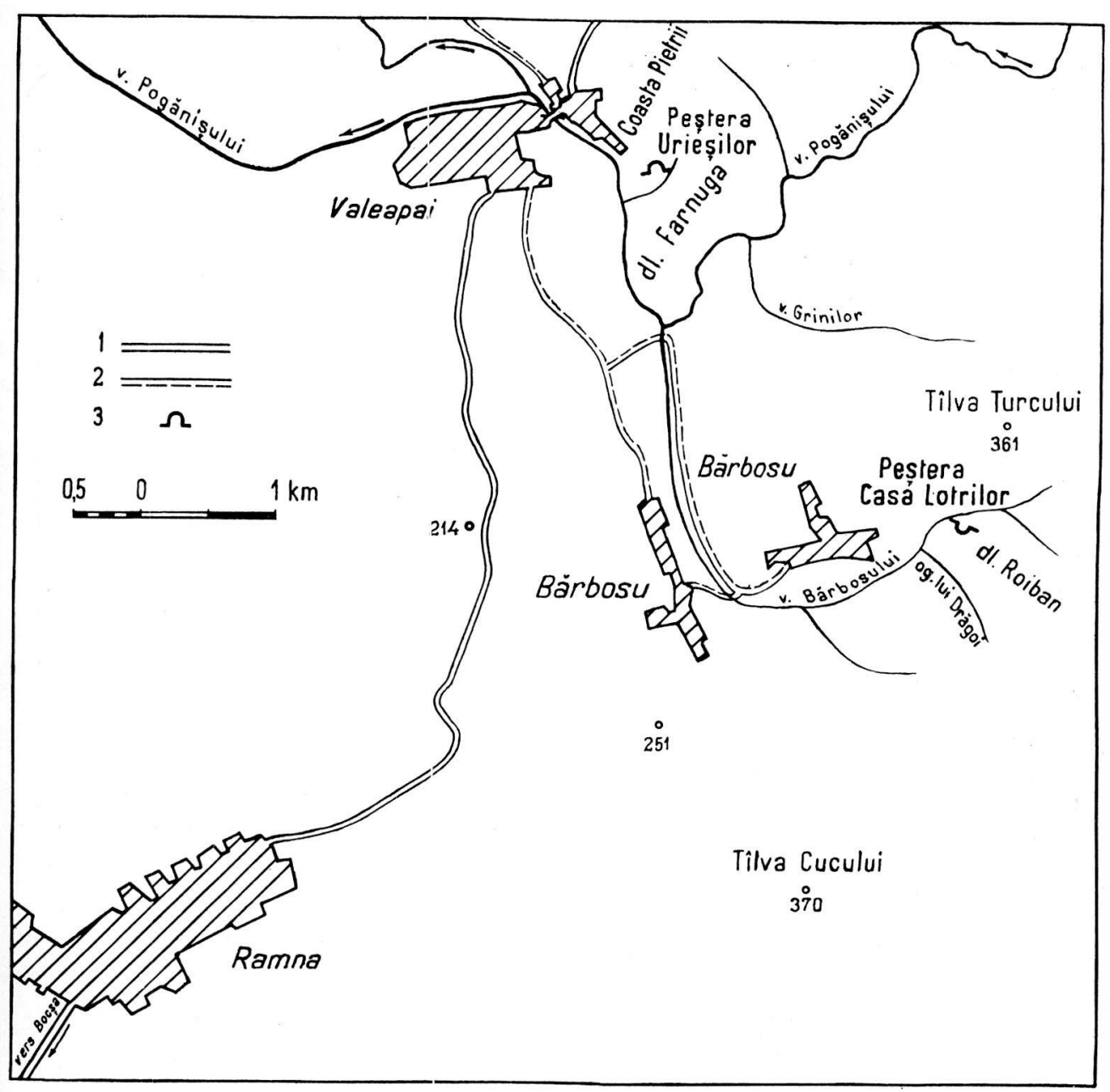



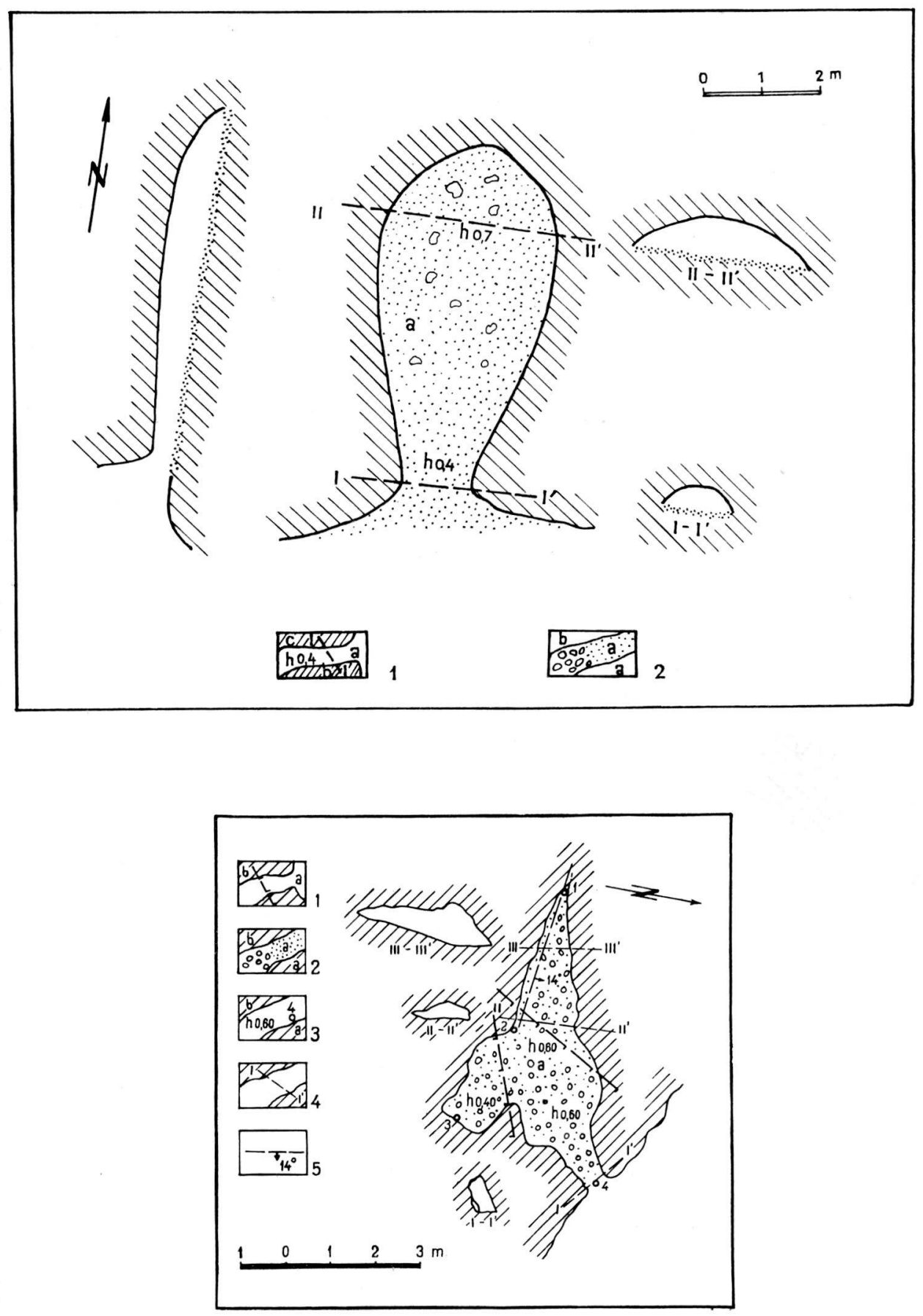

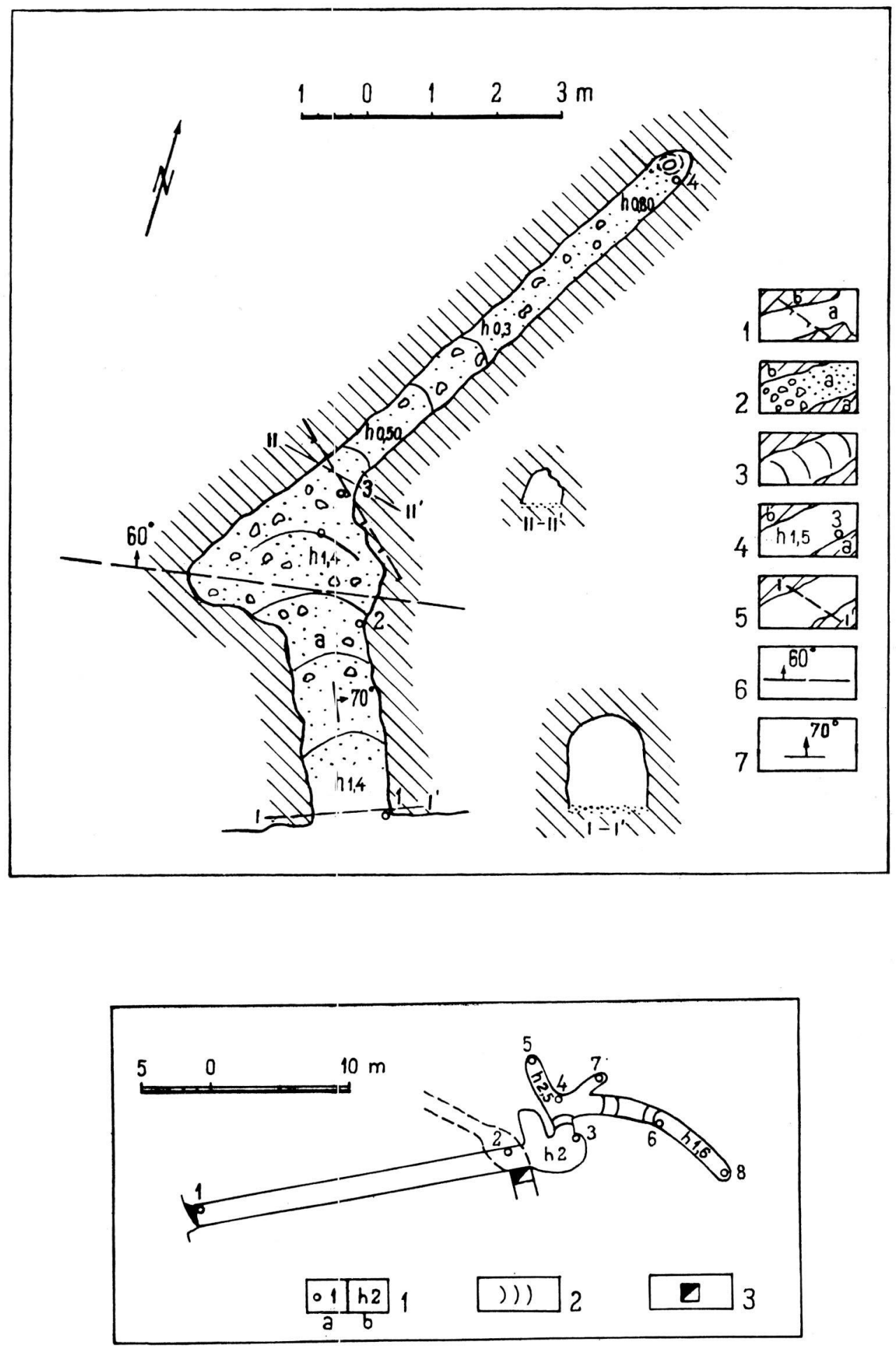
SPELEOLOGY, I

(Negrea et al., 10)

PLATE 88
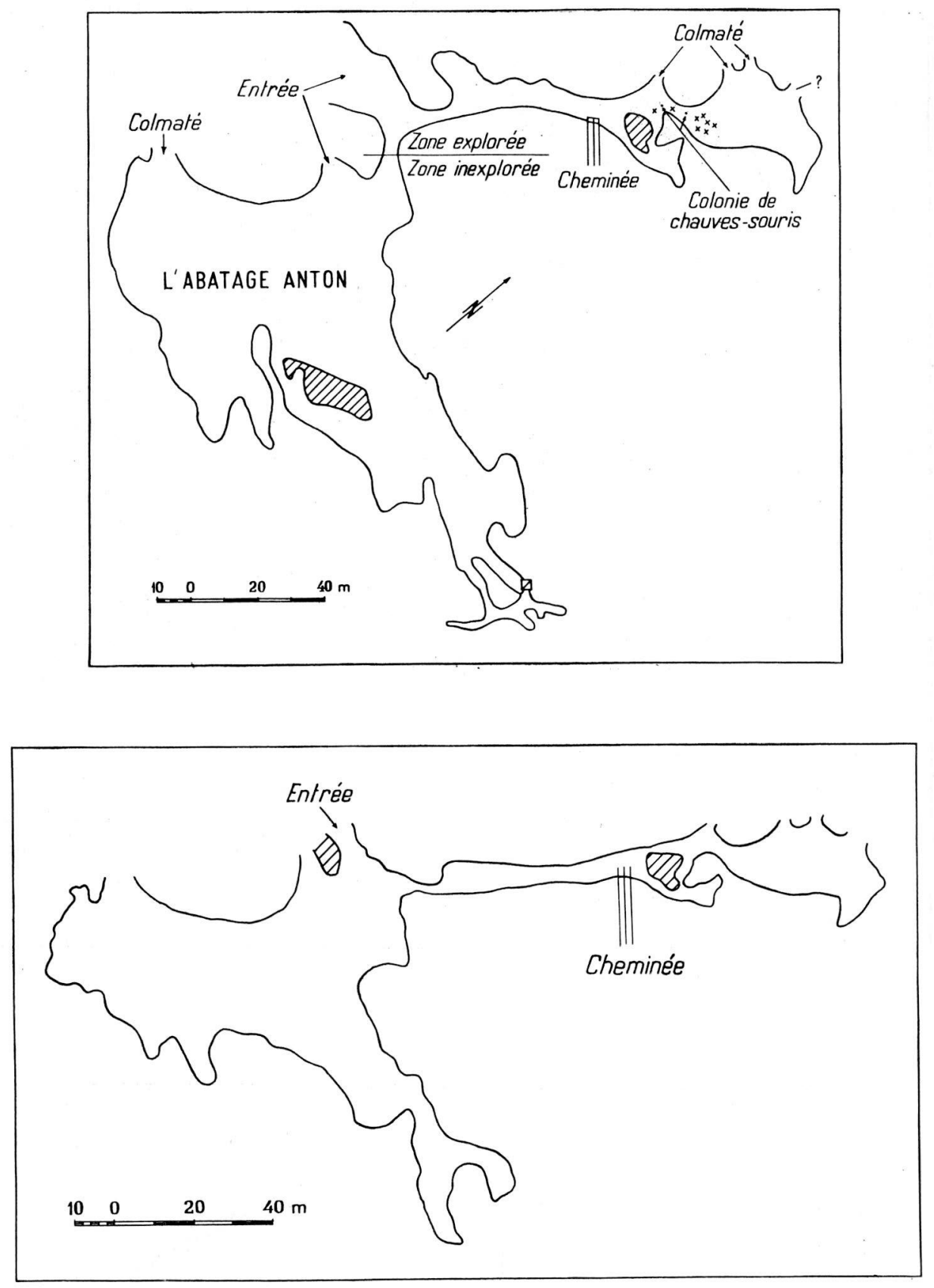


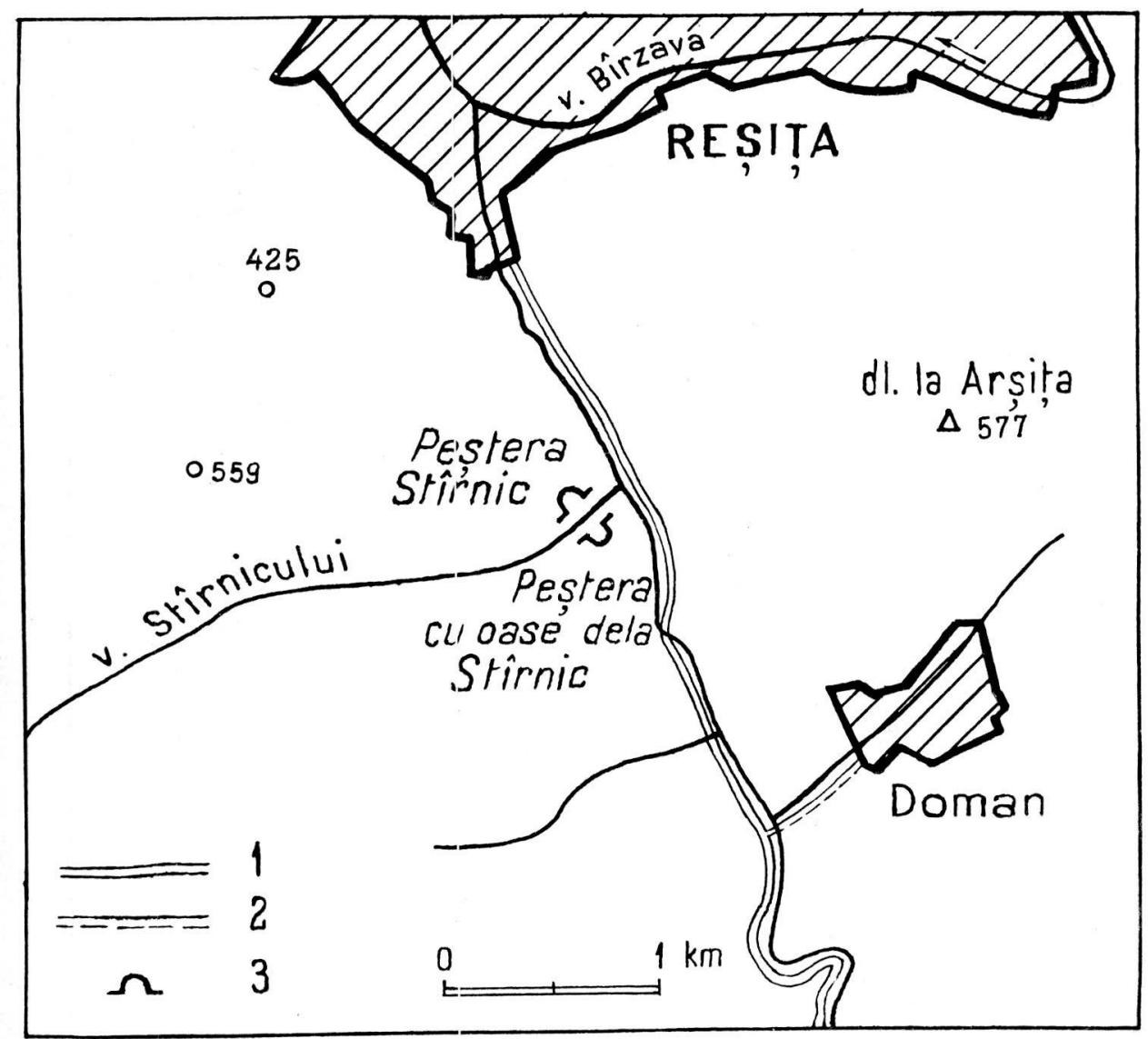




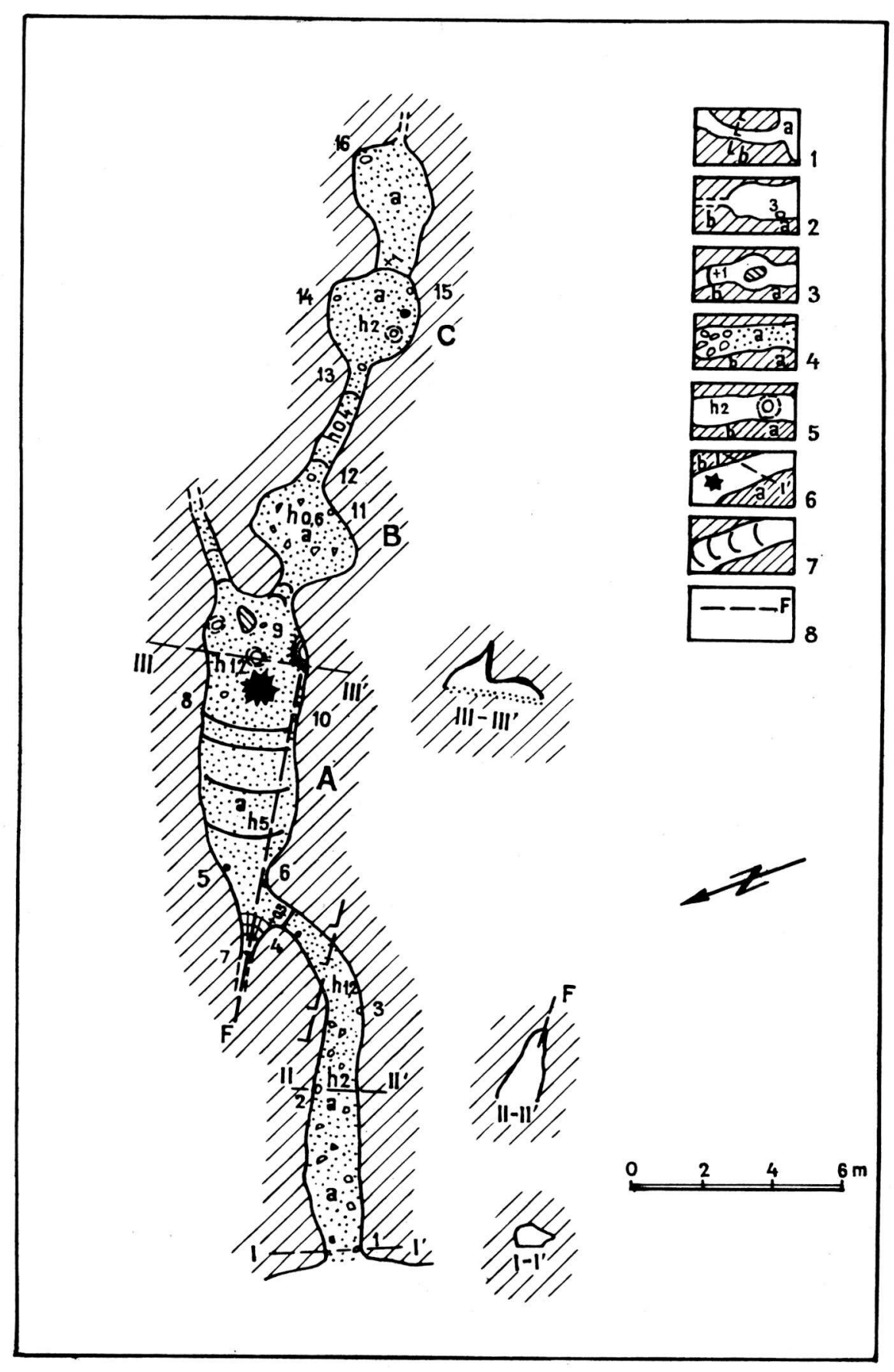




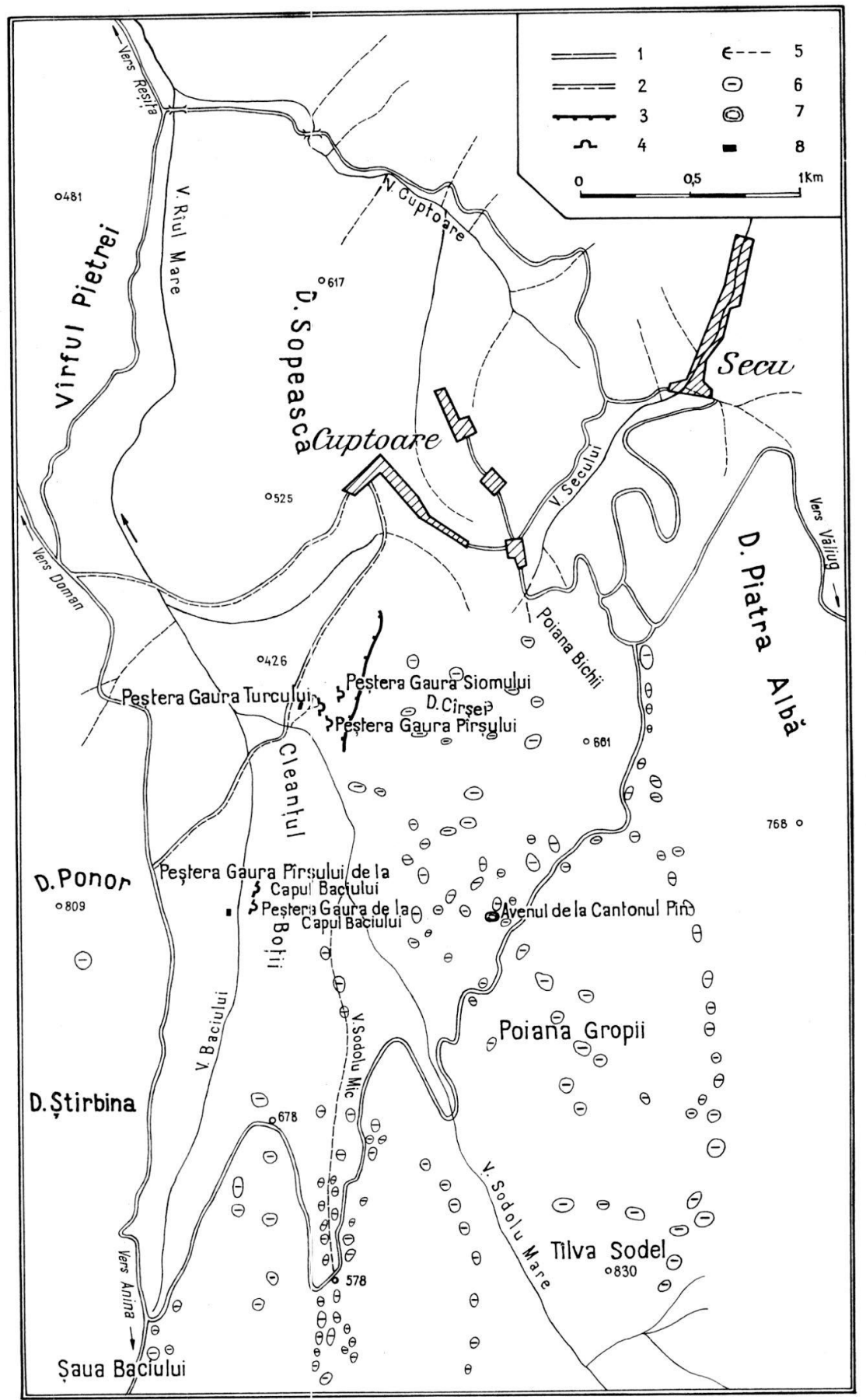




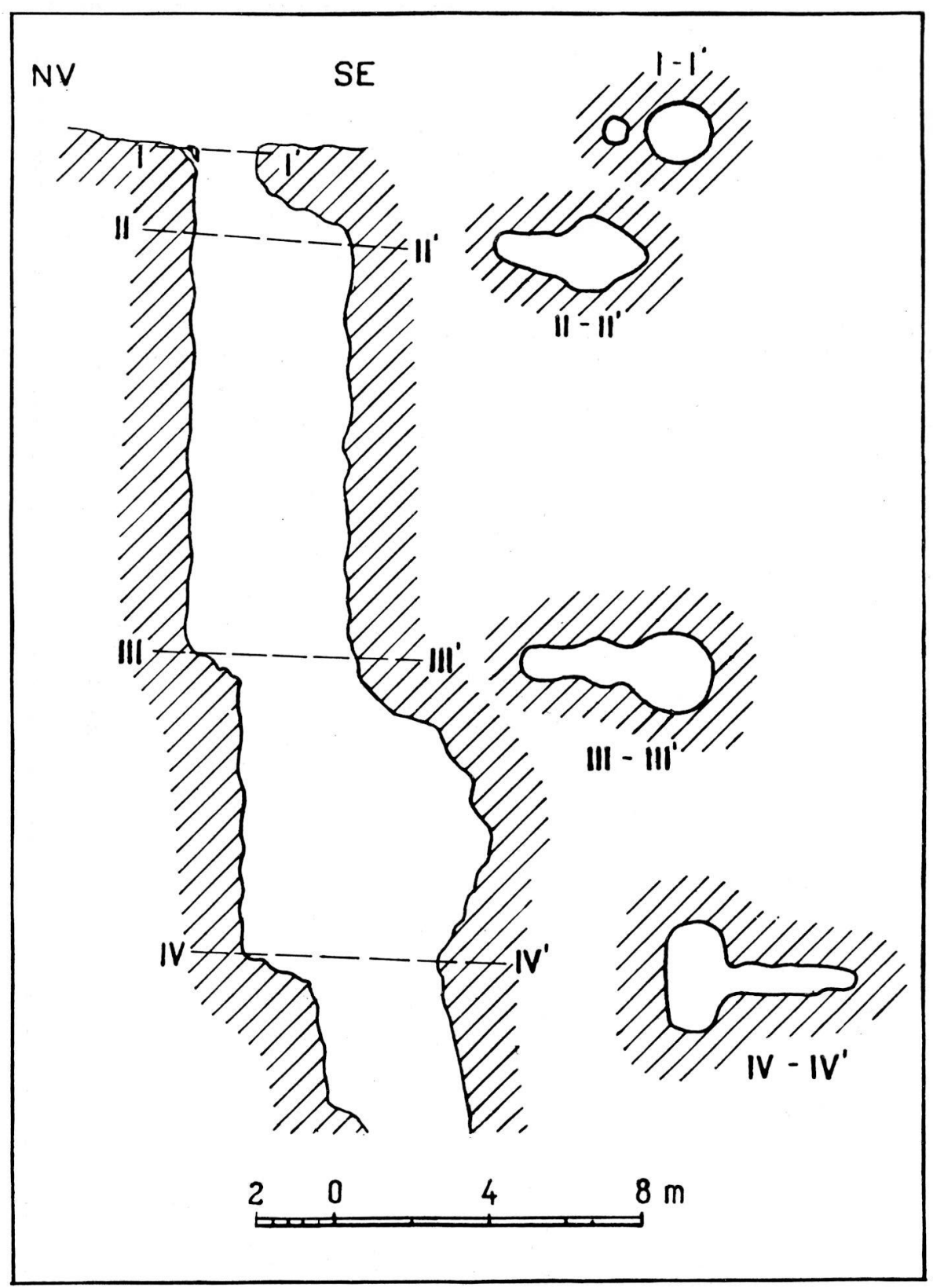




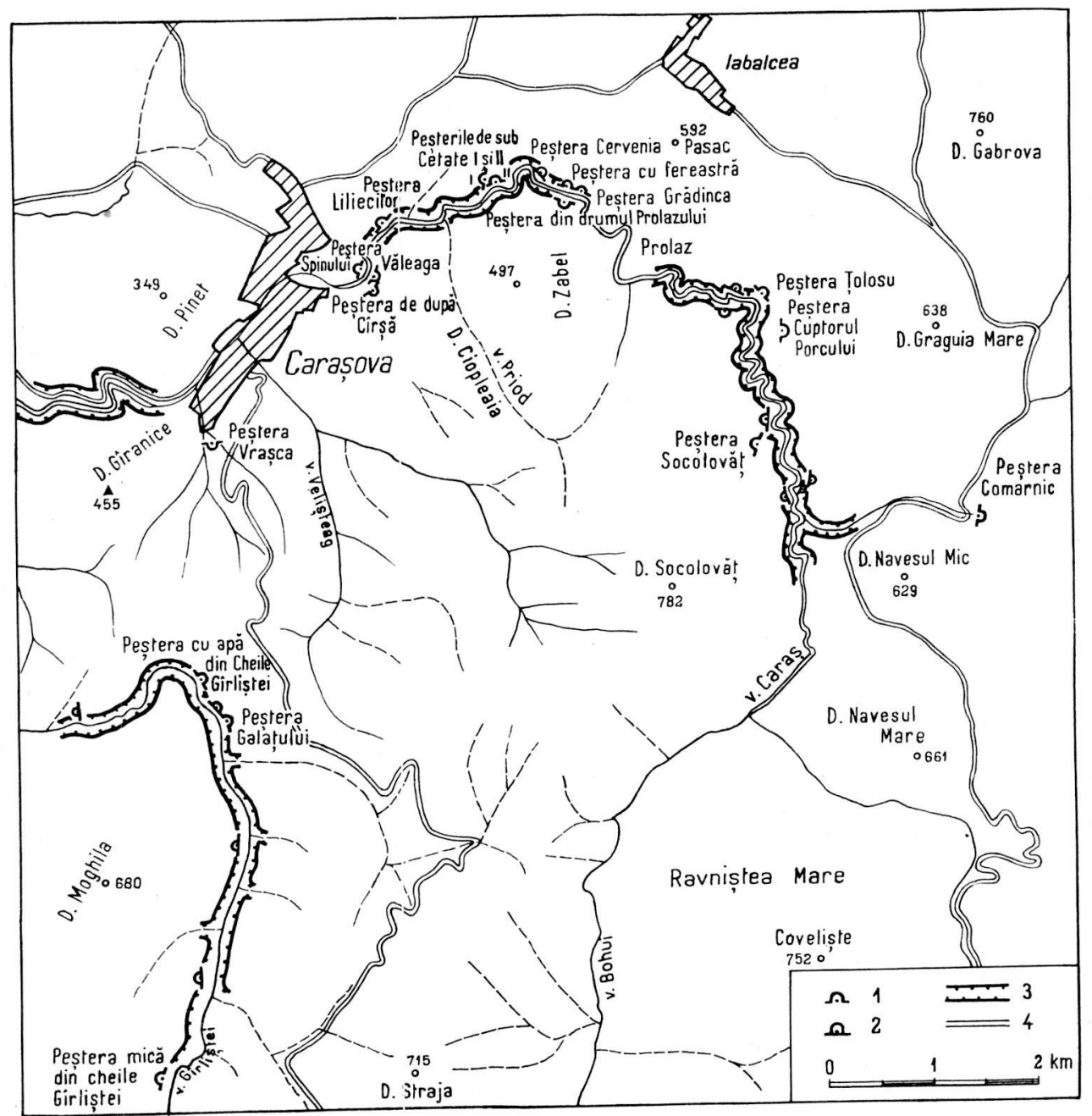



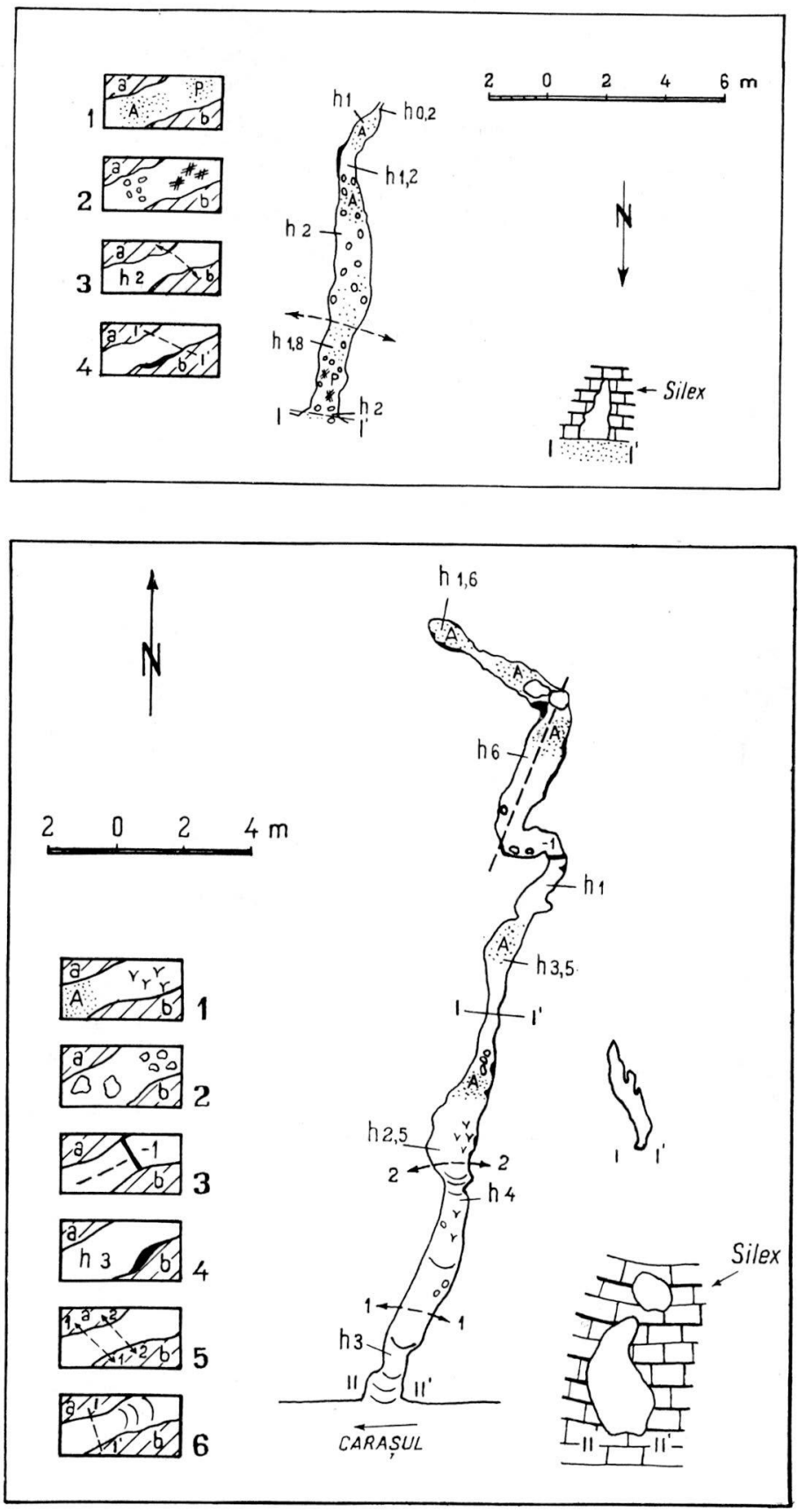

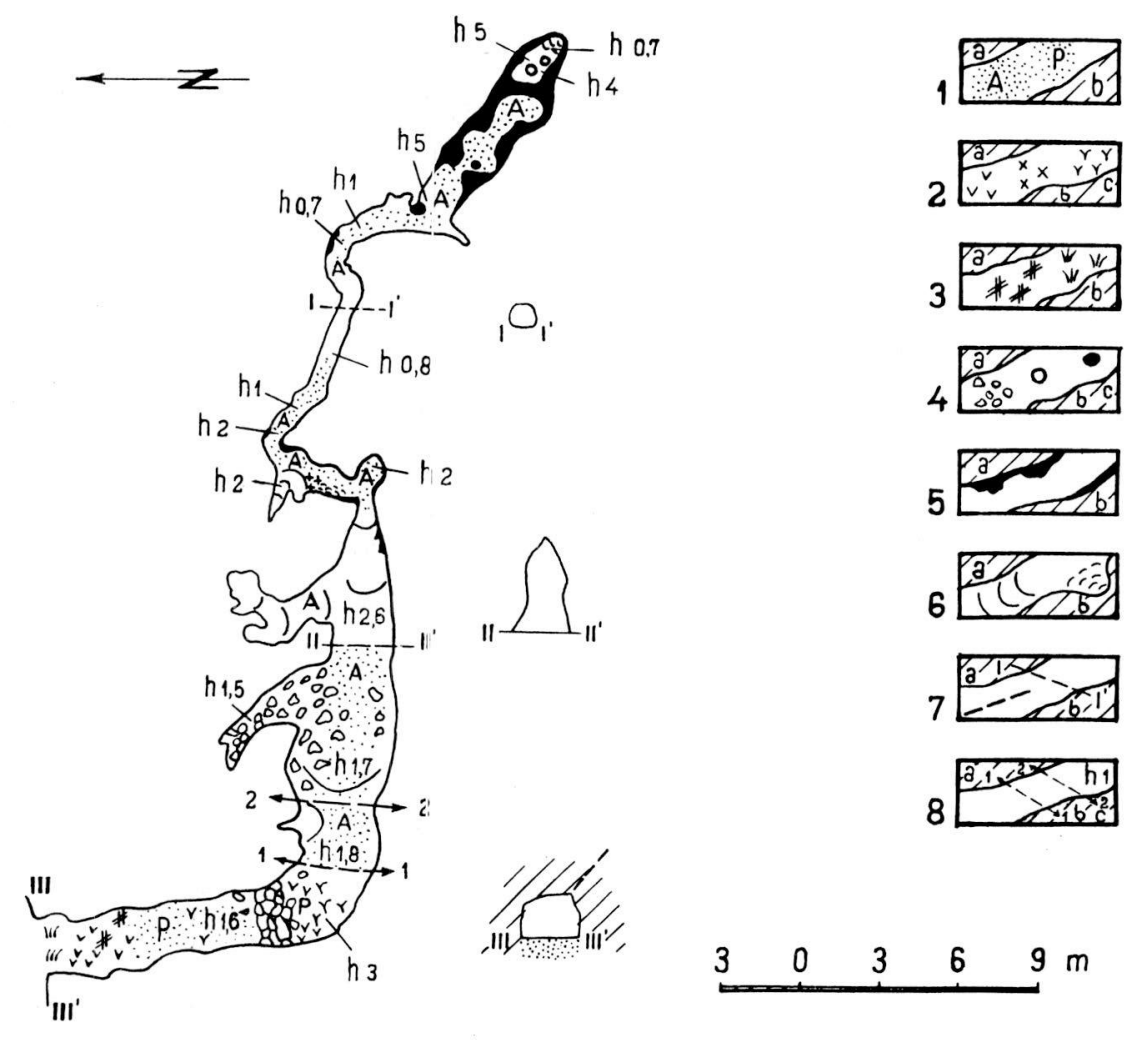

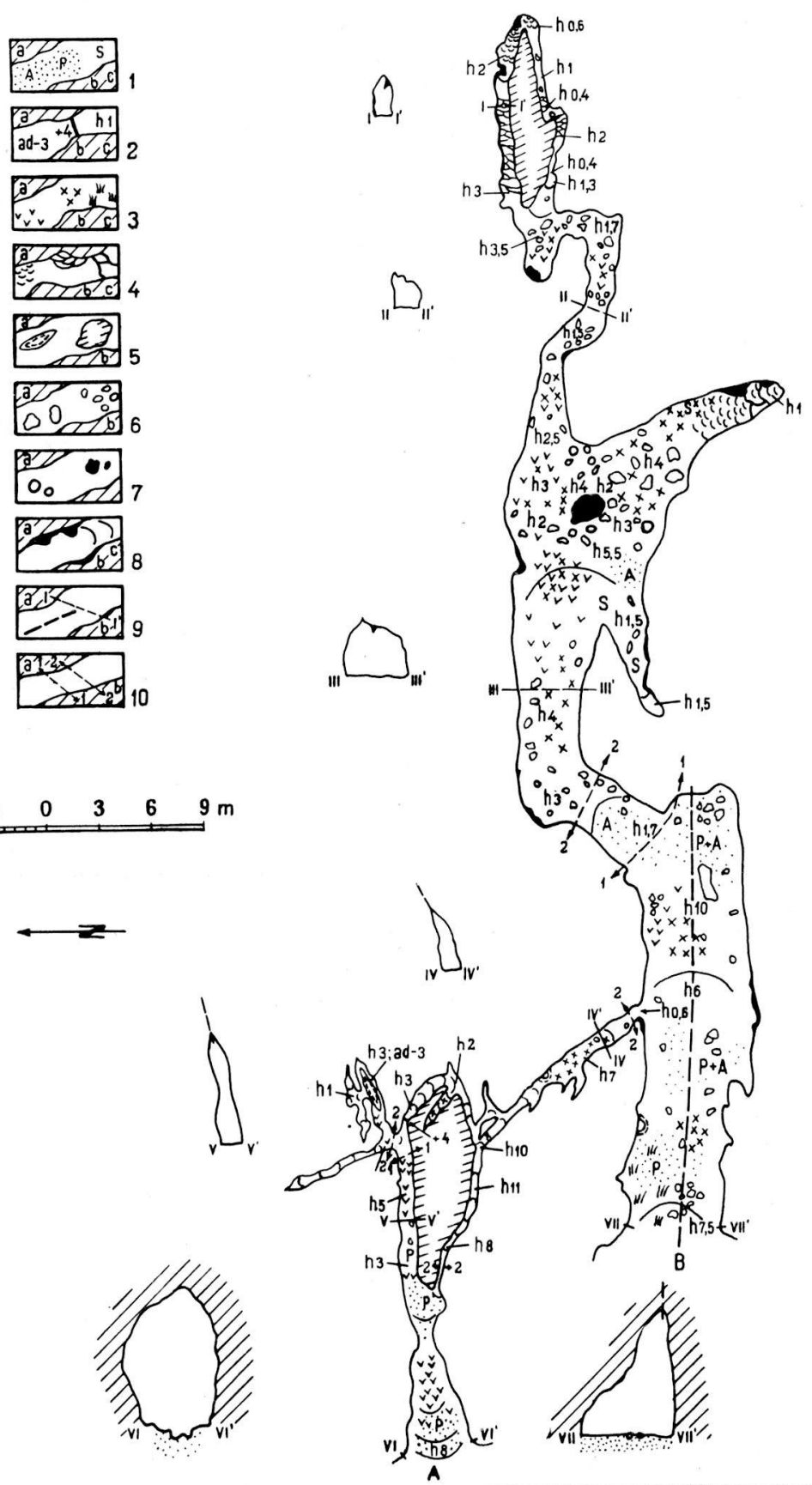

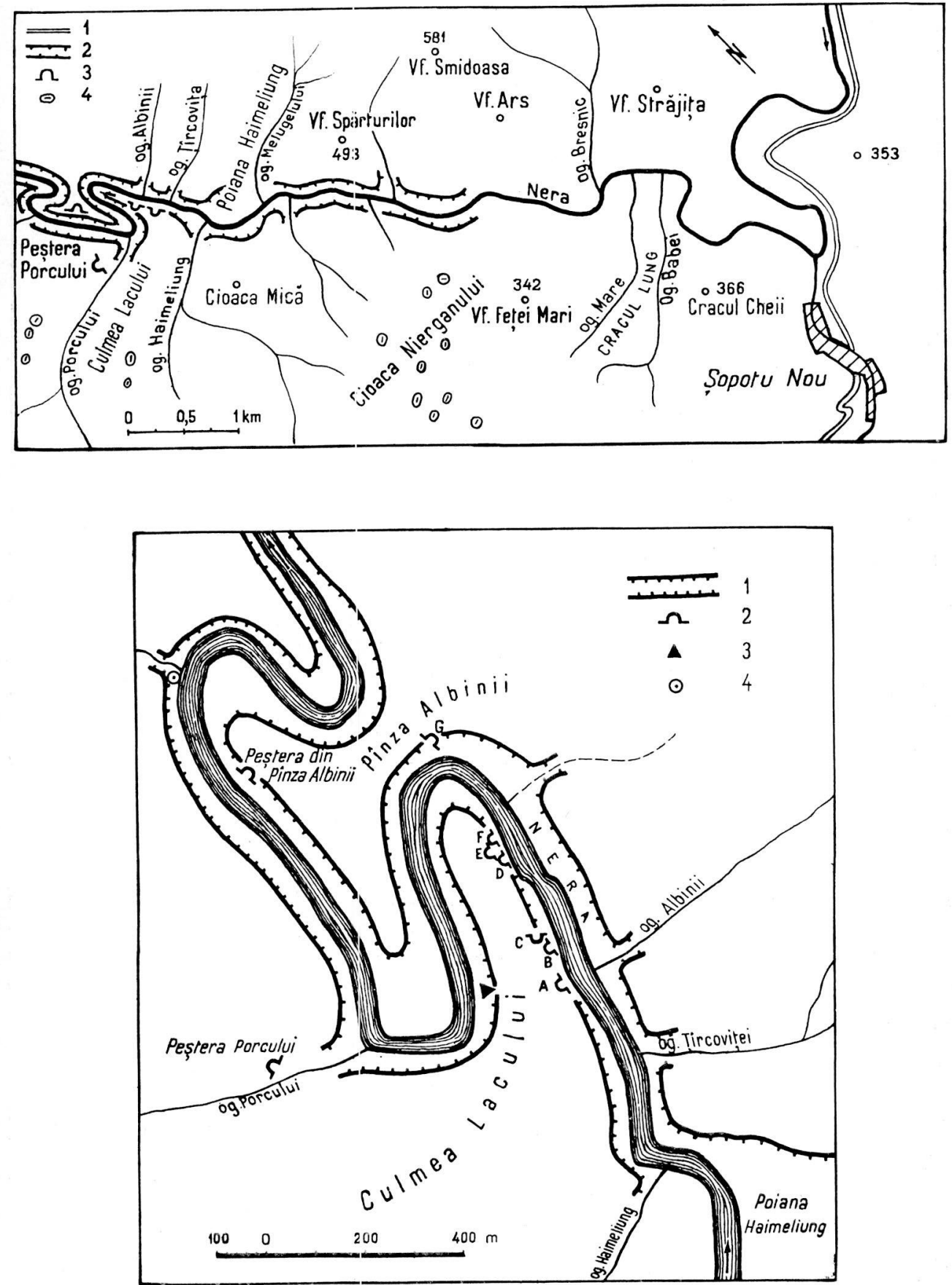

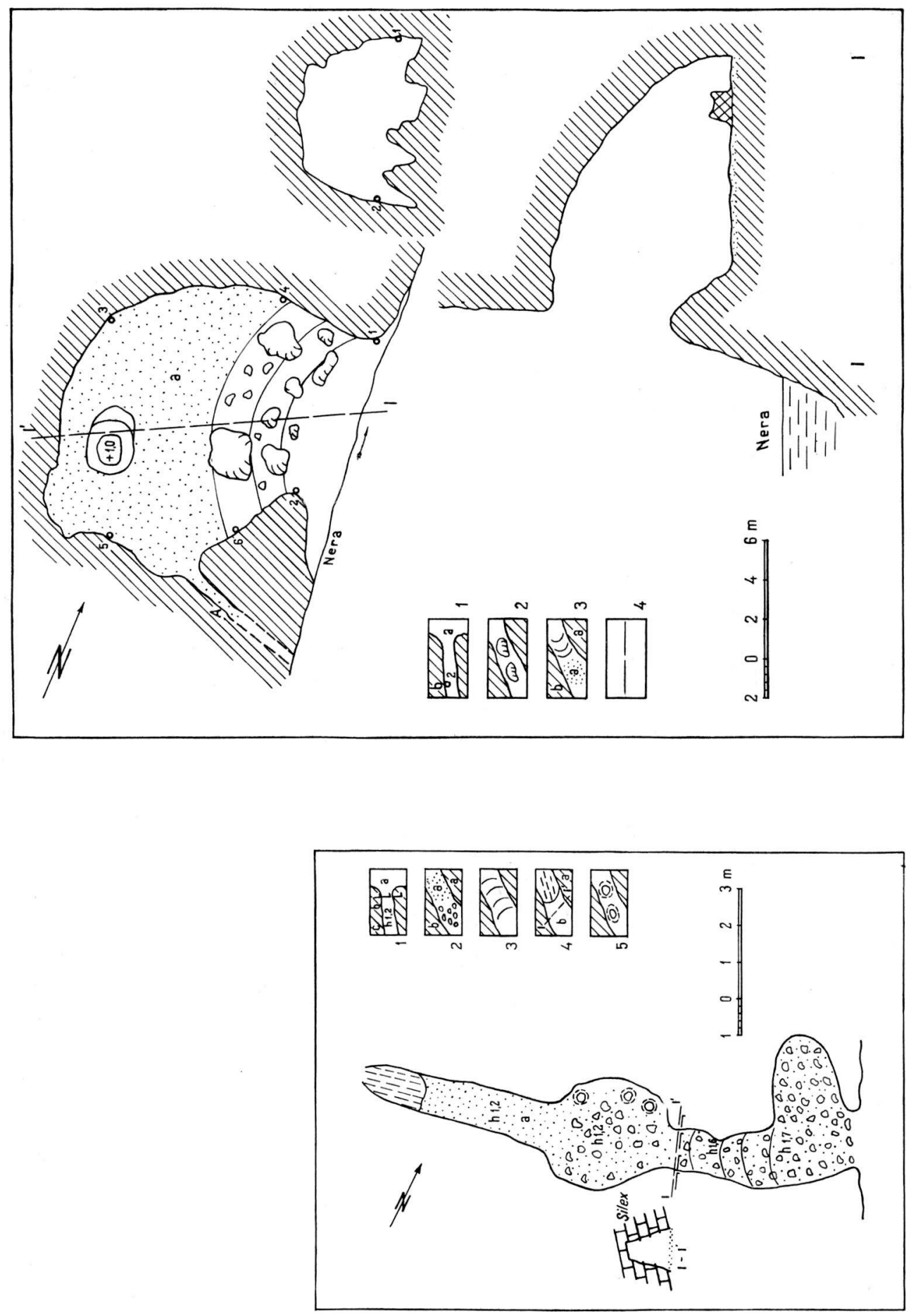

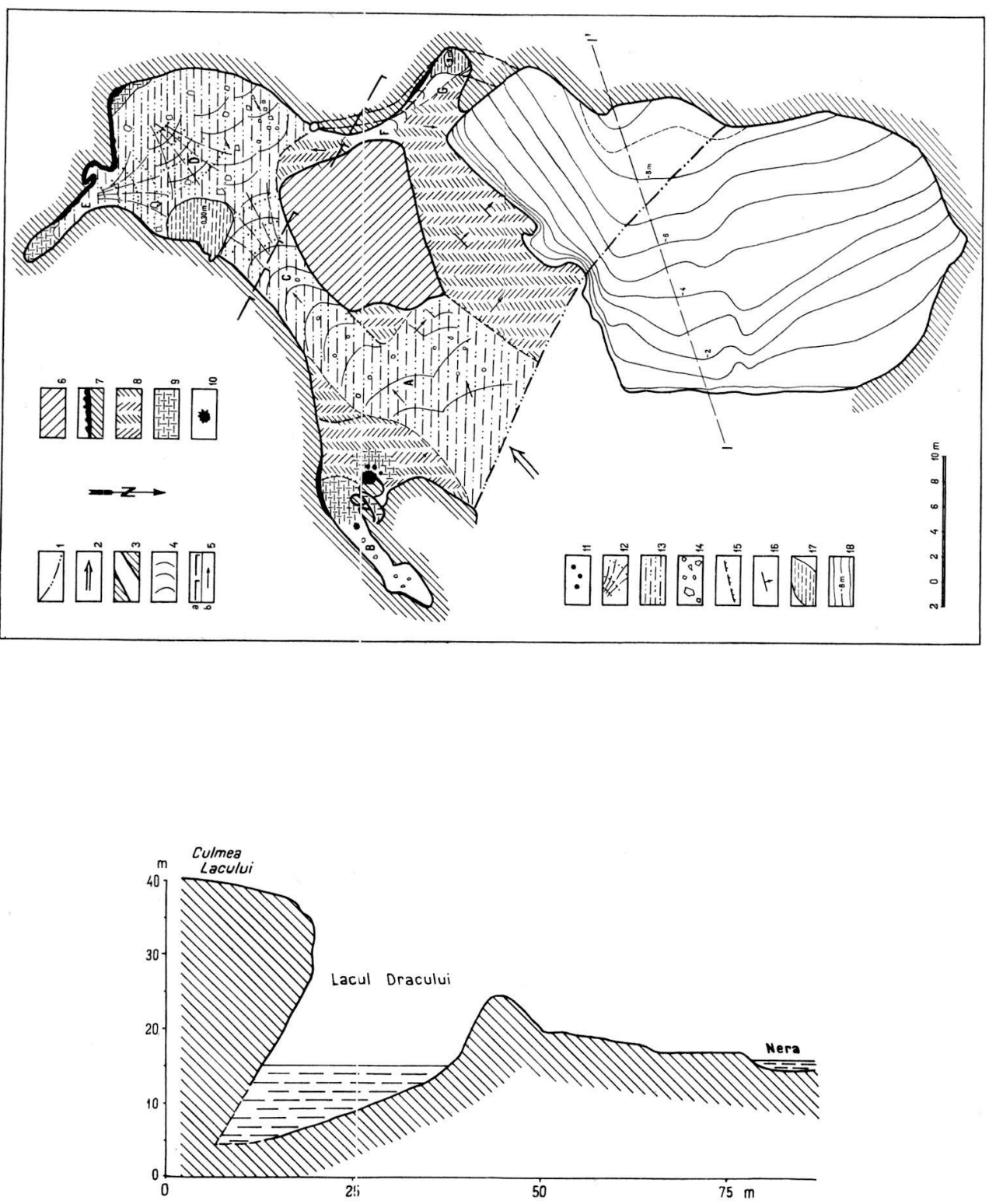


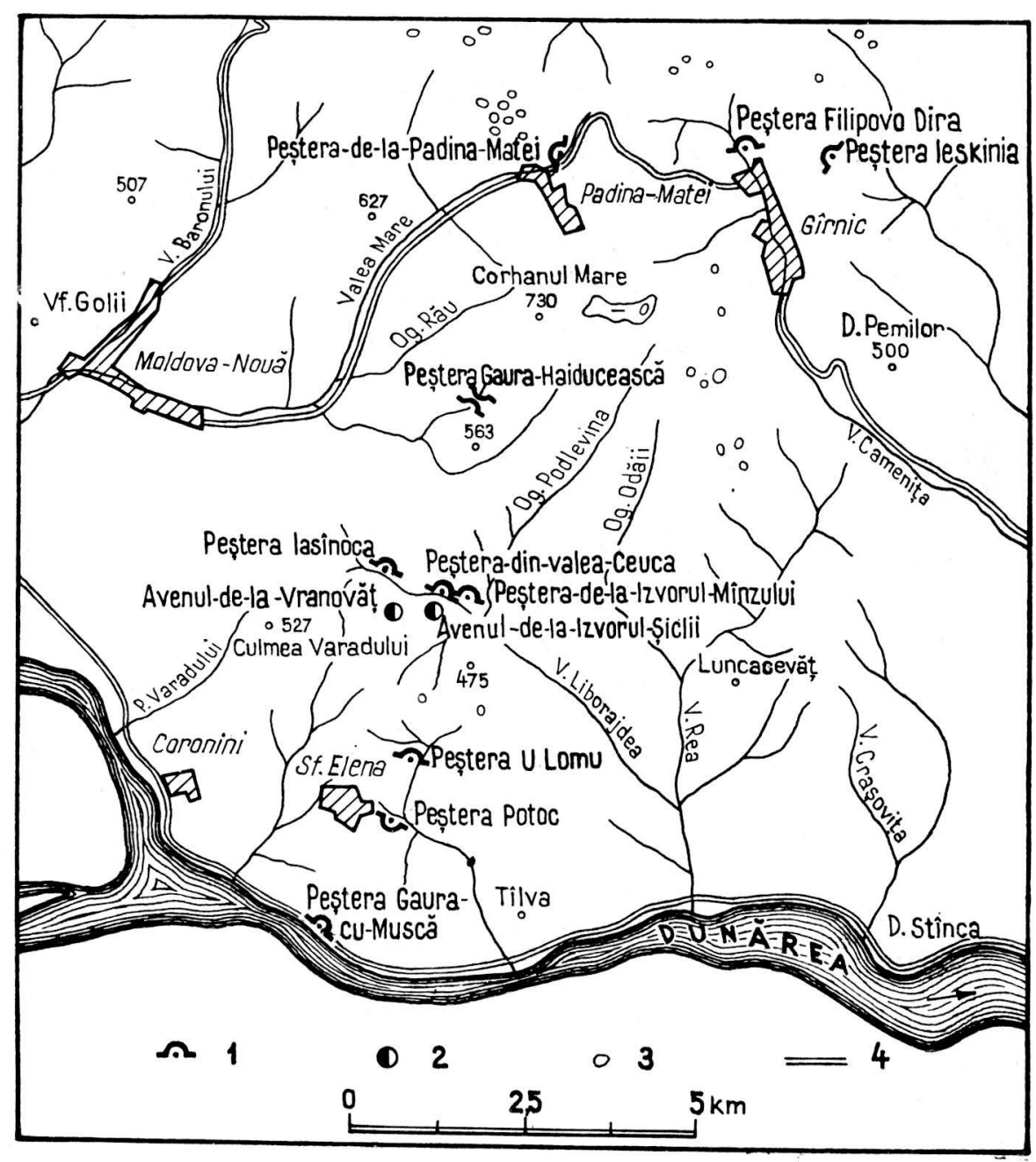




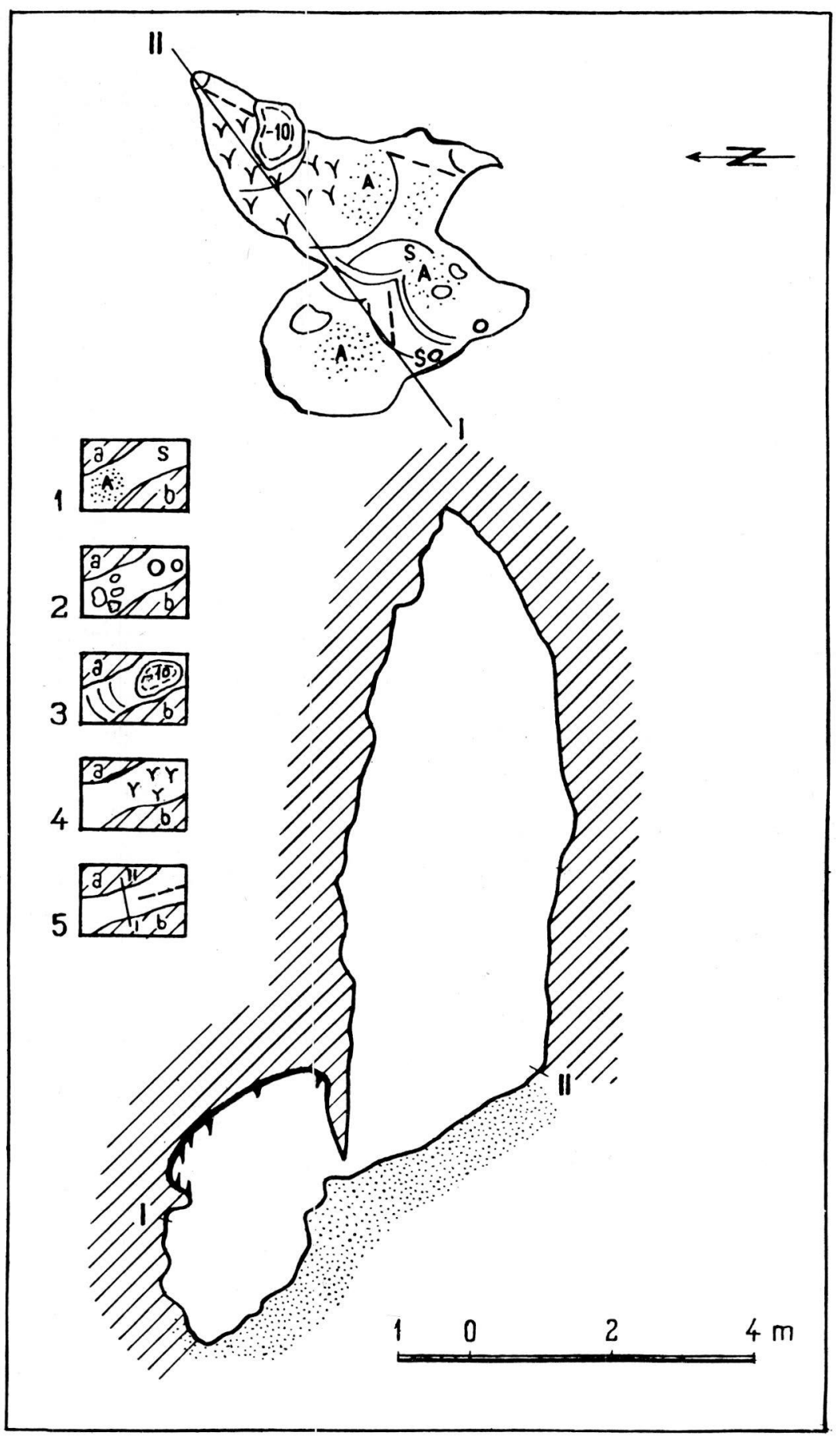




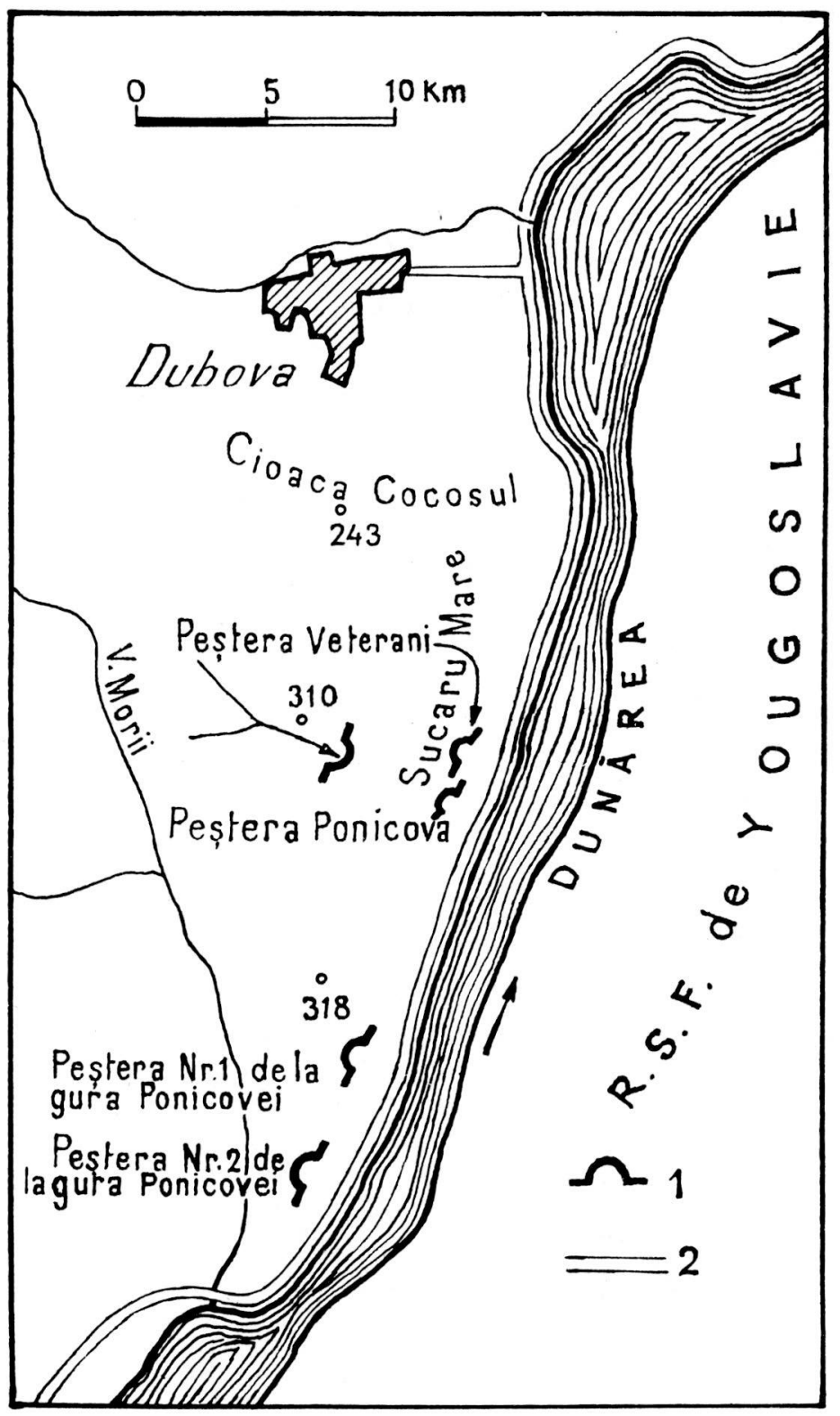



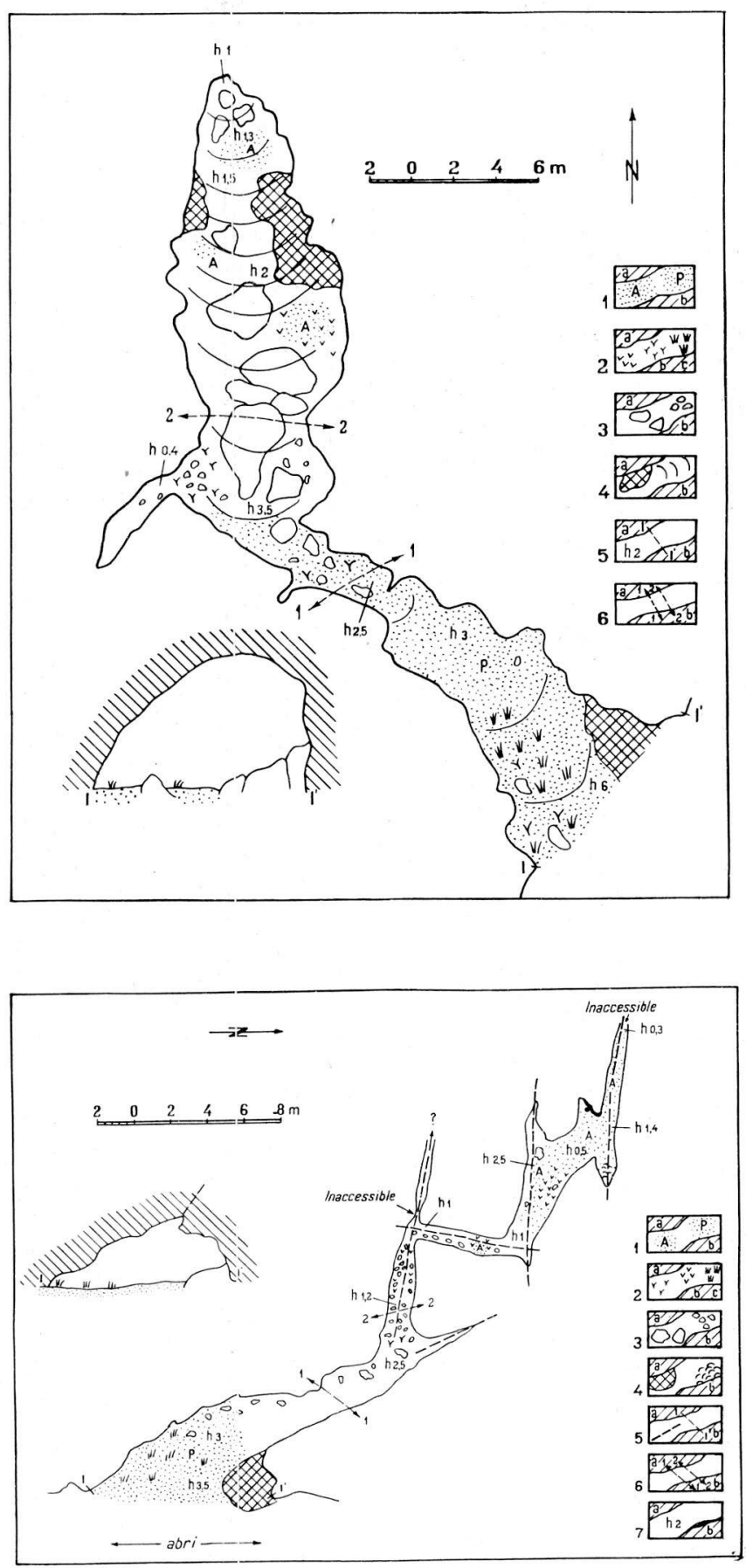